\title{
Laboratory Testing for the Diagnosis of HIV Infection
}

\section{Updated Recommendations}

Some aspects of this 2014 guidance have been updated, including the laboratory testing algorithm figure. For a summary of updates, see 2018 Quick Reference Guide: Recommended laboratory HIV testing algorithm for serum or plasma specimens (https://stacks.cdc.gov/view/cde/50872).
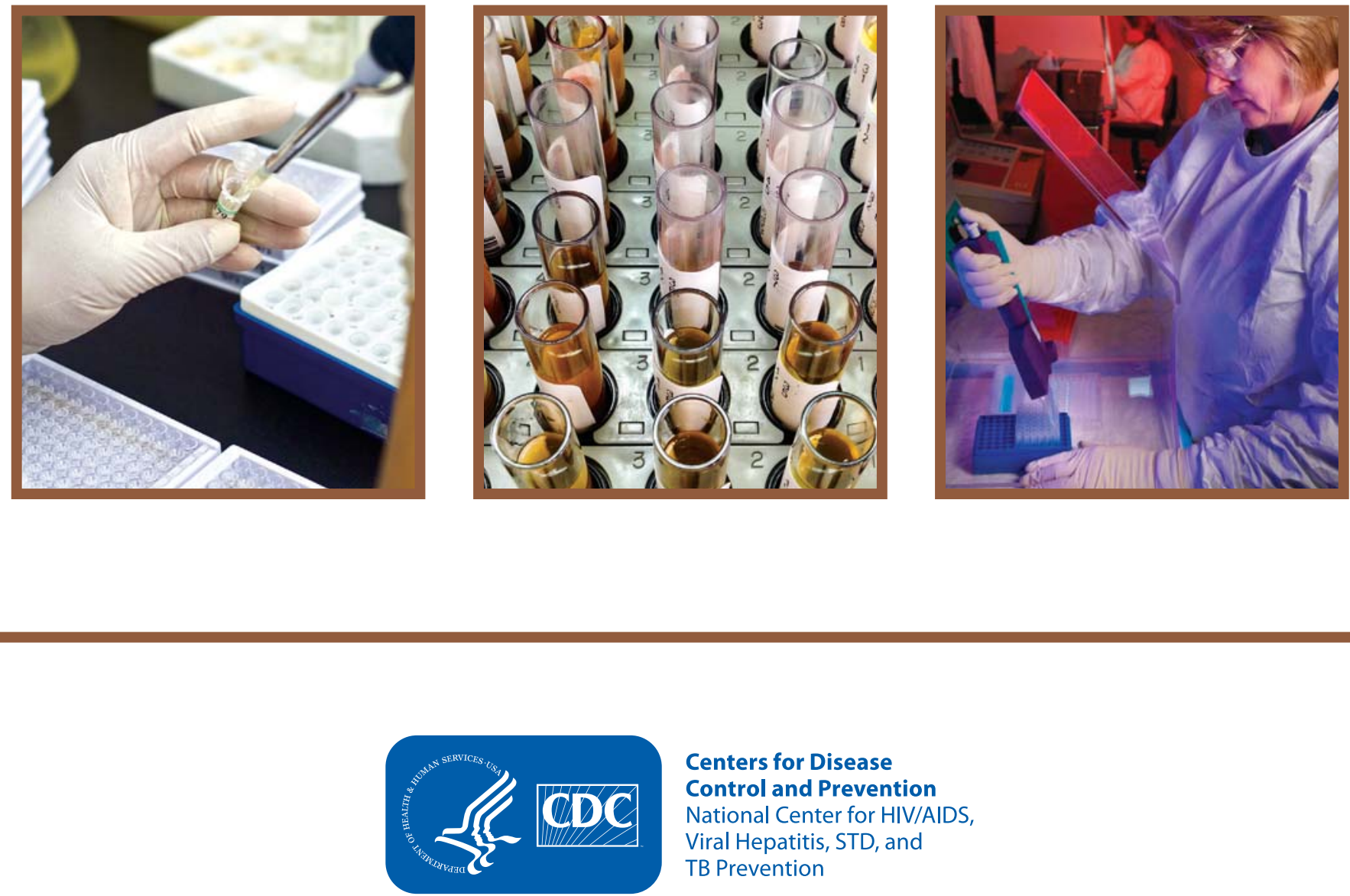


\section{Related Links}

\section{Centers for Disease Control and Prevention}

Quick Reference Guide-Laboratory testing for the diagnosis of HIV infection: updated recommendations

http://stacks.cdc.gov/view/cdc/23446

HIV testing

http://www.cdc.gov/hiv/testing/index.html

U.S. HIV tests

http://www.cdc.gov/hiv/testing/lab/index.html

\section{Association of Public Health Laboratories}

Suggested reporting language for the HIV laboratory diagnostic testing algorithm

http://stacks.cdc.gov/view/cdc/22423

\section{U.S. Food and Drug Administration}

Complete list of donor screening assays for infectious agents and HIV diagnostic assays

http://www.fda.gov/BiologicsBloodVaccines/BloodBloodProducts/ApprovedProducts/

LicensedProductsBLAs/BloodDonorScreening/InfectiousDisease/ucm080466.htm 


\section{Laboratory Testing for the Diagnosis of HIV Infection: Updated Recommendations}

Published June 27, 2014

Prepared by

Bernard M. Branson, MD

S. Michele Owen, $\mathrm{PhD}^{\mathrm{a}}$

Laura G. Wesolowski, $\mathrm{PhD}^{\mathrm{a}}$

Berry Bennett, $\mathrm{MPH}^{\mathrm{b}, \mathrm{c}}$

Barbara G. Werner, $\mathrm{PhD}^{\mathrm{b}, \mathrm{d}}$

Kelly E. Wroblewski, MPH ${ }^{\mathrm{b}}$

Michael A. Pentella, $\mathrm{PhD}^{\mathrm{b}, \mathrm{e}}$

${ }^{a}$ Division of HIV/AIDS Prevention, National Center for HIV/AIDS, Viral Hepatitis, and TB Prevention

${ }^{\mathrm{b}}$ Association of Public Health Laboratories, Silver Spring, Maryland

${ }^{\mathrm{c}}$ Florida Bureau of Public Health Laboratories, Jacksonville, Florida

${ }^{d}$ Massachusetts Department of Public Health Bureau of Infectious Disease, Boston, Massachusetts

${ }^{\mathrm{e}}$ Massachusetts Bureau of Laboratories, Boston, Massachusetts 
Disclosure of relationship: The Centers for Disease Control and Prevention (CDC) and our content experts wish to disclose that they have no financial interests or other relationships with the manufacturers of commercial products, suppliers of commercial services, or commercial supporters. External peer reviewers have reviewed content to ensure there is no bias.

Trade names are used for identification purposes only. Their use does not imply endorsement by CDC or the U.S. Department of Health and Human Services.

Suggested citation: Centers for Disease Control and Prevention and Association of Public Health Laboratories. Laboratory Testing for the Diagnosis of HIV Infection: Updated Recommendations. Available at http://dx.doi.org/10.15620/cdc.23447. Published June 27, 2014. Accessed [date].

PDF file navigation tip: This document contains hyperlinks to related topics in other sections of the document. To navigate to the related topic, click the hyperlink. To return from the topic back to the hyperlink location, press the ALT+left arrow keys on your keyboard. 


\section{Contents}

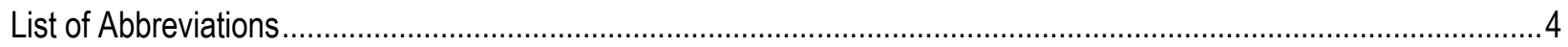

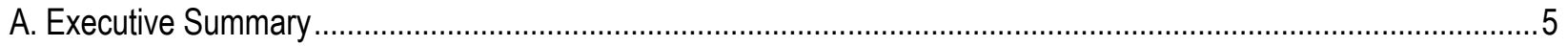

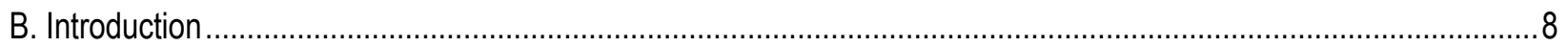

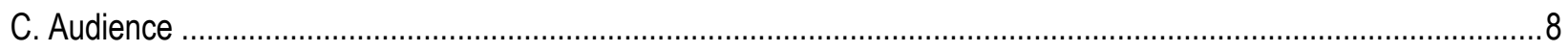

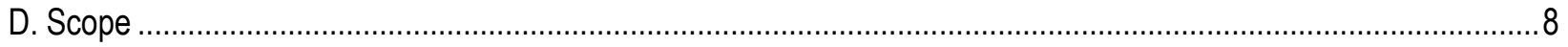

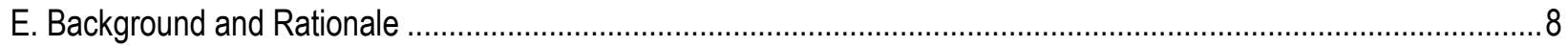

Laboratory markers of HIV infection and their detection by diagnostic tests ................................................10

Need for updated recommendations for the laboratory diagnosis of HIV-1 and HIV-2 infection ..........................11

F. Process for Developing Updated Recommendations .............................................................................

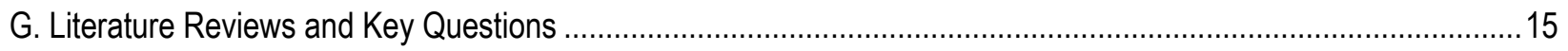

H. Recommendations for Laboratory Testing for the Diagnosis of HIV Infection ...................................................17

I. Alternative Testing Sequences When Tests in the Recommended Algorithm Cannot be Used ........................... 19

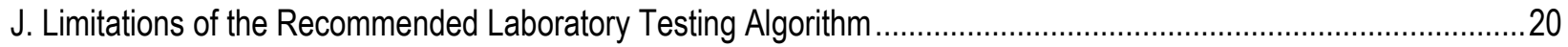

K. Limitations of the Evidence Supporting These Recommendations...........................................................22

L. How These Updated Recommendations Differ From Previous Recommendations .............................................23

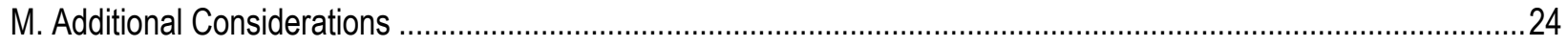

N. Reporting Results of the Recommended Algorithm for the Laboratory Diagnosis of HIV ..................................25

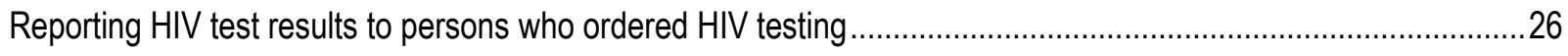

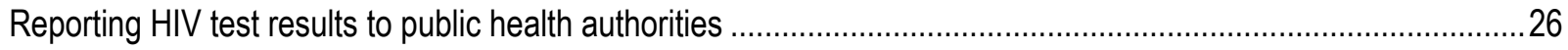

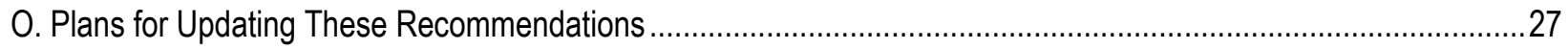

Appendix 1. Members of Working Group That Developed Updated Recommendations .........................................29

Appendix 2. Analytic Framework, Search Strategy, and Summary of Evidence...................................................30

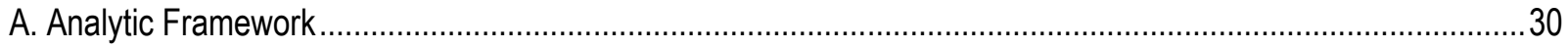

B. Strategy for Searching Published Literature and Conference Abstracts ..................................................... 32

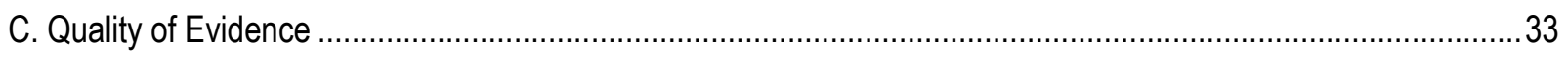

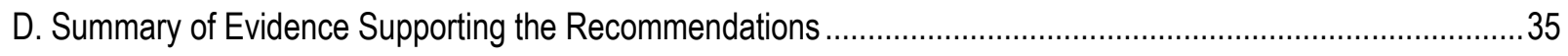

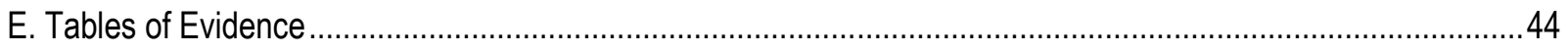

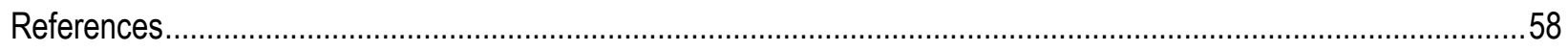




\section{List of Abbreviations}

$\mathrm{Ab} \quad$ antibody

Ag antigen

$\mathrm{Ag} / \mathrm{Ab} \quad$ antigen/antibody

AIDS acquired immune deficiency syndrome

APHL Association of Public Health Laboratories

ART antiretroviral therapy

CDC Centers for Disease Control and Prevention

CLIA Clinical Laboratory Improvement Amendments of 1988

FDA Food and Drug Administration

HIV human immunodeficiency virus

IA immunoassay

IFA indirect immunofluorescence assay

IgG immunoglobulin $\mathrm{G}$

IgM immunoglobulin $\mathrm{M}$

NASTAD National Alliance of State and Territorial AIDS Directors

NAT nucleic acid test

RNA ribonucleic acid

STD sexually transmitted disease

USPHS United States Public Health Service

WB Western blot 


\section{Laboratory Testing for the Diagnosis of HIV Infection: Updated Recommendations}

\section{A. Executive Summary}

This document updates recommendations for HIV testing by laboratories in the United States and offers approaches for reporting test results to persons ordering HIV tests and to public health authorities. The recommended algorithm is a sequence of tests used in combination to improve the accuracy of the laboratory diagnosis of HIV based on testing of serum or plasma specimens. The Centers for Disease Control and Prevention (CDC) previously published guidelines for the serodiagnosis of HIV Type 1 infections in 1989, guidelines for testing for antibodies for HIV Type 2 in 1992, and protocols for confirmation of reactive rapid antibody test results in $2004 .^{1-3}$ These previous guidelines employed only tests for HIV antibodies. ${ }^{1-3}$ The updated recommendations also include tests for HIV antigens and HIV nucleic acid because studies from populations at high risk for HIV demonstrate that antibody testing alone might miss a considerable percentage of HIV infections detectable by virologic tests. ${ }^{4-10}$

CDC and the Association of Public Health Laboratories (APHL) have issued these recommendations based on HIV tests approved by the Food and Drug Administration (FDA) as of December 2012 and scientific evidence, laboratory experience, and expert opinion collected from 2007 through December 2013. These recommendations do not include the rapid HIV1/HIV-2 antigen/antibody combination test approved by the FDA in August 2013 (for which evidence of performance in the algorithm was insufficient) or HIV-2 nucleic acid tests (NATs), which lack FDA approval.

These updated recommendations for HIV testing are necessary because of

- FDA approval of improved HIV assays that allow detection of HIV sooner after infection than previous immunoassays; ${ }^{11-14}$

- evidence that relying on Western blot or indirect immunofluorescence assay (IFA) for confirmation of reactive initial immunoassay results can produce false-negative or indeterminate results early in the course of HIV infection; ${ }^{4-6,15-18}$

- recognition that risk of HIV transmission from persons with acute and early infection is much higher than that from persons with established infection; ${ }^{19-22}$

- recent indications for the clinical benefits from antiretroviral treatment (ART) of all persons with HIV infection, including those with acute infection; ${ }^{23-26}$ and

- demonstration that the majority of HIV-2 infections detected by available HIV antibody immunoassays are misclassified as HIV-1 by the HIV-1 Western blot. ${ }^{27-29}$

This report provides recommendations to laboratory personnel on the use of FDA-approved assays for the diagnosis of HIV infection in adults and children $>24$ months of age (Box 1). In brief, testing begins with a combination immunoassay that detects HIV-1 and HIV-2 antibodies 
and HIV-1 p24 antigen. All specimens reactive on this initial assay undergo supplemental testing with an immunoassay that differentiates HIV-1 from HIV-2 antibodies. Specimens that are reactive on the initial immunoassay and nonreactive or indeterminate on the antibody differentiation assay proceed to HIV-1 nucleic acid testing for resolution. The results of this algorithm may be used to identify persons likely to benefit from treatment, to reassure persons who are uninfected, and for reporting evidence of HIV infection to public health authorities.

The recommended algorithm has several advantages over previous recommendations, including

- more accurate laboratory diagnosis of acute HIV-1 infection,

- equally accurate laboratory diagnosis of established HIV-1 infection,

- more accurate laboratory diagnosis of HIV-2 infection,

- fewer indeterminate results, and

- faster turnaround time for most test results.

The HIV-1 Western blot and HIV-1 IFA, previously recommended to make a laboratory diagnosis of HIV-1 infection, are no longer part of the recommended algorithm. Positive results from the recommended algorithm indicate the need for HIV medical care and an initial evaluation that includes additional laboratory tests (such as HIV-1 viral load, CD4+ Tlymphocyte determination, and an antiretroviral resistance assay) to confirm the presence of HIV-1 infection, to stage HIV disease, and to assist in the selection of an initial antiretroviral drug regimen. ${ }^{23}$ Because no diagnostic test or algorithm can be completely accurate in all cases of HIV infection, inconsistent or conflicting test results obtained during the clinical evaluation may warrant additional testing of follow-up specimens.

Anticipating continued improvements in laboratory diagnostic techniques, CDC and APHL will monitor the introduction and FDA approval of diagnostic assays for HIV infection and update these recommendations when necessary. CDC and APHL will continue to monitor the performance of the laboratory testing algorithm and review the performance of the recommended algorithm at least every five years. 
Box 1. Recommended Laboratory HIV Testing Algorithm for Serum or Plasma Specimens

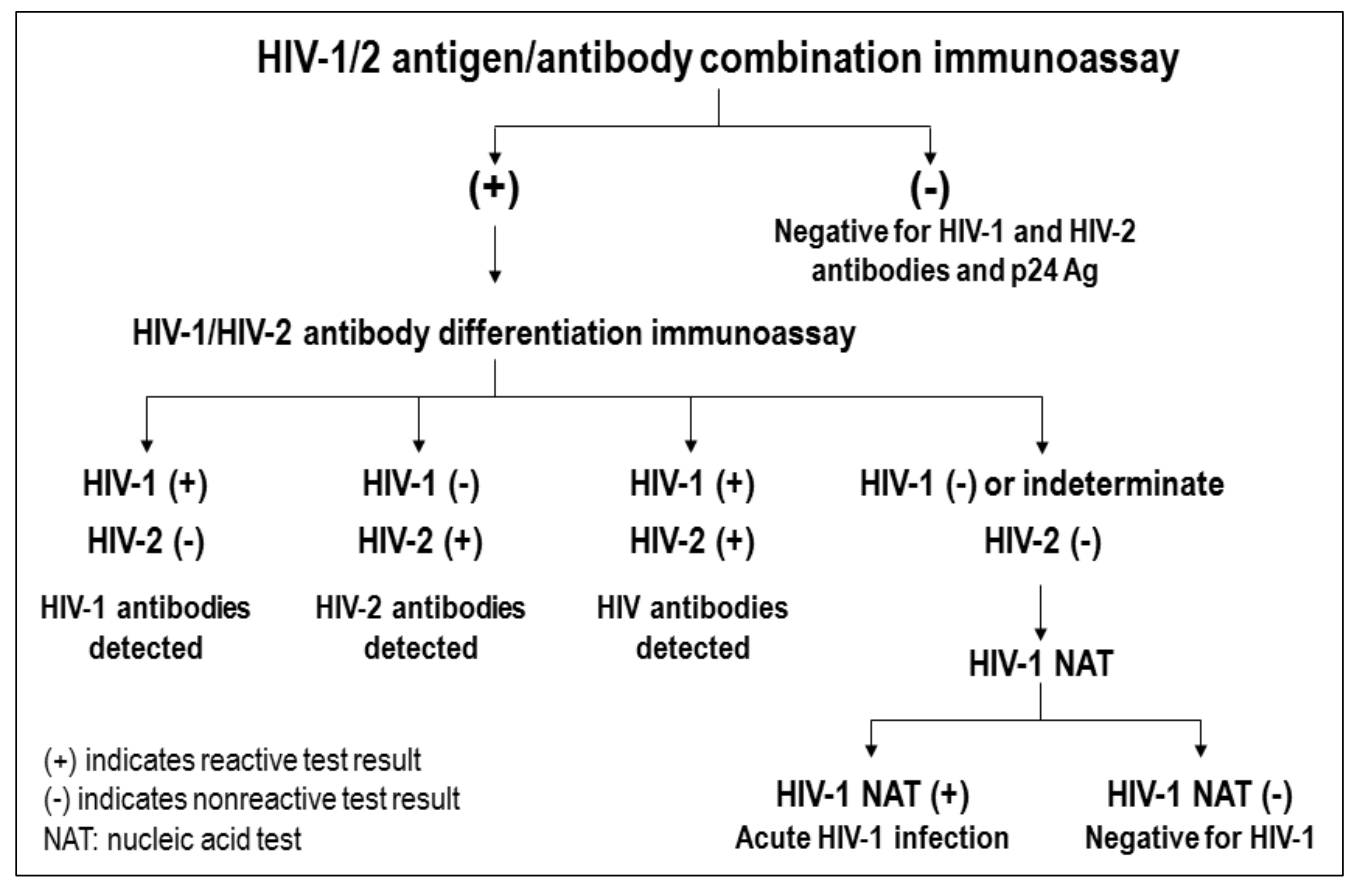

1. Laboratories should conduct initial testing for HIV with an FDA-approved antigen/antibody combination immunoassay that detects HIV-1 and HIV-2 antibodies and HIV-1 p24 antigen to screen for established infection with HIV-1 or HIV-2 and for acute HIV-1 infection. No further testing is required for specimens that are nonreactive on the initial immunoassay.

2. Specimens with a reactive antigen/antibody combination immunoassay result (or repeatedly reactive, if repeat testing is recommended by the manufacturer or required by regulatory authorities) should be tested with an FDA-approved antibody immunoassay that differentiates HIV-1 antibodies from HIV-2 antibodies. Reactive results on the initial antigen/antibody combination immunoassay and the HIV1/HIV-2 antibody differentiation immunoassay should be interpreted as positive for HIV-1 antibodies, HIV-2 antibodies, or HIV antibodies, undifferentiated.

3. Specimens that are reactive on the initial antigen/antibody combination immunoassay and nonreactive or indeterminate on the HIV-1/HIV-2 antibody differentiation immunoassay should be tested with an FDA-approved HIV-1 nucleic acid test (NAT).

- A reactive HIV-1 NAT result and nonreactive HIV-1/HIV-2 antibody differentiation immunoassay result indicates laboratory evidence for acute HIV-1 infection.

- A reactive HIV-1 NAT result and indeterminate HIV-1/HIV-2 antibody differentiation immunoassay result indicates the presence of HIV-1 infection confirmed by HIV-1 NAT.

- A negative HIV-1 NAT result and nonreactive or indeterminate HIV-1/HIV-2 antibody differentiation immunoassay result indicates a false-positive result on the initial immunoassay. ${ }^{b}$

4. Laboratories should use this same testing algorithm, beginning with an antigen/antibody combination immunoassay, with serum or plasma specimens submitted for testing after a reactive (preliminary positive) result from any rapid HIV test.

${ }^{\text {a }}$ Exception: As of April 2014, data are insufficient to recommend use of the FDA-approved single-use rapid HIV1/HIV-2 antigen/antibody combination immunoassay as the initial assay in the algorithm.

b See Section M, Additional Considerations, for a discussion of issues related to acute HIV-2 infection. 


\section{B. Introduction}

As of 2010, an estimated 1.1 million persons in the United States were living with human immunodeficiency virus (HIV) infection, of whom an estimated 181,000 were unaware of their infection. ${ }^{30}$ Approximately 49,000 new HIV diagnoses are reported to CDC each year, and the estimated number of new infections has remained stable at approximately 50,000 annually from 2008 to $2010 .^{31,32}$ As of 2009 , an estimated 83 million adults aged 18 to 64 years reported they had been tested for HIV. ${ }^{33}$ Accurate laboratory diagnosis of HIV is essential to identify persons who could benefit from treatment, to reassure persons who are uninfected, and to reduce HIV transmission. ${ }^{34}$

\section{Audience}

These recommendations describe the types and sequence of laboratory assays used to make the laboratory diagnosis of acute HIV-1 infection, established HIV-1 infection, and HIV-2 infection. They are intended for use by laboratories authorized to conduct testing on serum or plasma specimens with assays categorized as moderate or high complexity under the Clinical Laboratory Improvement Amendments of 1988 (CLIA). ${ }^{35}$

\section{Scope}

These updated recommendations are intended only for testing of serum or plasma specimens from adults and children aged 2 years or older. Because maternal antibodies against HIV might be present in uninfected infants born to HIV-infected mothers, ${ }^{36,37}$ specific recommendations to establish the presence or absence of the diagnosis of HIV infection in infants are described elsewhere. ${ }^{38}$ These updated recommendations do not address methods or strategies for screening blood or organ donors for HIV infection; the Food and Drug Administration (FDA) and U.S. Public Health Service (USPHS) have issued separate guidance and recommendations on this topic. $^{39-41}$

\section{E. Background and Rationale}

Accurate laboratory diagnosis of HIV infection relies on testing algorithms that maximize overall sensitivity and specificity by employing a sequence of tests in combination and applying decision rules for resolving discordant test results. ${ }^{42}$ Since 1989, the diagnostic algorithm for HIV testing in the United States recommended by CDC and the Association of Public Health Laboratories (APHL) initiated testing with a sensitive HIV-1 antibody immunoassay. Specimens with repeatedly reactive initial immunoassays were then tested with a more specific HIV-1 antibody test, either the HIV-1 Western blot or HIV-1 indirect immunofluorescence assay (IFA), to validate those results. ${ }^{1}$ In 1992, CDC recommended specific testing for both HIV-1 and HIV-2 antibodies if demographic or behavioral information suggested that HIV-2 infection might be present, if there was clinical evidence or suspicion of HIV disease in the absence of a positive test for antibodies to HIV-1, and in cases in which the HIV-1 Western blot exhibited an unusual 
indeterminate pattern. ${ }^{2}$ At that time, $\mathrm{CDC}$ also recommended that laboratories initiating testing with an HIV-1/HIV-2 antibody immunoassay conduct additional, more specific tests to detect the presence of antibodies against HIV-2 if the HIV-1 Western blot was negative or indeterminate. ${ }^{2}$ In 2004, CDC recommended confirmation of all reactive rapid HIV test results with either HIV-1 Western blot or HIV-1 IFA, irrespective of results of intermediate immunoassays that may have been conducted. ${ }^{3}$

Since those recommendations were issued, improved immunoassays (Box 2), an HIV-1 NAT, and a differentiation immunoassay that distinguishes HIV-1 from HIV-2 antibodies received FDA approval for use in the diagnosis of HIV infections. ${ }^{43,44}$ These developments prompted reevaluation of recommendations for HIV diagnostic testing.

\section{Box 2. Evolution of HIV Immunoassay Technology}

HIV immunoassays based on different design principles are generally grouped into "generations":

- 1st generation - All antigens used to bind HIV antibodies are from a lysate of HIV-1 viruses grown in cell culture. An indirect immunoassay format employs labeled antihuman IgG for detection of IgG antibodies. Significant specimen dilution is required to overcome cross-reactivity with cellular protein contaminants. Examples commercially available in the United States as of May 2014 include the HIV-1 Western blot and the HIV-I IFA.

- 2nd generation - Synthetic peptide or recombinant protein antigens alone or combined with viral lysates are used to bind HIV antibodies. An indirect immunoassay format employs labeled antihuman $\operatorname{IgG}$ or protein A (which binds to $\operatorname{IgG}$ with high affinity ${ }^{45}$ ) for detection of $\operatorname{IgG}$ antibodies. Design of the specific antigenic epitopes improves sensitivity for HIV-1 group O and HIV-2; eliminating cellular antigens that contaminate viral lysates improves specificity by eliminating cross-reactivity with cellular proteins. Examples commercially available in the United States as of May 2014 include one HIV-1 enzyme immunoassay and six rapid HIV antibody tests.

- 3rd generation-Synthetic peptide or recombinant protein antigens are used to bind HIV antibodies in an immunometric antigen sandwich format (HIV antibodies in the specimen bind to HIV antigens on the assay substrate and to antigens conjugated to indicator molecules). This allows detection of $\operatorname{IgM}$ and IgG antibodies. Lower sample dilutions and the ability to detect IgM antibodies (which are expressed before IgG antibodies) increase sensitivity during early seroconversion. Examples commercially available in the United States as of May 2014 include one HIV-1/HIV-2 enzyme immunoassay and two HIV-1/HIV-2 chemiluminescent immunoassays.

- 4th generation-Synthetic peptide or recombinant protein antigens are used in the same antigen sandwich format as 3 rd generation assays to detect IgM and IgG antibodies, and monoclonal antibodies are also included to detect p24 antigen. Inclusion of p24 antigen capture allows detection of HIV-1 infection before seroconversion. ${ }^{10,12,46,47}$ These assays (termed "combo" assays") usually do not distinguish antibody reactivity from antigen reactivity. Examples commercially available in the United States as of May 2014 include one HIV-1/HIV-2 enzyme immunoassay, one HIV-1/HIV-2 chemiluminescent immunoassay, and one HIV-1/HIV-2 rapid test that uses separate indicators for antigen and antibody reactivity. 


\section{Laboratory markers of HIV infection and their detection by diagnostic tests}

Analyses of specimens from seroconversion panels have established the dynamics of HIV-1 viremia after infection and the sequential appearance of different laboratory markers. The approximate time at which different markers appear, estimated from different data sources, are outlined schematically in Figure 1. ${ }^{48-50}$

Immediately after HIV infection, low levels of HIV-1 RNA (ribonucleic acid) might be present intermittently, but no viral markers are consistently detectable in plasma. ${ }^{51}$ Approximately 10 days after infection, HIV-1 RNA becomes detectable by NAT in plasma and quantities increase to very high levels. ${ }^{52-56}$ Next, HIV-1 p24 antigen is expressed and quantities rise to levels that can be detected by 4 th generation immunoassays within 4 to 10 days after the initial detection of HIV-1 RNA. ${ }^{46,48}$ However, $\mathrm{p} 24$ antigen detection is transient because, as antibodies begin to develop, they bind to the p24 antigen and form immune complexes that interfere with p24 assay detection unless the assay includes steps to disrupt the antigen-antibody complexes. ${ }^{57-60} \mathrm{Next}$, immunoglobulin (Ig) $\mathrm{M}$ antibodies are expressed which can be detected by 3rd and 4th generation immunoassays 3 to 5 days after p 24 antigen is first detectable, 10 to 13 days after the appearance of viral RNA. ${ }^{46,48,49,61}$ Finally, IgG antibodies emerge and persist throughout the course of HIV infection. First and second generation immunoassays designed to detect only IgG antibodies exhibit considerable variability in their sensitivity during early infection, becoming reactive 18 to 38 days or more after the initial detection of viral RNA. ${ }^{46,48,49,62,63}$

The pattern of emergence of laboratory markers is highly consistent and allows classification of HIV infection into distinct laboratory stages ${ }^{48,64}$ :

- The eclipse period is the initial interval after infection with HIV when no laboratory markers are consistently detectable.

- The seroconversion window period is the interval between infection with HIV and the first detection of antibodies. Its duration depends on the design of the antibody immunoassay and the sensitivity of the immunoassay during seroconversion.

- Acute HIV infection is the interval between the appearance of detectable HIV RNA and the first detection of antibodies. Its duration also depends on the design of the antibody immunoassay and the sensitivity of the immunoassay during seroconversion.

- Established HIV infection is the stage characterized by a fully developed IgG antibody response sufficient to meet the interpretive criteria for a positive Western blot or IFA. ${ }^{1,61,65}$ 
Figure 1. Sequence of appearance of laboratory markers for HIV-1 infection

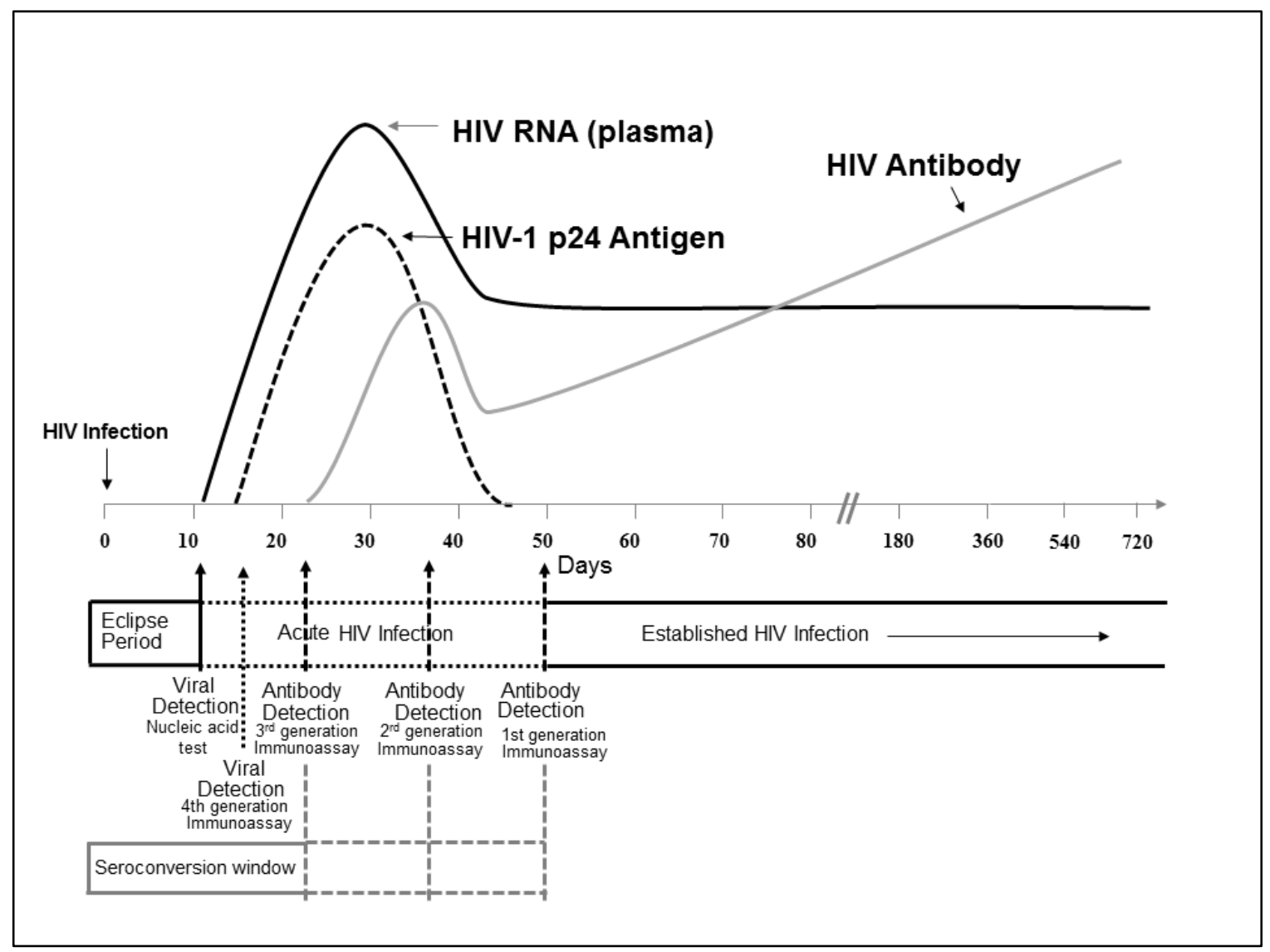

Note. Units for vertical axis are not noted because their magnitude differs for RNA, p24 antigen, and antibody. Modified from MP Busch, GA Satten $(1997){ }^{50}$ with updated data from Fiebig (2003), ${ }^{48}$ Owen $(2008),{ }^{49}$ and Masciotra $(2011,2013){ }^{46,66}$

\section{Need for updated recommendations for the laboratory diagnosis of HIV-1 and HIV-2 infection}

The previous algorithm, consisting of a repeatedly reactive immunoassay for HIV antibodies and positive HIV-1 Western blot or HIV-1 IFA, has been the gold standard for laboratory diagnosis of HIV-1 infection in the United States since 1989. False-positive results from this combination are rare ${ }^{67} \mathrm{HIV}-2$ infection remains uncommon in the United States, and no definitive criteria have been recommended for HIV-2 diagnosis. ${ }^{27}$ Developments and observations in five areas led CDC to update recommendations for the laboratory diagnosis of HIV-1 and HIV-2 infections:

\section{The previous testing algorithm for HIV-1 fails to identify acute HIV-1 infections}

Since 1999, blood screening centers in the United States have used pooled HIV-1 NAT to identify acute HIV infection in donors who had nonreactive 3rd generation immunoassay results. ${ }^{68}$ (To reduce costs, multiple specimens are pooled for screening with a single NAT; specimens from reactive pools undergo individual NAT to identify the specimen with HIV-1 RNA.) Among persons seeking HIV testing, programs that used pooled NAT after a nonreactive 
initial antibody immunoassay result have demonstrated detectable HIV-1 RNA in 2 per 10,000 to 2 per 1,000 persons, depending on the population tested and the generation of the initial immunoassay. ${ }^{4-6,8,16,18}$ Specimens with nonreactive antibody immunoassay results and reactive NAT results that represent acute HIV infection have been described in $4 \%$ to $32 \%$ of all new HIV diagnoses at the time of testing in some populations, especially men who have sex with men. ${ }^{4,6,8,10}$ Retrospective testing of specimens from high-risk persons demonstrated that 3rd generation immunoassays were reactive in $20 \%$ to $37 \%$ of specimens that were HIV-1 Western blot-negative but NAT-reactive, ${ }^{69-71}$ and that 4 th generation immunoassays were reactive in $62 \%$ to $83 \%$ of specimens that were NAT-reactive but nonreactive with earlier generation immunoassays. $^{71-73}$

\section{Assays that detect HIV-1 infection earlier are now widely available}

New generations of immunoassays with improved sensitivity for detecting early HIV-1 infection can narrow the interval between the time of infection and initial immunoassay reactivity (Box 2 , Figure 1). In 2006, 74\% of U.S. public health laboratories used a 1st or 2 nd generation immunoassay as the initial test in the previous algorithm. ${ }^{74}$ In $2012,92 \%$ of public health laboratories used a $3 \mathrm{rd}$ or 4 th generation immunoassay as the initial test in the previous algorithm. ${ }^{75}$ However, these immunoassays become reactive days to weeks before the HIV-1 Western blot becomes positive. ${ }^{46,49}$ Using the HIV-1 Western blot for confirmation of these immunoassays can produce false-negative results during seroconversion. ${ }^{10,76}$

\section{The risk of HIV-1 transmission from persons with acute and early infection is much higher than that from persons with established infection.}

Extremely high levels of infectious virus become detectable in serum and genital secretions during acute HIV-1 infection and persist for 10-12 weeks. ${ }^{77-79}$ Models based on data from cohort studies suggest that the rate of sexual transmission during acute infection is 26 times as high as that during established HIV-1 infection. ${ }^{20}$ Acute HIV-1 infection, despite its short duration, can account for $10 \%-50 \%$ of all new HIV-1 transmissions, especially in persons who have multiple concurrent sex partners or high rates of partner change. ${ }^{19,21,22,80}$

\section{Initiation of antiretroviral therapy (ART) during the early stage of HIV-1 infection can benefit patients and reduce HIV transmission}

Treatment of acute and early HIV-1 infection with combination ART improves laboratory markers of disease progression. ${ }^{81,82}$ Limited data also suggest that treatment of acute HIV-1 infection might decrease the severity of acute disease, lower the viral set point, slow disease progression rates in the event therapy is stopped, reduce the size of the viral reservoir, and decrease the rate of viral mutation by suppressing viral replication and preserving immune function. ${ }^{23-26,83}$ Because very high levels of virus in blood and genital secretions increase infectiousness during and immediately after acute HIV infection, initiating treatment during acute infection can also reduce the risk of HIV-1 transmission substantially. ${ }^{23,77,84}$ In March 
2012, the U.S. Department of Health and Human Services Panel on Antiretroviral Guidelines for Adults and Adolescents recommended initiation of ART for all persons with HIV-1 infection to reduce the risk of disease progression and to prevent HIV transmission. ${ }^{23}$

\section{The use of HIV-1 Western blot in the previous algorithm misclassifies the majority of HIV-2 infections}

Correct identification of HIV-2 infections is challenging, but accurate diagnosis of HIV-2 is clinically important because some antiretroviral agents effective against HIV-1 (including nonnucleoside reverse transcriptase inhibitors and some protease inhibitors) are not effective against HIV-2 ${ }^{85,86}$ Considerable serologic cross-reaction occurs between HIV-1 and HIV-2, but screening exclusively with tests for HIV-1 antibodies failed to detect $15 \%$ to $53 \%$ of HIV-2 infections. ${ }^{49}$ As of May 2014, all FDA-approved 3rd and 4th generation immunoassays incorporate specific antigens to detect antibodies directed against both HIV-1 and HIV-2. ${ }^{87}$ When HIV-1/HIV-2 immunoassays are repeatedly reactive, CDC's previous recommendations advised specific testing for HIV-2 for specimens with negative or indeterminate HIV-1 Western blot results. ${ }^{2}$ However, studies published in 2010 and 2011 showed that the HIV-1 Western blot was interpreted as positive for HIV-1 in $46 \%$ to $85 \%$ of specimens from persons found to be infected with HIV-2, resulting in incorrect or delayed diagnosis. ${ }^{27-29}$ The rapid immunoassay approved by the FDA in 2013 for use in algorithms to differentiate HIV-1 from HIV-2 antibodies correctly classifies the majority of both HIV-1 and HIV-2 infections in antibody-positive specimens, including the subset misclassified as HIV-1 by the HIV-1 Western blot. ${ }^{28,29,47,76,88}$

\section{F. Process for Developing Updated Recommendations}

These updated recommendations are the product of a lengthy, multistep process. In 2004, CDC and APHL established an HIV Steering Committee --composed of CDC and public health laboratory scientists with expertise in HIV diagnostics-- to monitor HIV testing practices, investigate reports of problems with the performance or availability of HIV testing reagents, and assess potential implications of new assays as they received FDA approval. When the shortcomings of previous HIV testing recommendations became evident, ${ }^{5,9,16,18}$ the HIV Steering Committee organized a working group in August 2006 with representatives from CDC, APHL, FDA, the National Alliance of State and Territorial AIDS Directors (NASTAD), HIV testing program managers, and scientists from academic, hospital, and commercial laboratories and blood donor screening programs who had expertise in HIV, immunology, laboratory medicine, and evaluation of diagnostic tests (Appendix 1). The Steering Committee asked the working group to examine the evidence for the performance of HIV assays and the previous algorithm for laboratory HIV diagnosis and to propose new algorithms for HIV diagnosis that maximized accuracy, relied on FDA-approved tests, and considered testing costs and cost-effectiveness. A subset of this working group served as the writing group that drafted these recommendations (Appendix 1). 
The working group sought assistance from CDC laboratory scientists, who evaluated the performance of available FDA-approved assays on panels of plasma specimens from HIVinfected and uninfected persons and on sequential specimens from persons early in seroconversion; analyzed test combinations in two-test and three-test algorithms; and compared these results to results of the 1989 algorithm for HIV-1 diagnosis. The working group conducted a nonsystematic literature review on the performance characteristics of HIV tests and their use in combinations for HIV-1 diagnosis and examined unpublished data generated by studies at CDC and other public health laboratories. Based on the information from the literature review, unpublished data, and expert opinion, the working group proposed several candidate HIV diagnostic algorithms, disseminated descriptions of the candidate algorithms, and solicited data evaluating the algorithms in the call for abstracts for the 2007 HIV Diagnostics Conference. ${ }^{89}$ New research findings were presented and discussed at the conference, and the working group obtained oral comments during the closing session of the conference about the feasibility, benefits, harms, and costs of new testing strategies from conference attendees, who included managers and staff members from public health department HIV testing programs and scientists from clinical, commercial, and public health laboratories, blood donation programs, and manufacturers of HIV tests and testing equipment.

Based on the literature review, expert opinion, and new research findings presented at the 2007 HIV Diagnostics Conference, ${ }^{89}$ including CDC's analysis of the relative sensitivity during seroconversion of FDA-approved immunoassays compared with the HIV-1 Western blot, ${ }^{49}$ the working group developed a synopsis, HIV Testing Algorithms: A Status Report, ${ }^{90}$ issued in April 2009 , that described the candidate algorithms and their limitations. The report outlined the key elements of each candidate algorithm, available performance data, potential benefits and drawbacks, and additional data needed to substantiate and refine the algorithm. In that report, the working group acknowledged that none of the candidate algorithms offered a distinct advantage over previous recommendations. For example, performing NAT after all nonreactive antibody test results could detect acute HIV-1 infection, but its routine use would be impractical and costly. Additionally, most algorithms still included the HIV-1 Western blot and could not consistently detect acute HIV-1 infections or HIV-2 infections without the collection of demographic, behavioral, or clinical information that might suggest the need for additional testing. Moreover, new tests such as 4th generation assays were nearing commercialization, and their routine use could render the candidate algorithms obsolete.

In July 2009, the HIV Steering Committee solicited additional data on the performance of candidate algorithms and 4th generation immunoassays in the call for abstracts for the $2010 \mathrm{HIV}$ Diagnostics Conference. ${ }^{91}$ At the March 2010 conference, representatives from the American Society for Microbiology, the College of American Pathologists, the Department of Defense, FDA, NASTAD, the Pan American Society for Clinical Virology, public health department HIV testing programs, and scientists from clinical, commercial, and public health laboratories, blood donation programs, and the diagnostics industry reviewed and discussed the research findings and their implications for new testing algorithms. (Manuscripts from conference presentations 
were submitted for peer review and published in the December 2011 supplement to the Journal of Clinical Virology. ${ }^{92}$ ) Based on expert opinion, new data presented at the conference (including evidence for misclassification of HIV-2 infections by the HIV-1 Western blot), and anticipation of commercialization of 4th generation immunoassays in the United States, CDC and APHL laboratory experts proposed a new diagnostic algorithm. The algorithm included 4th generation HIV-1/HIV-2 antigen/antibody combination immunoassays (approved by FDA in 2010 and 2011) and an HIV-1/HIV-2 antibody differentiation assay. The proposed algorithm was intended to improve the accurate diagnosis of acute HIV-1 infection and HIV-2 infection in the absence of clinical, behavioral, or demographic information that is not routinely available to laboratories. ${ }^{93}$

To validate the proposed algorithm for supplemental testing, CDC and public health laboratories retrospectively applied available existing test results in the sequence specified by the proposed algorithm ${ }^{29,70,76,94}$ and evaluated the 4th generation immunoassays and proposed algorithm on the same specimen collections that had been tested previously. ${ }^{46,66}$ The HIV Steering Committee then used the call for abstracts for the 2012 HIV Diagnostics Conference to solicit additional data on the performance of new tests and the proposed algorithm. Three CDC writing group members (Branson, Owen, Wesolowski) developed a figure and draft statements for consideration during the conference describing the proposed algorithm and possible variations if different assays were substituted for those in the proposed algorithm. ${ }^{95} \mathrm{CDC}$ writing group members solicited oral comments on the proposed algorithm from stakeholders who attended the December 2012 HIV Diagnostics Conference, representing commercial and public health laboratories that conduct HIV testing, HIV testing programs, manufacturers of HIV tests and testing equipment, providers of HIV clinical and preventive services, and persons with HIV. ${ }^{96}$ Their input on the proposed algorithm was informed by conference presentations that compared the performance, cost, and cost-effectiveness of the proposed algorithm with the previous algorithm and alternatives. ${ }^{97-99}$ Manuscripts from conference presentations were submitted for peer review and published in the December 2013 supplement to the Journal of Clinical Virology. ${ }^{100} \mathrm{CDC}$ writing group members also solicited oral comments on the proposed algorithm from other stakeholders at meetings of the CDC-HRSA Advisory Committee, American Association of Clinical Chemistry, Association of Medical Laboratory Immunologists, College of American Pathologists, and the Pan American Society for Clinical Virology. After stakeholders expressed support for the proposed recommendations, the writing group finalized the recommendations. The draft recommendations and their underlying evidence were then reviewed by three independent HIV testing experts not involved in development of the recommendations (in accordance with Office of Management and Budget Regulations for peer review of influential scientific information from the federal government ${ }^{101}$ ) and by officials at CDC, the FDA, and the Department of Health and Human Services.

\section{G. Literature Reviews and Key Questions}

The CDC/APHL working group members conducted a nonsystematic review of the literature, unpublished data, meeting abstracts and presentations, and manufacturers' package inserts in 
2009 to assess the performance of FDA-approved HIV diagnostic assays and their use in combination for the laboratory diagnosis of acute and established HIV-1 infection. Three CDC writing group members (Branson, Owen, Wesolowski) updated this with a systematic literature review in 2013 focused on 10 key questions:

1. What is the sensitivity of individual assays in specimens from persons

a. with established HIV-1 and established HIV-2 infection?

b. with acute HIV-1 infection?

2. What is the specificity of individual assays in specimens from uninfected persons?

3. What is the accuracy of the previous and recommended algorithms based on combinations of assays in specimens from persons

a. with established HIV-1 infection?

b. with acute HIV-1 infection?

c. with established HIV-2 infection?

d. not infected with HIV-1 or HIV-2?

4. What algorithm(s) requires the minimum number of assays to maximize the accuracy of the laboratory diagnosis of HIV-1 infection and HIV-2 infection and minimize the number of specimens with indeterminate or inconclusive test results?

5. Do the costs and cost-effectiveness of the proposed algorithm for the diagnosis of HIV infection differ from the costs and cost-effectiveness of the previous algorithm?

6. Do benefits and harms for patients associated with the proposed diagnostic algorithm differ from benefits and harms associated with the previous diagnostic algorithm?

Three CDC writing group members who reviewed the evidence used the following definitions and reference criteria for evaluation of study outcomes:

- Established HIV-1 infection: repeatedly reactive immunoassay results and positive HIV-1 Western blot or HIV-1 IFA result

- Acute HIV-1 infection: reactive HIV-1 NAT result and negative or indeterminate HIV-1 antibody immunoassay, HIV-1 Western blot, or HIV-1 IFA result

- False-positive immunoassay result: repeatedly reactive immunoassay results, negative or indeterminate HIV-1 Western blot or HIV-1 IFA result, negative HIV-1 NAT result, and negative HIV-2 test results

- False-negative immunoassay result: nonreactive immunoassay result and reactive HIV-1 NAT result

- False-negative NAT result: repeatedly reactive immunoassay results, positive HIV-1 Western blot result and negative HIV-1 NAT result

- Established HIV-2 infection: expert interpretation based on the results of tests described in each study (because no definitive diagnostic algorithm and no FDA-approved test for confirming the presence of HIV-2 infection existed as of May 2014) 
- Accuracy of algorithms: the number or percentage of all specimens from a given algorithm that, based on all available test results and follow-up information, yielded a correct laboratory diagnosis of HIV-1 infection, HIV-2 infection, or the absence of HIV infection. True-positive and true-negative results were classified as correct laboratory diagnoses. False-negative, false-positive, and indeterminate results, and HIV-2 infections misclassified as HIV-1 were classified as incorrect laboratory diagnoses.

Appendix 2 provides details of the search strategy and a detailed summary and tables of evidence for the published studies relevant to the key questions.

\section{H. Recommendations for Laboratory Testing for the Diagnosis of HIV Infection}

CDC and APHL recommend that laboratories conduct the following sequence of assays with serum or plasma specimens for the accurate diagnosis of HIV infection. Each recommendation lists the rationale for the recommendation and refers to additional evidence and limitations in the corresponding summary and tables of evidence in Appendix 2. These updated recommendations for testing of serum or plasma specimens supersede the 1989 recommendations for interpretation and use of the HIV-1 Western blot in the serologic diagnosis of HIV Type 1 infections, ${ }^{1}$ the 1992 recommendations for testing for antibodies to HIV Type 2 in the United States, ${ }^{2}$ and the 2004 recommended protocol for confirmation of rapid HIV tests. ${ }^{3}$ Because none of the assays in the recommended algorithm are FDA-approved for use with oral fluid or dried blood spot specimens, these updated recommendations do not supersede previous recommendations for testing of dried blood spots or oral fluid for HIV-1 using the FDA-approved immunoassay and HIV-1 Western blot for these specimen types. ${ }^{1}$

1. Laboratories should conduct initial testing for HIV with an FDA-approved antigen/antibody combination (4th generation) immunoassay ${ }^{*}$ that detects HIV-1 and HIV-2 antibodies and HIV-1 p24 antigen to screen for established infection with HIV-1 or HIV-2 and for acute HIV-1 infection. No further testing is required for specimens that are nonreactive on the initial immunoassay.

Rationale: Initial testing with a 4th generation antigen/antibody combination immunoassay detects more acute HIV-1 infections than initial testing with a 3rd generation antibody immunoassay and identifies comparable numbers of established HIV-1 and HIV-2 infections, with comparable specificity.

Evidence basis (Appendix 2): 1.a.1, 1.a.2, 1.b.1, 2.a, 2.b, 3.a, 3.b, 3.c, 4.a, 4.b, $\underline{5}$

2. Specimens with a reactive antigen/antibody combination immunoassay result (or repeatedly reactive, if repeat testing is recommended by the manufacturer or required by regulatory authorities) should be tested with an FDA-approved antibody immunoassay

\footnotetext{
* Exception: As of April 2014, data are insufficient to recommend use of the FDA-approved single-use rapid HIV1/HIV-2 antigen/antibody combination immunoassay as the initial assay in the algorithm.
} 
that differentiates HIV-1 antibodies from HIV-2 antibodies. Reactive results on the initial antigen/antibody combination immunoassay and the HIV-1/HIV-2 antibody differentiation immunoassay should be interpreted as positive for HIV-1 antibodies, HIV2 antibodies, or HIV-1 and HIV-2 antibodies, undifferentiated.

Rationale: Use of the HIV-1/HIV-2 antibody differentiation assay after a reactive initial 4th generation HIV-1/HIV-2 antibody immunoassay detects HIV-1 antibodies earlier than the HIV-1 Western blot, reduces indeterminate results, and identifies HIV-2 infections. Turnaround time for test results is shorter and the cost is lower for the HIV1/HIV-2 antibody differentiation assay compared with the HIV-1 Western blot. Available evidence is insufficient to recommend specific additional testing, without clinical follow-up, for specimens that are dually reactive for HIV-1 and HIV-2 antibodies on the differentiation immunoassay (see Section J, Limitations of the

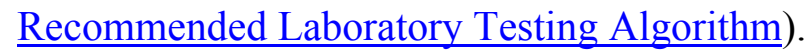

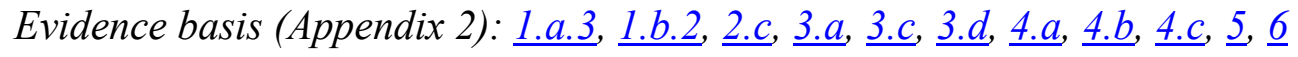

3. Specimens that are reactive on the initial antigen/antibody combination immunoassay and nonreactive or indeterminate on the HIV-1/HIV-2 antibody differentiation immunoassay should be tested with an FDA-approved HIV-1 NAT.

- A reactive HIV-1 NAT result and nonreactive HIV-1/HIV-2 antibody differentiation immunoassay result indicates laboratory evidence for acute HIV-1 infection.

- A reactive HIV-1 NAT result and indeterminate HIV-1/HIV-2 antibody differentiation immunoassay result indicates the presence of HIV-1 antibodies confirmed by HIV-1 NAT.

- A negative HIV-1 NAT result and nonreactive or indeterminate HIV-1/HIV-2 antibody differentiation assay result indicates a false-positive result on the initial immunoassay. ${ }^{\dagger}$

Rationale: HIV-1 NAT results can distinguish acute HIV-1 infection from falsepositive initial immunoassay results in specimens with a reactive antigen/antibody immunoassay and a nonreactive HIV-1/HIV-2 antibody differentiation assay result. HIV-1 NAT does not detect HIV-2, and no HIV-2 NAT is FDA-approved. Available evidence is insufficient to recommend testing for acute HIV-2 infection after a nonreactive HIV-1 NAT result (see Section K, Limitations of the Evidence Supporting These Recommendations).

Evidence basis: (Appendix 2): 1.b.1, 2.e, $\underline{3 . b}, \underline{3 . d}, \underline{4 . a}, \underline{4 . b}, \underline{5}, \underline{6}$

\footnotetext{
${ }^{\dagger}$ See Section M, Additional Considerations, for a discussion of issues related to acute HIV-2 infection.
} 
4. Laboratories should use this same testing algorithm, beginning with a laboratory-based antigen/antibody combination immunoassay, with serum or plasma specimens submitted for testing after a reactive (preliminary positive) result from any rapid HIV test.

Rationale: Previously, supplemental testing (HIV-1 Western blot or HIV-1 IFA) was recommended after a reactive rapid HIV test result regardless of the result of the initial laboratory immunoassay. This was based on observations of some false-negative results from earlier generations of immunoassays (no longer commercially available in the United States) that became reactive later during seroconversion than rapid HIV antibody tests. ${ }^{3}$ With the recommended algorithm, the FDA-approved laboratory-based antigen/antibody combination immunoassays detect HIV infection earlier during seroconversion than any of the rapid HIV tests available in the United States as of May 2014, including the rapid HIV-1/HIV-2 antigen/antibody combination test. Therefore, no supplemental testing is required for specimens that are nonreactive on the initial immunoassay in the recommended algorithm.

Evidence basis (Appendix 2): 1.a.1, 1.b.1, $\underline{4 . d}$

\section{Alternative Testing Sequences When Tests in the Recommended Algorithm Cannot be Used}

During their review and comment on these recommendations, stakeholders described circumstances that might delay or prevent implementation of some of the assays in the recommended algorithm. Based on the evidence review and expert opinion from stakeholders and the working group, CDC members of the writing group identified testing sequences that might be used to improve the laboratory diagnosis of HIV infection if an alternative FDAapproved assay is substituted for one of the classes of assays specified in the recommended algorithm. Replacing a recommended assay has limitations described below that may reduce the accuracy of the testing algorithm.

- Use of a 3rd generation HIV-1/2 antibody immunoassay instead of a 4th generation antigen/antibody combination immunoassay as the initial test: perform subsequent testing as specified in the recommended algorithm.

Limitations: This alternative will miss some acute HIV-1 infections in antibodynegative persons that would be detected by 4th generation antigen/antibody combination immunoassays.

Supporting evidence (Appendix 2): $\underline{1 . a .1}, \underline{1 . a .3}, \underline{1 . b .1}, \underline{1 . b .2}, \underline{3 . a}, \underline{3 . b}, \underline{3 . c}, \underline{3 . d}, \underline{4 . a}, \underline{5}, \underline{6}$

- Use of the HIV-1 Western blot or HIV-1 IFA as the second test in the algorithm instead of an HIV-1/HIV-2 antibody differentiation immunoassay: if test results are negative or indeterminate, perform HIV-1 NAT; if HIV-1 NAT is negative, perform HIV-2 antibody immunoassay. 
Limitations: This alternative might misclassify some HIV-2 infections as HIV-1, requires a larger number of tests, and increases turnaround time for test results.

Supporting evidence (Appendix 2): 1.a.3, 1.b.2, 2.c, 3.b, 3.c, 3.d, 4.a, 4.c, 5, 6

- Use of HIV-1 NAT as the second test instead of an HIV-1/HIV-2 antibody differentiation immunoassay: If HIV-1 NAT result is negative, perform an HIV-1/HIV-2 antibody differentiation immunoassay or other FDA-approved HIV-1 supplemental antibody test. If result of an HIV-1 supplemental antibody test is nonreactive or indeterminate, perform an HIV-2 antibody test.

Limitations: This alternative fails to distinguish acute HIV-1 infection from established HIV-1 infection, increases turnaround time for test results and incurs additional costs.

Supporting Evidence (Appendix 2): 1.a.2, 2.e, $\underline{3 . b}, \underline{4 . b}, \underline{5}, \underline{6}$

- Use of HIV-1 NAT (or pooled HIV-1 NAT) after a nonreactive 3rd or 4th generation immunoassay result: a reactive NAT result provides evidence of acute HIV-1 infection, but false-positive results occur. Follow-up testing to document seroconversion should be conducted if a laboratory HIV diagnosis is based on the result of HIV-1 NAT only.

Limitations: No HIV-1 NAT is FDA-approved for pooled testing for HIV diagnosis. Individual or pooled HIV-1 NAT can detect acute infections not detected by a 4th generation immunoassay, but occasionally produces a false-positive result, requires more tests on each specimen, increases turnaround time for test results, and is more costly than the recommended algorithm.

Supporting evidence (Appendix 2): $\underline{2 . e}, \underline{4 . b}, \underline{5}, \underline{6}$

\section{J. Limitations of the Recommended Laboratory Testing Algorithm}

1. No diagnostic test or algorithm can be completely accurate in all cases of HIV infection. Rare instances have been reported of persons who remained persistently negative for antibodies despite detectable HIV RNA. ${ }^{102}$ False-positive HIV test results have been attributed to specimen mix-up, mislabeling, and to autoimmune disorders. ${ }^{103-106}$ Inconsistent or conflicting test results should be investigated with follow-up testing on a newly collected specimen.

2. A small percentage of specimens produce results that are undifferentiated (dually reactive for HIV-1 and HIV-2 antibodies) on the HIV-1/HIV-2 antibody differentiation assay after completing all testing procedures recommended by the manufacturer. The frequency of dually reactive results on the HIV-1/HIV-2 antibody differentiation assay in the United States is unknown and follow-up data are limited. One study reported $5(0.50 \%)$ of 993 specimens with repeatedly reactive immunoassay results were dually reactive with the HIV-1/HIV-2 antibody differentiation assay approved by the FDA as of March 2013. ${ }^{107}$ Three specimens with strong HIV-1 reactivity and weak HIV-2 reactivity were negative 
by HIV-2 immunoblot and positive for all HIV-1 Western blot bands. One specimen with strong reactivity for both the HIV-1 and HIV-2 indicators was positive by HIV-2 immunoblot; HIV-2 RNA was detected and HIV-1 RNA was undetectable. The fifth specimen, with weak reactivity for both the HIV-1 and HIV-2 indicators, lacked sufficient volume for definitive resolution. The authors concluded that strong reactivity at the indicator for HIV-2 suggested the need for more specific HIV-2 testing. ${ }^{107}$ Published data and genotypic analyses from West Africa, where HIV-2 infection is endemic and where the largest number of dual HIV-1/HIV-2 infections have been reported, indicate that most specimens dually reactive for HIV-1 and HIV-2 antibodies represent HIV-1 infections with cross-reactivity to HIV-2 antigens. ${ }^{108,109}$ A single case of dual HIV$1 /$ HIV-2 infection has been reported in the United States in a patient who reported sexual contact with a person from Gambia. ${ }^{110}$ No other published studies of U.S. populations provide evidence to recommend specific additional tests for specimens with dually reactive antibody test results. Based on expert opinion, the low prevalence of HIV-2 infection in the United States, and the lack of an FDA-approved NAT for HIV-2, laboratories should report dually reactive test results as positive for HIV antibodies that could not be differentiated as HIV-1 or HIV-2, and recommend further investigation for HIV-2 if clinically indicated (for example, if HIV-1 RNA is undetectable on the viral load assay conducted as part of the initial medical workup). See Section M, Additional Considerations, for information related to HIV-2 infection.

3. None of the assays in the updated recommended algorithm are FDA-approved for use with oral fluid or dried blood spot specimens. Laboratories should follow the 1989 recommendations ${ }^{1}$ (http://stacks.cdc.gov/view/cdc/7344) for using the HIV-1 immunoassay and HIV-1 Western blot approved by the FDA for these specimen types.

4. The recommended algorithm has not been evaluated in persons taking ART for preexposure or postexposure prophylaxis. Occurrences of delayed seroconversion have been reported in persons taking ART for preexposure ${ }^{111}$ and postexposure prophylaxis. ${ }^{112}$ As of May 2014, data are insufficient to determine whether additional follow-up testing might be indicated for persons taking ART.

5. The recommended algorithm has not been evaluated in specimens from persons with long-term HIV suppression from antiretroviral therapy. Studies document that antibody levels diminish, some immunoassays become nonreactive, and the HIV-1 Western blot reverts from positive to indeterminate in a small percentage of patients who maintain undetectable levels of HIV, especially after antiretroviral therapy initiated early during the acute phase of infection. ${ }^{113-116}$ It has been postulated that rapid and effective virologic suppression due to potent, early antiretroviral therapy may result in levels of antigenic stimulation that are inadequate for developing and maintaining HIV-1-specific antibody responses. ${ }^{115}$ Although one study demonstrated the FDA-approved HIV-1/HIV-2 antibody differentiation assay remained reactive in patients with various levels of 
exposure to antiretroviral therapy ${ }^{117}$ as of May 2014, data are insufficient to determine whether the recommended algorithm might produce false-negative results with specimens from persons taking antiretroviral therapy who have maintained long-term viral suppression.

6. The recommended algorithm increases the ability to detect acute HIV-1 infection, but no laboratory assay can detect HIV infection immediately after it is acquired. The duration of the eclipse period between infection and the appearance of HIV RNA is not welldefined from clinical studies and likely varies with the infection route, inoculum size, and sensitivity of the NAT used to detect HIV-1 nucleic acids.

\section{K. Limitations of the Evidence Supporting These Recommendations}

1. Evaluations of test performance were based on comparison with a composite standard for the presence of HIV infection that consisted of a positive HIV-1 Western blot, the presence of HIV-1 RNA, or both. Clinical evidence from follow-up evaluations was rarely available to document true HIV status (for example, antibody seroconversion after a specimen reactive only for HIV-1 NAT, or the subsequent detection of HIV-1 RNA in specimens that were classified as positive for HIV-1 antibody by the HIV-1/HIV-2 differentiation assay). Therefore, it is possible that some false-positive test results might have gone undetected in the performance evaluations.

2. Only two HIV-1/HIV-2 antigen/antibody combination immunoassays, one HIV-1/HIV-2 antibody differentiation immunoassay, and one HIV-1 NAT were approved by the FDA for HIV diagnosis as of December 2012 (Appendix 2, Table 2). All performance evaluations of the recommended diagnostic testing algorithm were conducted with these assays. Additional evaluations will be required with new assays as they are introduced and receive FDA approval.

3. Published studies document indeterminate results (reactivity to only the synthetic gp41 peptide or recombinant gp 41 protein, but not both) in $0.8 \%$ to $1.4 \%$ of specimens with reactivity on the FDA-approved HIV-1/HIV-2 antibody differentiation immunoassay; $11 \%$ to $15 \%$ of specimens with indeterminate results proved to be HIV-negative. ${ }^{76,118}$ No published data from follow-up testing are available to definitively determine whether indeterminate results in specimens with detectable HIV-1 RNA represent an evolving antibody response consistent with antibody development during acute infection or whether indeterminate results might persist during established infection in some persons.

4. Little evidence exists for the timing of antibody development after infection with HIV-2 or the occurrence of acute HIV-2 infection in the United States, and no HIV-2 NAT is FDA-approved. The 4th generation antigen/antibody combination assays detect IgM and IgG antibodies against both HIV-1 and HIV-2 and also p24 antigen, specific for HIV-1, but not $\mathrm{p} 26 / 27$, the counterpart core protein in HIV-2. ${ }^{66}$ The HIV-1/HIV-2 antibody differentiation assay detects only IgG antibodies against HIV-1 and HIV-2. Therefore, it 
is possible that IgM antibodies against HIV-2 might have been present in a small number of specimens with a repeatedly reactive 4 th generation immunoassay result that were classified as HIV-negative on the basis of a nonreactive HIV-1/HIV-2 antibody differentiation assay result and negative HIV-1 NAT. See Section M, Additional Considerations, for a discussion of issues related to acute HIV-2 infection.

5. Rare cases of a "second window" during early seroconversion during which antigen/antibody combination tests transiently revert to nonreactive have been reported outside the United States with older versions of 4th generation tests than those that are FDA-approved. ${ }^{119-121}$ One case of a "second window" of 8 days' duration was observed in a study of 28 patients in Africa and Thailand with acute, non-B subtype HIV infections identified by frequent RNA testing. ${ }^{122}$ Subsequent testing was conducted with immunoassays and viral load assays at frequent intervals. In this case, an FDA-approved 4th generation assay became reactive for antigen at day 9 after RNA detection, was subsequently nonreactive between days 17-25, and became reactive again at day 29 when antibody levels, detected by a 3rd generation assay, began to rise. Presumably, this phenomenon was due to the short interval when antibodies begin to appear during which antigen bound to antibody inhibits detection of either antigen or antibody by the assays. Experience with the FDA-approved 4th generation immunoassays is too limited to predict whether or how often transient seroreversion might occur in patients with subtype B infections.

\section{How These Updated Recommendations Differ From Previous Recommendations}

Compared with previous testing recommendations, the updated algorithm increases sensitivity for acute HIV-1 infection by including an initial immunoassay that detects antibodies to both HIV-1 and HIV-2 and also HIV-1 p24 antigen, which can be detected before antibodies develop. The updated algorithm identifies acute HIV-1 infection by using HIV-1 NAT for specimens that are reactive on the initial immunoassay but negative for antibodies on the second immunoassay.

The previously recommended HIV testing algorithms were predicated on screening for HIV-1 antibodies, ${ }^{1}$ specific testing for HIV-2 antibodies was confined to only limited circumstances. ${ }^{2}$ The updated algorithm screens for both HIV-1 and HIV-2 antibodies, and distinguishes HIV-1 from HIV-2 antibodies using a single supplemental antibody differentiation immunoassay. This diagnostic approach is simpler and more accurate than CDC's 1992 recommendations because it no longer depends on laboratory access to clinical, demographic or behavioral information suggestive of possible HIV-2 exposure. Because the recommended algorithm no longer relies on HIV-1 Western blot or HIV-1 IFA as a supplemental test, it yields fewer specimens with indeterminate results that require resolution by a follow-up test conducted several months later.

Previously, supplemental testing with HIV-1 Western blot or HIV-1 IFA was recommended for all specimens submitted for testing after a reactive rapid HIV test result even if the initial laboratory immunoassay was nonreactive. With the updated recommendation, specimens 
submitted after any reactive rapid HIV test result (including the HIV-1/HIV-2 antibody differentiation assay, when it is used as an initial rapid test, and the HIV-1/HIV-2 antigen/antibody combination rapid test) are tested according to the same algorithm as all other specimens. No further supplemental testing is required if the result of the initial antigen/antibody combination immunoassay is nonreactive.

\section{Additional Considerations}

Medical evaluation and follow-up testing. A laboratory diagnosis of HIV infection identifies the need for HIV medical care. Rarely, specimen mix-up or unexplained cross-reactivity may result in an incorrect laboratory diagnosis with either the previous or the recommended algorithm. ${ }^{76,123}$ The Department of Health and Human Services Panel on Antiretroviral Guidelines for Adults and Adolescents recommends a baseline evaluation for every HIV-infected patient entering into care, with a complete medical history, physical examination, and laboratory evaluation, including plasma HIV-1 RNA viral load, CD4 determination, and an antiretroviral resistance assay, to confirm the presence of HIV infection, stage HIV disease, and assist in the selection of an initial antiretroviral drug regimen. ${ }^{23}$ If HIV-1 RNA is below the assay's limit of detection, repeat or additional testing is indicated to verify the diagnosis of HIV infection.

Participants in HIV vaccine trials. Recipients of HIV vaccines might have vaccine-induced antibodies that produce reactive HIV antibody test results. ${ }^{124}$ Laboratories should advise persons who order HIV testing that vaccine recipients with reactive immunoassay results should be encouraged to contact a vaccine trial site for specialized testing necessary to determine their HIV infection status. ${ }^{125}$

$\boldsymbol{H I V}-2$ infection. Fewer than 200 cases of HIV-2 in the United States had been reported to CDC through $2009,{ }^{27}$ although criteria for an HIV-2 case definition were not specified until $2014 .{ }^{126}$ The majority of HIV-2 diagnoses in the United States have been made in persons born in Africa, especially West Africa, but $12 \%$ of HIV-2 diagnoses were made in persons whose birthplace was India, North America or Europe. ${ }^{27,28}$ It is theoretically possible that acute HIV-2 infection might produce a repeatedly reactive $\mathrm{HIV}-1 / \mathrm{HIV}-2$ antigen/antibody combination immunoassay result with nonreactive HIV-1/HIV-2 antibody differentiation assay and HIV-1 NAT results. Based on expert opinion and the low prevalence of HIV-2 infection in the United States, this sequence of test results most likely indicates a false-positive initial immunoassay result. Laboratories should report that such test results indicate no laboratory evidence for HIV-1 infection and suggest follow-up testing for HIV-2 if clinically indicated. Although accurate diagnosis of HIV-2 is clinically important because HIV-2 strains are naturally resistant to several antiretroviral drugs developed to suppress HIV-1, ${ }^{127}$ diagnosis of HIV-2 can be problematic. Only two reports of acute HIV-2 infections have been published; both occurred in West Africa and were documented by seroconversion. ${ }^{128,129}$ The reliability of HIV-2 NAT during acute HIV-2 infection is unknown. In specimens obtained 5 to 6 months after seroconversion, plasma HIV-2 viral load was 28 times lower in HIV-2 seroconverters than among comparable HIV-1 seroconverters. ${ }^{130}$ 
Because HIV-2 RNA is undetectable in at least half of HIV-2 infected patients, testing for proviral DNA may be required for definitive diagnosis. ${ }^{131,132}$ No tests for HIV-2 RNA or DNA have received FDA approval. If additional testing for HIV-2 is requested, HIV-2 NAT for which the analytic performance characteristics have been determined may be available from commercial laboratories, city or state public health laboratories, or CDC. ${ }^{28,133,134}$

Specimen collection and storage requirements. Freshly collected serum or plasma specimens yield the most accurate HIV test results. Specimen volume also influences the ability to perform the recommended algorithm because a larger volume is needed for specimens that require testing by both the HIV-1/HIV-2 differentiation immunoassay and HIV-1 NAT. A venipuncture specimen of at least $5 \mathrm{ml}$ of whole blood is necessary to yield at least $2 \mathrm{ml}$ of serum or plasma needed to conduct all assays in the recommended algorithm. Some laboratories require a separate specimen for NAT. Specific assays that can be used in the recommended algorithm have different requirements for specimen collection, storage temperatures, and the need for or timing of separating cells from serum or plasma. These requirements are specified by the manufacturer and sometimes change. Ensuring accurate results requires that laboratories

- carefully review manufacturer's instructions in each assay's package insert to determine requirements for acceptable specimen types (serum, plasma), volume, collection tubes, anticoagulants, cell separation, storage and shipping requirements, and timeframes (keeping in mind that these include shipping periods)

- communicate these specific requirements to the persons who submit specimens for testing

- request collection of another specimen from a second venipuncture if all tests cannot be performed on the same specimen

- confirm handling, storage, and shipping requirements before sending specimens to reference laboratories for additional testing

\section{N. Reporting Results of the Recommended Algorithm for the Laboratory Diagnosis of HIV}

Laboratory practices for reporting test results and providing interpretation of results to the persons who ordered the HIV test are influenced by

- the assay manufacturer's instructions (specified in product inserts),

- guidance or recommendations from regulatory or scientific agencies and professional associations,

- local clinical practice needs (communicated through requests from institutional clinical practice committees),

- requirements of the laboratory information system, and

- requirements of the electronic health record. 
Table 1 summarizes suggested interpretations for reporting each potential outcome of the recommended testing algorithm to persons ordering the HIV test and to health department surveillance programs, adapted from those developed by the New York State Clinical Laboratory Evaluation Program. ${ }^{135}$ Additional suggestions for reporting HIV test results are available from APHL at http://stacks.cdc.gov/view/cde/22423 and from the Clinical Laboratory Standards Institute. $^{136}$

\section{Reporting HIV test results to persons who ordered HIV testing}

Laboratory experts identified several elements of reports of test results and interpretation that can help guide persons who ordered the HIV test and avoid interpretive errors. Reports to persons who ordered HIV testing should specify

- all assays that were used

- the results of each assay

- interpretation of the results

- any additional testing that is recommended using existing specimens or new specimens that should be submitted

- if alternatives to the recommended assays or algorithm sequence were used, the assays that were used and limitations of these tests or sequence compared with the recommended algorithm

Laboratories should report final results when all testing is complete, but can also report test results of individual assays used in the algorithm as they become available. If results of all tests are not reported at one time, the report should specify which test results are pending.

Laboratories should establish methods to expedite reporting of test results consistent with acute HIV infection to the person who ordered HIV testing and to public health authorities to facilitate prompt notification and provision of services for acutely infected persons and their sex and drug injection partners.

\section{Reporting HIV test results to public health authorities}

All states, the District of Columbia, and United States territories and dependent areas require that laboratories report test results indicative of HIV infection to public health authorities in the patient's jurisdiction of residence. ${ }^{137}$ Table 1 lists suggested elements that should be reported to public health authorities for each potential outcome of the recommended algorithm. However, specific requirements of state or local health departments might differ. The following reporting principles will facilitate accurate case reporting:

1. Results from the recommended laboratory testing algorithm with a negative overall conclusion (i.e., indicating that the patient is uninfected) should not be reported. 
2. If the conclusion of the laboratory diagnostic testing algorithm is positive, indicating the presence of HIV infection, laboratories should report, in the same data transmission to the public health authorities:

a. the overall result or conclusion of the lab algorithm, and

b. results from each test performed (including negative/nonreactive or indeterminate results)

3. If the recommended laboratory diagnostic testing algorithm was not completed and the overall conclusion was not determined (indicating possible HIV infection that requires additional testing or follow-up), the laboratory should follow local requirements for reporting incomplete or inconclusive results.

\section{O. Plans for Updating These Recommendations}

Anticipating continued improvements in laboratory diagnostic techniques, CDC will monitor the introduction and FDA approval of diagnostic assays for HIV infection and update these recommendations when necessary. CDC's Division of HIV/AIDS Prevention in the National Center for HIV, Viral Hepatitis, STD, and TB Prevention, with APHL, will continue to monitor the performance of the laboratory testing algorithm and review the performance of the recommended algorithm at least every five years. 
Table 1. Reporting results from the HIV diagnostic testing algorithm to persons ordering HIV tests and public health authorities

\begin{tabular}{|c|c|c|c|}
\hline Test performed & Test results & Final interpretation for provider report & $\begin{array}{l}\text { Test results to be reported } \\
\text { to public health authorities }\end{array}$ \\
\hline 1. HIV-1/2 Ag/Ab combination immunoassay & 1. Nonreactive & $\begin{array}{l}\text { Negative for HIV-1 antigen and HIV-1/HIV-2 antibodies. No } \\
\text { laboratory evidence of HIV infection. If acute HIV infection is } \\
\text { suspected, consider testing for HIV-1 RNA. }\end{array}$ & $\begin{array}{l}\text { Reporting this test result is not } \\
\text { required. }\end{array}$ \\
\hline $\begin{array}{l}\text { 1. HIV-1/2 Ag/Ab combination immunoassay } \\
\text { 2. HIV-1/HIV-2 antibody differentiation immunoassay }\end{array}$ & $\begin{array}{l}\text { 1. Reactive } \\
\text { 2. HIV-1 reactive and HIV-2 nonreactive }\end{array}$ & $\begin{array}{l}\text { Positive for HIV-1 antibodies. Laboratory evidence consistent } \\
\text { with established HIV-1 infection is present. }\end{array}$ & Report test results 1 and 2 . \\
\hline $\begin{array}{l}\text { 1. HIV-1/2 Ag/Ab combo immunoassay } \\
\text { 2. HIV-1/HIV-2 antibody differentiation immunoassay }\end{array}$ & $\begin{array}{l}\text { 1. Reactive } \\
\text { 2. HIV-1 nonreactive and HIV-2 reactive }\end{array}$ & $\begin{array}{l}\text { Positive for HIV-2 antibodies. Laboratory evidence of HIV-2 } \\
\text { infection is present. }\end{array}$ & Report test results 1 and 2 . \\
\hline $\begin{array}{l}\text { 1. HIV-1/2 Ag/Ab combination immunoassay } \\
\text { 2. HIV-1/HIV-2 antibody differentiation immunoassay } \\
\text { 3. HIV-1 RNA assay }\end{array}$ & $\begin{array}{l}\text { 1. Reactive } \\
\text { 2. Nonreactive or indeterminate } \\
\text { 3. RNA not detected }\end{array}$ & $\begin{array}{l}\text { HIV antibodies were not confirmed and HIV-1 RNA was not } \\
\text { detected. No laboratory evidence of HIV-1 infection. Follow-up } \\
\text { testing for HIV-2 should be performed if clinically indicated. }\end{array}$ & $\begin{array}{l}\text { Reporting this test result is not } \\
\text { required. }\end{array}$ \\
\hline $\begin{array}{l}\text { 1. HIV-1/2 Ag/Ab combination immunoassay } \\
\text { 2. HIV-1/HIV-2 antibody differentiation immunoassay } \\
\text { 3. HIV-1 RNA assay }\end{array}$ & $\begin{array}{l}\text { 1. Reactive } \\
\text { 2. Nonreactive } \\
\text { 3. RNA detected }\end{array}$ & $\begin{array}{l}\text { Positive for HIV-1. Laboratory evidence consistent with acute } \\
\text { HIV-1 infection is present. }\end{array}$ & Report test results 1,2 , and 3. \\
\hline $\begin{array}{l}\text { 1. HIV-1/2 Ag/Ab combination immunoassay } \\
\text { 2. HIV-1/HIV-2 antibody differentiation immunoassay } \\
\text { 3. HIV-1 RNA assay }\end{array}$ & $\begin{array}{l}\text { 1. Reactive } \\
\text { 2. Indeterminate } \\
\text { 3. RNA detected }\end{array}$ & $\begin{array}{l}\text { Positive for HIV-1 antibodies. Laboratory evidence of HIV-1 } \\
\text { infection confirmed by HIV-1 RNA. }\end{array}$ & Report test results 1,2 , and 3 . \\
\hline $\begin{array}{l}\text { 1. HIV-1/2 Ag/Ab combination immunoassay } \\
\text { 2. HIV-1/HIV-2 antibody differentiation immunoassay }\end{array}$ & $\begin{array}{l}\text { 1. Reactive } \\
\text { 2. HIV-1 and HIV-2 reactive }\end{array}$ & $\begin{array}{l}\text { Positive for HIV antibodies. Laboratory evidence of HIV } \\
\text { infection is present. HIV antibodies could not be differentiated } \\
\text { as HIV-1 or HIV-2. Additional testing for HIV-1 RNA or HIV-2 } \\
\text { RNA should be performed if clinically indicated. }\end{array}$ & Report test results 1 and 2 . \\
\hline $\begin{array}{l}\text { 1. HIV-1/2 Ag/Ab combination immunoassay } \\
\text { 2. HIV-1/HIV-2 antibody differentiation immunoassay }\end{array}$ & $\begin{array}{l}\text { 1. Reactive } \\
\text { 2. Nonreactive or indeterminate }\end{array}$ & $\begin{array}{l}\text { HIV-1 antibodies were not confirmed and HIV-1 RNA testing } \\
\text { was not performed. Testing of this specimen is incomplete. } \\
\text { Follow-up testing for HIV antibodies and HIV-1 RNA is } \\
\text { recommended as soon as possible. }\end{array}$ & Report test results 1 and 2 . \\
\hline
\end{tabular}

Adapted from Interim Guidelines for Laboratories on the Use of a New Diagnostic Testing Algorithm for Human Immunodeficiency Virus (HIV) Infection. New York State

Department of Health. ${ }^{135}$ 


\section{Appendix 1.}

\section{Members of Working Group That Developed Updated Recommendations for Laboratory Testing for the Diagnosis of HIV Infection}

Project Leader: Bernard M Branson, MD, CDC

External Members: Berry Bennett, MPH, Florida Bureau of Laboratories and APHL; Barbara G. Werner, PhD, Massachusetts Department of Public Health Bureau of Infectious Disease and APHL; Kelly E. Wroblewski, MPH, APHL; Michael A Pentella, PhD, Massachusetts Bureau of Laboratories and APHL.

CDC Writing Group Members: Bernard M. Branson, MD; S. Michele Owen, PhD; Laura G. Wesolowski, PhD; Kathleen Irwin, MD, MPH; Priya Jakhmola, MS, MBA.

Additional Contributors: Pollyanna Chavez, PhD; Steven Ethridge, MT (ASCP); Kristen Mahle Gray, MPH, CDC; Monica Parker, Wadsworth Center, New York State Department of Health and APHL.

\section{CDC/APHL Working Group on Laboratory HIV Diagnostic Testing Algorithms}

\section{External Representatives}

Berry Bennett MPH, Florida Bureau of Public Health Laboratories; Robert Boromisa PhD, New York State Department of Health; Michael Busch MD, PhD, Blood Systems Research Institute; Sheldon Campbell MD, Yale University School of Medicine; Elliott Cowan PhD, Food and Drug Administration; Richard Hodinka PhD, University of Pennsylvania School of Medicine; Sally Liska DrPH, San Francisco Public Health Laboratory; Brian Louie, San Francisco Department of Public Health; William Meyer PhD, Quest Diagnostics; Robert Myers PhD, Maryland Department of Health and Mental Hygiene Laboratories; Robert O'Connell MD FACP, Walter Reed Army Institute of Research; Mark Pandori PhD, San Francisco Public Health Laboratory; Sheila Peel PhD, Walter Reed Army Institute of Research; Michael Pentella PhD, University of Iowa; Liisa Randall PhD, National Alliance of State and Territorial AIDS Directors; Barbara Werner PhD, Massachusetts Department of Public Health.

\section{CDC Representatives}

Bernard Branson MD; Salvatore Butera DVM, PhD; David Cross MS; Kevin Delaney MPH; Steven Ethridge MT (ASCP); Joanne Mei PhD; Michele Owen PhD; Pragna Patel MD MPH; Mark Rayfield PhD.

\section{External Peer Reviewers}

Kathleen G. Beavis, MD, University of Chicago, Chicago, IL; Christine Ginocchio, PhD, MT (ASCP), Hofstra North Shore-LIJ School of Medicine, Hempstead, NY; Eric Rosenberg, MD, Harvard Medical School, Boston, MA; John L. Schmitz, PhD, University of North Carolina, Chapel Hill, NC; Paul D. Swenson, Ph.D., Public Health Seattle-King County, Seattle, WA. (External peer review process described at http://www.cdc.gov/hiv/pdf/Peer_Review_Plan_final.pdf.) 


\section{Appendix 2.}

\section{Analytic Framework, Search Strategy, and Summary of Evidence}

\section{A. Analytic Framework}

Three CDC writing group members (Branson, Owen, Wesolowski) identified key questions and conducted a systematic literature review to compare outcomes of the previous and proposed algorithm recommendations based on the premise that an accurate HIV test result constituted an outcome important to patients. ${ }^{138,139}$ The CDC working group members evaluated the evidence using criteria adapted to the types of study designs necessary to answer the key questions and an analytic framework that links the key questions to outcomes related to the performance of individual assays and their use in combinations (Figure 2).

The evidence synthesis focused on the relative effects of the previous and recommended testing algorithms on diagnostic accuracy and yield. The CDC reviewers considered tests or algorithms that classified specimens as true-positive or true-negative for HIV-1 or HIV-2 as benefits to patients and being classified as false-positive or false-negative or receiving indeterminate or inconclusive results as harms. They considered reduced turnaround time as a benefit, and delayed diagnosis due to the need for additional specimens or follow-up testing as a harm. ${ }^{42,139,140}$ Services after diagnosis for persons with HIV and for those identified as uninfected would be needed regardless of which testing algorithm is used. 
Figure 2. Analytic Framework: Laboratory Testing for Accurate Diagnosis of HIV Infection

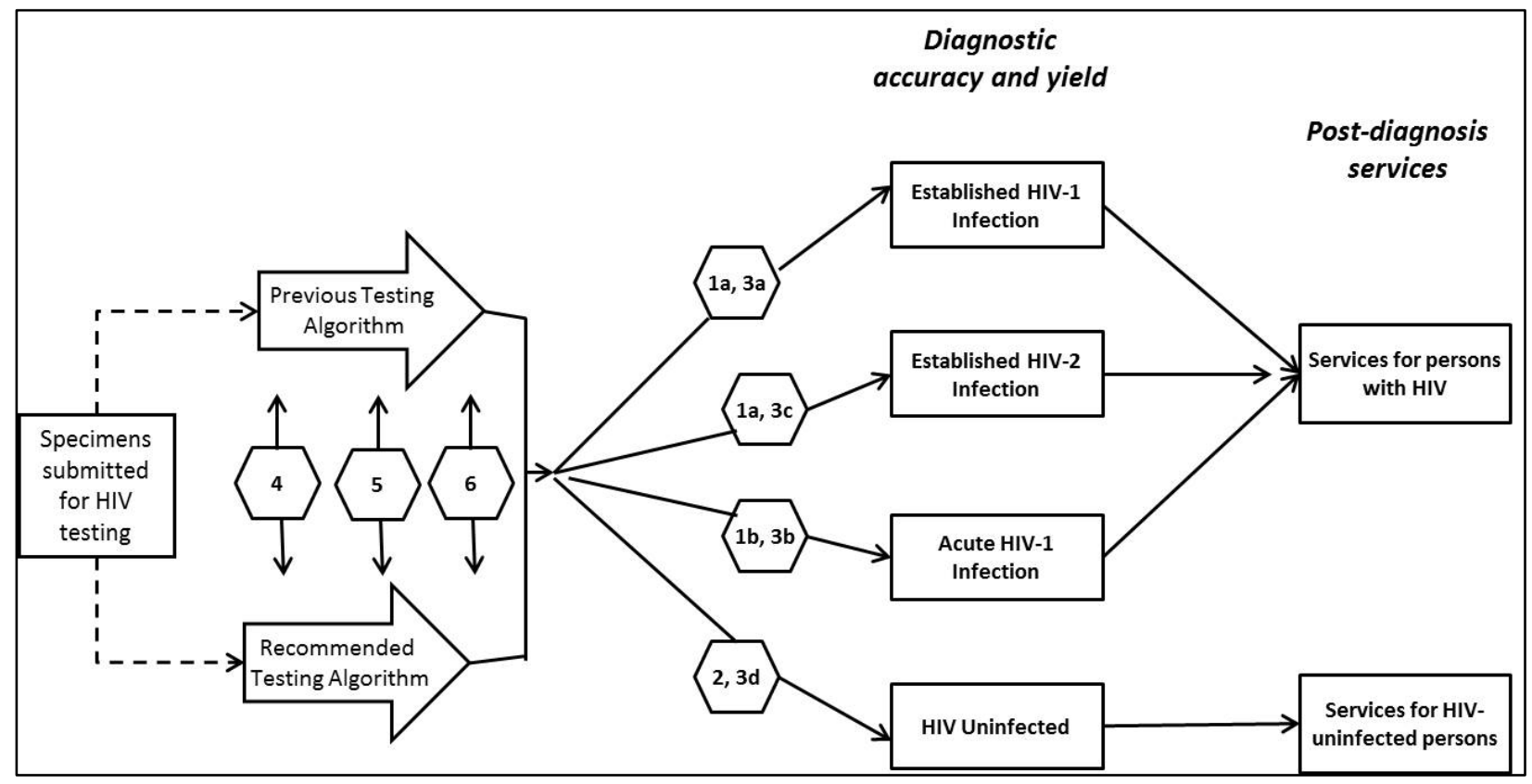

Key Questions:

1a. What is the sensitivity of individual assays in specimens from persons with established HIV-1 and HIV-2 infection?

1b. What is the sensitivity of individual assays in specimens from persons with acute HIV-1 infection?

2. What is the specificity of individual assays in specimens from uninfected persons?

3a. What is the accuracy of algorithms based on combinations of assays in specimens from persons with established HIV-1 infection?

3b. What is the accuracy of algorithms based on combinations of assays in specimens from persons with acute HIV-1 infection?

3c. What is the accuracy of algorithms based on combinations of assays in specimens from persons with established HIV-2 infection?

$3 \mathrm{~d}$. What is the accuracy of algorithms based on combinations of assays in specimens from persons not infected with HIV?

4. What algorithm(s) required the fewest number of assays to maximize accuracy and minimize indeterminate or inconclusive test results?

5. Do the costs and cost-effectiveness of the proposed algorithm for the diagnosis of HIV infection differ from the costs and cost-effectiveness of the previous algorithm?

6. Do benefits and harms for patients associated with the proposed diagnostic algorithm differ from benefits and harms associated with the previous diagnostic algorithm? 


\section{B. Strategy for Searching Published Literature and Conference Abstracts}

CDC writing group members conducted literature searches in PubMed, in abstracts and presentations from the Conferences on Retroviruses and Opportunistic Infections, and in abstracts and presentations from the 2007, 2010, and 2012 HIV Diagnostics Conferences (available at http://hivtestingconference.org). They also consulted data submitted to the FDA and published in the manufacturers' FDA-approved package inserts. The writing group evaluated only studies reported in English and conducted with specimens from U.S. populations, except for questions related to HIV-2. Studies that reported results for assays that were not approved or under consideration by the FDA were excluded.

$\mathrm{CDC}$ writing group members conducted the literature search using the terms $H I V, H I V-1$, and $H I V-2$ in combination with antibody assay, antigen/antibody combination assay, acute HIV infection, testing, clinical diagnostics, serologic tests, third generation assay, fourth generation assay, 24 antigen, seroconversion, indeterminate, false-positive, false-negative, nucleic acid test, nucleic acid amplification test, RNA assay, Western blot, costs, and cost-effectiveness. CDC writing group members identified additional published reports by examining references listed in the retrieved articles. Only studies published or accepted for publication from January 2000 through December 2013 that evaluated laboratory assays approved by the FDA as of December 2012 (Table 2) were included in the evidence synthesis.

The literature search identified 1,858 abstracts of potentially relevant articles. Of these, 1,778 were excluded because they were background articles, did not contain assay performance data, or evaluated assays that were not FDA-approved. Of the remaining 80, 39 articles contained data relevant to the key questions for evaluating individual assays or diagnostic algorithms for HIV; 4 studies related to costs or cost-effectiveness; 2 studies related to potential harms from indeterminate HIV test results; 14 studies described viral dynamics of HIV and generic laboratory markers without identifying specific assays; 6 studies described HIV-2 distribution and diagnosis with assays that are not FDA-approved; 3 studies evaluated HIV-1 diagnosis in infants; 7 studies modeled transmission attributable to acute HIV-1 infection; and 5 studies evaluated the potential benefits of antiretroviral therapy for acute HIV-1 infection.

Each of the three CDC writing group members experienced with HIV diagnostic testing studies reviewed the studies independently. For each study, one member abstracted details about the study design, source of specimens, assays evaluated, and study results. Another one of the three CDC writing group members reviewed data abstraction for accuracy. Discrepancies regarding the applicability of the evidence or limitations of the studies were resolved by consensus. 
Table 2. FDA-approved assays included in evidence synthesis

\begin{tabular}{|c|c|c|}
\hline Assay class & $\begin{array}{l}\text { Trade name } \\
\text { (Manufacturer) }\end{array}$ & $\begin{array}{l}\text { Abbreviation used in } \\
\text { evidence tables }\end{array}$ \\
\hline \multirow[t]{3}{*}{$\begin{array}{l}\text { HIV-1/HIV/2 immunoassay } \\
\text { "3rd generation" }\end{array}$} & $\begin{array}{l}\text { Advia Centaur HIV 1/O/2 Enhanced } \\
\text { (Siemens Healthcare Diagnostics, Malvern, PA) }\end{array}$ & Advia \\
\hline & $\begin{array}{l}\text { GS HIV-1/HIV-2 PLUS O EIA } \\
\text { (Bio-Rad Laboratories, Redmond, WA) }\end{array}$ & GS Plus 0 \\
\hline & $\begin{array}{l}\text { Vitros Anti-HIV 1+2 Assay } \\
\text { (Ortho Clinical Diagnostics, Rochester, NY) }\end{array}$ & Vitros \\
\hline \multirow{2}{*}{$\begin{array}{l}\text { HIV/1-HIV/2 antigen/antibody } \\
\text { combination immunoassay } \\
\text { "4th generation"a }\end{array}$} & $\begin{array}{l}\text { Architect HIV Ag/Ab Combo } \\
\text { (Abbott Laboratories, Abbott Park, IL) }\end{array}$ & Architect Ag/Ab \\
\hline & $\begin{array}{l}\text { GS HIV Combo Ag/Ab EIA } \\
\text { (Bio-Rad Laboratories, Redmond, WA) }\end{array}$ & GS Ag/Ab \\
\hline \multirow[t]{2}{*}{ HIV-1 Western blot } & $\begin{array}{l}\text { GS HIV-1 Western Blot } \\
\text { (Bio-Rad Laboratories, Redmond, WA) }\end{array}$ & WB \\
\hline & $\begin{array}{l}\text { Cambridge Biotech HIV-1 Serum Western Blot } \\
\text { (Maxim Biomedical, Inc. Rockville, MD) }\end{array}$ & WB \\
\hline HIV-1/HIV-2 differentiation assay & $\begin{array}{l}\text { Multispot HIV-1/HIV-0 Rapid Test } \\
\text { (Bio-Rad Laboratories, Redmond, WA) }\end{array}$ & Multispot \\
\hline \multirow[t]{2}{*}{ HIV-1 nucleic acid amplification test ${ }^{b}$} & $\begin{array}{l}\text { APTIMA HIV-1 RNA Qualitative Assay } \\
\text { (Hologic Gen-Probe Inc., San Diego, CA) }\end{array}$ & APTIMA \\
\hline & $\begin{array}{l}\text { Procleix Ultrio } \\
\text { (Novartis Diagnostics, Cambridge, MA) }\end{array}$ & Procleix \\
\hline \multicolumn{3}{|c|}{$\begin{array}{l}\text { a The Determine HIV 1-2 Ag/Ab Combo rapid test, approved by the FDA in August 2013, was not included in the evidence synthesis because } \\
\text { there were no studies evaluating its performance as part of the algorithm. }\end{array}$} \\
\hline \multicolumn{3}{|c|}{$\begin{array}{l}\text { b APTIMA, FDA-approved for HIV diagnosis, and Procleix Ultrio, FDA-licensed for screening blood donations, are two brand names for the } \\
\text { same qualitative RNA assay. }\end{array}$} \\
\hline
\end{tabular}

\section{Quality of Evidence}

The quality of available studies comparing the performance of individual HIV tests or algorithms was inherently limited. No randomized controlled trials comparing individual assays or algorithms were conducted with specimens from populations with unknown infection status. Limitations affected many of the studies identified during the literature review and are identified for each study in the tables of evidence (Appendix 2, Section E).

- Nearly all studies identified during the literature review were cross-sectional analyses that used previously tested specimens and compared test results with a reference standard in different studies and not directly with each other in the same study. Because the prevalence of acute HIV-1 infection and HIV-2 infection is extremely low in the United States, testing specimens from a population representative of persons screened for HIV infection in the United States would yield very few cases of these infections. Studies therefore used specimen collections enriched with specimens from known cases of acute HIV-1 infection or HIV-2 infection to allow performance evaluations using a smaller 
number of specimens and a shorter time frame. These were the only study designs that could feasibly answer questions of accuracy, but such studies might be subject to selection bias.

- Available studies evaluated tests and algorithms against different reference standards for a laboratory diagnosis of HIV-1 or HIV-2 infection. Some of the HIV-1 NAT or HIV-2 assays that were used are not FDA-approved for HIV diagnosis. Differences in reference standards can reduce the comparability of results for index tests evaluated in different studies.

- No studies conducted all assays on all specimens. Studies initiated testing with different immunoassays, and selected specimens for additional testing based on repeatedly reactive immunoassay results or conducted pooled HIV-1 NAT on immunoassay-negative specimens. Some studies conducted only HIV-1 Western blot or HIV-1 IFA; others also performed HIV-1 NAT. These procedures might result in selection bias and reduce the comparability of results for index tests.

- Studies of previously tested specimen sets did not specify whether testing personnel were unaware of the results of the previous tests ("blinded") before conducting the index test. This might have resulted in biased interpretation of test results, especially for assays that require subjective interpretation of results, such as the HIV-1 Western blot and HIV1/HIV-2 antibody differentiation assay.

- Studies that present longitudinal data on natural history of HIV-1 infection such as seroconversion panels typically have small numbers of subjects because subjects must provide multiple blood specimens over a period of weeks or months. The small numbers may not be representative of all persons in populations at risk for HIV-infection.

- The 4th generation antigen/antibody combination immunoassays were only recently FDA-approved for clinical use. This limited the number and size of studies that evaluated these tests, which resulted in wide confidence intervals for point estimates in some studies.

Studies that systematically assessed sensitivity, specificity, and accuracy (key questions 1, 2, and 3 ) are identified in the tables of evidence. No studies systematically assessed the minimum number of assays necessary to obtain an accurate laboratory diagnosis (key question 4) or compared the harms and benefits of the previous and recommended algorithms (key question 6). Three models examined cost and cost effectiveness (key question 5), but no observational studies directly compared costs of the previous and recommended algorithms. Available data related to key questions 4, 5, and 6 are included and cited in the summary of evidence.

Twelve studies directly compared two or more different immunoassays on the same specimens. ${ }^{18,46,47,49,63,66,70,71,76,94,123,141}$ Four of these tested the same specimens from seroconversion panels at different times. ${ }^{46,47,49,66}$ Fourteen studies evaluated the performance of different immunoassays and algorithms with different specimen collections and compared results to a reference standard. ${ }^{18,29,47,71,72,76,88,107,142-147}$ Four studies of assay performance for acute HIV- 
1 infection used specimens that had been identified by pooled HIV-1 RNA screening programs and collected and stored consistent with requirements specified for the assay by the manufacturer. ${ }^{18,62,71,72}$ Two studies of previously tested specimens with negative or indeterminate Western blot results conducted retrospective testing with the HIV-1/HIV-2 differentiation assay and HIV-1 NAT, but had no information about whether specimens were stored and handled consistent with requirements for the HIV-1 NAT assays. ${ }^{148,149}$

CDC writing group members did not conduct pooled data analyses because the studies were conducted with different assays of the same or different classes (that is, three 3rd generation and two 4th generation immunoassays) using specimen collections from different populations with different pre-test probabilities of infection, or enriched with pedigreed specimens with known laboratory diagnosis of HIV-1 or HIV-2 infection. The number of significant digits reported for values in the evidence summary and tables are those as published in the original studies. The writing group did not conduct recalculations or rounding.

Inferring that an accurate test result improves outcomes important to patients requires availability of effective treatment, improved well-being through prognostic information, and, by excluding an ominous diagnosis, reduction of anxiety. ${ }^{138}$ The workgroup relied on other systematic reviews and recommendations for documentation of benefits and harms associated with screening and diagnostic testing for HIV in different populations, effectiveness of treatment for persons with HIV infection, and interventions for HIV-negative persons. ${ }^{23,150-156}$

\section{Summary of Evidence Supporting the Recommendations}

1. Sensitivity of individual assays

a. What is the sensitivity of individual assays for established HIV-1 and HIV-2 infections?

1.a.1. The sensitivity of immunoassays for established HIV-1 and HIV-2 infections is very high and comparable for all FDA-approved 3rd generation and 4th generation immunoassays. Sensitivities of the 3 FDA-approved 3rd generation assays for established HIV-1 infection ranged from $99.80 \%$ to $100 \%$ (4 studies and 3 product inserts), ${ }^{46,47,49,94,157-159}$ and of the 2 FDA-approved 4th generation assays, $99.76 \%$ to $100 \%$ (4 studies and 2 product inserts). ${ }^{46,47,72,143,160,161} \mathrm{Few}$ independent studies have examined sensitivity for HIV-2. One study that evaluated a 3rd generation HIV-1/HIV-2 immunoassay and one with a 4th generation HIV-1/HIV-2 combination immunoassay found $100 \%$ sensitivity for HIV-2. ${ }^{49,144}$ Data from manufacturers indicate FDA-approved 3rd and 4th generation HIV-1/HIV-2 immunoassays are 100\% sensitive for HIV-2. ${ }^{143,157-161}$

1.a.2. Only NATs for HIV-1 RNA, which do not detect HIV-2, ${ }^{49,162}$ are FDA-approved. Sensitivity of HIV-1 NAT for established HIV-1 infection is lower than that of immunoassays. In 2 cross-sectional and 2 prospective studies, HIV-1 RNA NAT produced negative results in $2 \%$ to $4 \%$ of specimens that were reactive on 3 rd 
generation immunoassays and positive on HIV-1 Western blot. ${ }^{18,49,142,145}$ Some specimens with undetectable RNA might have come from persons taking ART, but one study documented NAT-negative specimens from antibody-positive persons who were not receiving ART. ${ }^{18}$ Some NAT-negative specimens might have come from persons who suppress HIV replication without ART (so-called elite controllers). ${ }^{163,164}$ However, this phenomenon is estimated to occur in only 1 of 300 persons with HIV infection. ${ }^{165}$

1.a.3. Only one assay is FDA-approved for differentiating HIV-1 from HIV-2 antibodies. Criteria for a positive interpretation as revised in March 2013 require the presence of both HIV-1 indicators (synthetic gp41 peptide and recombinant gp41 protein) when the assay is used as a supplemental test; presence of only one indicator is interpreted as an indeterminate result. ${ }^{166}$ Sensitivity of the differentiation assay for established HIV-1 infection in 9 studies ranged from $98.5 \%$ to $100 \%$, but not all studies reported whether their diagnostic criteria required one or both of the HIV-1 indicators. ${ }^{29,47,63,76,88,107,118,146,147}$ In 2 studies that required both indicators, $11(85 \%)$ of 13 specimens and $8(89) \%$ of 9 specimens with only one HIV-1 indicator had either a positive HIV-1 Western blot result or detectable HIV-1 RNA. ${ }^{76,118}$

Four studies reported the results of parallel testing of specimens with the HIV-1 Western blot and the HIV-1/HIV-2 antibody differentiation assay. One prospective study of 993 specimens repeatedly reactive by 3 rd or 4 th generation immunoassays identified 882 specimens reactive for HIV-1 only on the antibody differentiation assay. ${ }^{107} \mathrm{HIV}-1$ Western blot was positive in 871 and indeterminate in 11 of these specimens. Six of the 11 patients with indeterminate results were eventually traced and found to have serologically confirmed HIV-1 infection. In this same study, 3 specimens were reactive for HIV-2 and 5 specimens were reactive for both HIV-1 and HIV-2 on the antibody differentiation assay ( 1 with strong reactivity for both HIV-1 and HIV-2, 3 with strong HIV-1 and weak HIV-2 indicators, and 1 with weak reactivity for both HIV-1 and HIV-2). ${ }^{107}$ The 3 specimens reactive for HIV-2 only and the specimen with strong dual reactivity were positive by HIV-2 immunoblot and negative by HIV-1 NAT; the dually reactive specimen also had detectable HIV-2 RNA. ${ }^{107}$ All 4 HIV-2 specimens showed 3 or 4 bands on the HIV-1 Western blot, sufficient to classify 3 as HIV-1 positive and 1 as indeterminate. The 3 specimens with strong HIV-1 reactivity and weak HIV-2 reactivity were reactive for all bands on the HIV-1 Western blot and negative on the HIV-2 immunoblot. The specimen with weak reactivity for both HIV-1 and HIV-2 was reactive only to the gp160 band on HIV-1 Western blot and negative by HIV-2 immunoblot; volume was insufficient for HIV-1 NAT. ${ }^{107}$ 
In a study of 8,760 specimens repeatedly reactive by 3 rd generation immunoassay, the HIV-1/HIV-2 antibody differentiation assay classified 26 $(0.3 \%)$ of 8,678 specimens with positive HIV-1 Western blot results and 12 $(19 \%)$ of 63 specimens with indeterminate HIV-1 Western blot results as HIV-2, but no other HIV-2 tests were performed to validate these results. ${ }^{88}$ In a second study, the HIV-1/HIV-2 differentiation assay was positive for HIV-1 in 491 and for HIV-2 infection in $2(0.4 \%)$ of 493 specimens that had positive HIV-1 Western blot results; these 2 were also positive by HIV-2 Western blot. ${ }^{47}$ One retrospective study of 34 specimens and the product insert description of 207 specimens demonstrated $100 \%$ sensitivity of the HIV-1/HIV-2 differentiation assay for HIV-2. ${ }^{49,166}$

b. What is the sensitivity of individual assays for acute HIV-1 infection?

1.b.1. Third generation HIV-1/HIV-2 assays, fourth generation HIV-1/HIV-2 antigen/antibody combination assays, and HIV-1 RNA assays each confer incremental improvements in sensitivity for acute HIV-1 infection. Retrospective testing of specimens from high-risk persons demonstrated that 3 rd generation immunoassays were reactive in $20 \%$ to $37 \%$ and 4 th generation assays were reactive in $62 \%$ to $83 \%$ of specimens that were negative by HIV-1 Western blot but reactive by HIV-1 NAT. ${ }^{69,70,72,73}$ In a study of 228 specimens from 26 commercial HIV-1 seroconversion panels, HIV-1 Western blot was positive in 56 specimens (25\%); 3 different 3rd generation assays were reactive in 102 (44.7\%), $108(47.4 \%)$, and $111(48.6 \%)$ specimens, respectively, and 2 different 4 th generation assays were reactive in $131(57.5 \%)$ and $135(59.2 \%)$ specimens. ${ }^{46,47}$ In 3 retrospective studies of 42 specimens with detectable HIV-1 RNA but nonreactive $3 \mathrm{rd}$ generation antibody immunoassays, $62 \%$ to $77 \%$ were reactive by 4 th generation HIV-1/HIV-2 antigen/antibody combination immunoassays. ${ }^{18,73,167}$ In a study involving retrospective testing of 74 specimens reactive by HIV-1 NAT after negative 1st or 2nd generation immunoassays, Western blot was positive in $12.5 \%$, a 3 rd generation immunoassay was reactive in $42.2 \%$, and a 4 th generation immunoassay was reactive in $89.1 \%{ }^{71}$ In one study of 99,111 specimens screened with immunoassays, HIV-1 Western blot, and pooled NAT, 1,186 specimens were positive by either HIV-1 Western blot or HIV-1 NAT. ${ }^{18}$ Pooled HIV-1 NAT increased the yield of new HIV diagnoses by $2.2 \%$ in specimens with a nonreactive 3 rd generation immunoassay and by $0.7 \%$ in specimens with a nonreactive 4 th generation immunoassay. ${ }^{18}$

1.b.2. The HIV-1/HIV-2 antibody differentiation assay detects HIV-1 infection earlier than the HIV-1 Western blot. In one prospective study, Multispot was reactive for HIV-1 in 11 specimens that were indeterminate by HIV-1 Western blot; 6 of the 11 patients were eventually traced and serologically confirmed to have HIV-1 
infection. ${ }^{107}$ Two studies of 183 specimens from 15 seroconverters demonstrated the HIV-1/HIV-2 differentiation assay became reactive 7 days before the HIV-1 Western blot. ${ }^{46,49}$ Among 8,760 specimens repeatedly reactive by 3 rd generation immunoassay, the HIV-1/HIV-2 differentiation assay was reactive for HIV-1 in 3 $(15.8 \%)$ of 19 specimens that were negative by HIV-1 Western blot and in 11 $(17.5 \%)$ of 63 specimens indeterminate by HIV-1 Western blot. ${ }^{88}$ Five studies documented reactive HIV-1/HIV-2 antibody differentiation assay results in specimens repeatedly reactive by 3 rd or 4 th generation IA, reactive by HIV-1 NAT, but negative or indeterminate by HIV-1 Western blot. ${ }^{47,76,107,148,149}$

2. What is the specificity of individual assays in specimens from uninfected persons? Most studies compared immunoassays with specimens defined as negative for HIV by negative immunoassay or HIV-1 Western blot results. Thus, specificity estimates for immunoassays from such studies might be artificially lowered by specimens from persons with acute or recent HIV infection that were misclassified as negative by the Western blot. $^{63,70}$

a. Specificities of the 3 FDA-approved 3rd generation assays ranged from $99.13 \%$ to $100 \%$ (6 studies, 3 product inserts). ${ }^{46,47,49,94,141,157-159,168}$

b. Specificities of the 2 FDA-approved 4th generation assays ranged from $99.50 \%$ to $100 \%$ (6 studies, 2 product inserts). ${ }^{46,47,72,141,143,160,161,168}$

c. Specificity of the HIV-1/HIV/2 differentiation assay ranged from $99.03 \%$ to $99.93 \%$ (3 studies, product insert). ${ }^{46,63,166,169}$

d. No recent studies examined Western blot results in specimens without previous repeatedly reactive immunoassay results. A 1990 study demonstrated indeterminate Western blot results in $32 \%$ of healthy adults. ${ }^{170}$

e. Specificity of HIV-1 NAT for HIV-1 infection was $99.6 \%$ in one retrospective study of 513 reference-negative specimens ${ }^{49}$ and $99.9 \%$ in 2 studies of pooled NAT screening of HIV-1 antibody-negative specimens. ${ }^{16,18}$ The 2 studies of pooled NAT screening reported follow-up test results on persons with NAT-reactive specimens. In one, 1 of 5 persons with NAT-reactive results from 8,505 antibody-negative specimens did not seroconvert, ${ }^{16}$ in the second, 3 of 15 persons with NAT-reactive results from 54,000 specimens screened did not seroconvert. ${ }^{18}$

3. Accuracy of algorithms based on combinations of assays

a. What is the accuracy of algorithms based on combinations of assays in specimens from persons with established HIV-1 infection?

Six studies indicate that the accuracy of the recommended algorithm is equivalent to or better than that of the previous algorithm for correctly classifying established HIV-1 infections; it also produces fewer indeterminate results. The New York State laboratory's 
routine testing algorithm allowed direct comparison of the recommended and previous algorithms on 38,257 specimens that were tested prospectively with a 3rd generation immunoassay followed by both Western blot and HIV-1/HIV-2 antibody differentiation immunoassay on repeatedly reactive specimens and HIV-1 RNA NAT on HIV-2negative, Western blot-negative, or indeterminate specimens. The recommended algorithm correctly classified 1,578 (100\%) specimens as HIV-1 positive; the previous algorithm classified 1,546 (98\%) as HIV-1 positive, 4 as negative, and 28 as inconclusive. ${ }^{76}$ In 4 retrospective studies of more than 3,200 HIV-1 Western blot-positive specimens, correct results when the recommended algorithm was initiated with 3rd generation immunoassays ranged from $99.8 \%$ to $100 \%{ }^{47,70,94,123}$ Three similar studies that initiated retrospective testing with 4th generation immunoassays on 4,200 HIV-1 Western blot-positive specimens did not demonstrate a statistically significant difference between the results of the recommended and the previous algorithms. ${ }^{46,47,123}$

b. What is the accuracy of algorithms based on combinations of assays in specimens from persons with acute HIV-1 infection?

In two studies using 230 specimens from the same seroconversion panels, the new algorithm with two 3rd generation assays as the initial test correctly identified acute HIV1 infections in $14(6.1 \%)$ and $12(5.2 \%)$ specimens, respectively, that were negative with the previous algorithm. ${ }^{46,47}$ With the two 4 th generation assays as the initial test, the recommended algorithm identified acute HIV-1 infections in $36(15.7 \%)$ and 41 (17.8\%) specimens, respectively, that were negative with the previous algorithm. ${ }^{46,47}$ One ongoing prospective study identified 654 specimens that were repeatedly-reactive by 4 th generation antigen/antibody immunoassay. ${ }^{10} \mathrm{HIV}-1 / \mathrm{HIV}-2$ antibody differentiation assay results were reactive in $555(84.9 \%)$ specimens and negative or indeterminate in 99 (15.1\%). HIV-1 RNA NAT was reactive in 55 (55.6\%) of these 99: $47(52.2 \%)$ of 90 specimens with negative and $8(88.9 \%)$ of 9 specimens with indeterminate HIV-1/HIV-2 antibody differentiation immunoassay results. ${ }^{118}$ One study of 37 patients with repeatedly reactive 4th generation antigen/antibody combination immunoassay results identified detectable HIV-1 RNA in 11 (29.7\%) specimens with nonreactive HIV-1/HIV-2 antibody differentiation assay results. ${ }^{10}$ Two studies retrospectively tested specimens that were Western blot-negative or indeterminate after repeatedly reactive 3rd generation immunoassays with the HIV-1/HIV-2 differentiation immunoassay and HIV-1 NAT. In one, application of these two supplemental tests identified HIV-1 infections in 184 (5.6\%) of 3,273 specimens; 96 (2.9\%) were acute HIV-1 infections. ${ }^{148}$ In the second study, among 570 specimens obtained from public health laboratories, application of the two supplemental tests identified HIV-1 infection in 55 (9.6\%); 19 (3.3\%) were acute HIV-1 infections. ${ }^{149}$ In a prospective analysis of 51,000 specimens during the first 5 months using the recommended testing algorithm in the Florida Bureau of Public Health Laboratories, the recommended algorithm detected 922 HIV-1 infections, of which 4 $(0.4 \%)$ were acute. ${ }^{123}$ In prospective analysis after implementation of the recommended 
algorithm with 7,984 specimens from Massachusetts, 8 (3.1\%) of $258 \mathrm{HIV}-1$ infections were acute. $^{167}$

c. What is the accuracy of algorithms based on combinations of assays in specimens from persons with established HIV-2 infection?

This question could not be answered directly because there is no FDA-approved NAT for HIV-2 and different diagnostic criteria were used in studies of HIV-2 infections. According to the previous recommendations, specimens with a positive HIV-1 Western blot would not undergo specific testing for HIV $-2 ;{ }^{2}$ most studies evaluating algorithms involved specimens with evidence of HIV-2 infection that had been misclassified as HIV-1 infection. In a prospective study, parallel testing with both the differentiation assay and HIV-1 Western blot classified $26(0.29 \%)$ of 8,678 HIV-1 Western blotpositive specimens as HIV-2. ${ }^{88}$ In a retrospective study, the recommended algorithm reclassified $2(0.4 \%)$ of 493 specimens with positive HIV-1 Western blot results as HIV $-2 .^{47}$

d. What is the accuracy of algorithms based on combinations of assays in specimens from persons not infected with HIV?

The recommended algorithm accurately classifies more persons who are not infected with HIV than the previous algorithm by reducing the number of specimens with indeterminate test results. In the New York State analysis that directly compared the recommended and previous algorithms after an initial 3rd generation immunoassay on the same specimens, the recommended algorithm classified 36,661 (99.98\%) specimens as negative compared with $36,649(99.95 \%)$ by the previous algorithm. ${ }^{76}$ In this study, 48 $(2.9 \%)$ specimens had indeterminate HIV-1 Western blot results with the previous algorithm. Applying test results from the recommended algorithm, only $9(0.5 \%)$ of these 48 specimens would have been classified as inconclusive by the recommended algorithm, because the specimens submitted were unsuitable for NAT testing. ${ }^{76}$ A study of 10,014 specimens from life insurance applicants with low HIV prevalence identified $13(0.1 \%)$ specimens repeatedly reactive on at least one $3 \mathrm{rd}$ or 4 th generation immunoassay. ${ }^{47}$ Two were classified as HIV-1 positive by both the previous and recommended algorithms. One specimen repeatedly reactive only by 3 rd generation and 8 repeatedly reactive only by 4 th generation were negative by both algorithms. One specimen repeatedly reactive only by $3 \mathrm{rd}$ generation and one specimen repeatedly reactive only by 4 th generation immunoassay were indeterminate by the previous algorithm and negative by the recommended algorithm. ${ }^{47}$ 
4. What algorithm(s) required the fewest assays to maximize accuracy and minimize indeterminate or inconclusive test results?

a. Required supplemental assays

The recommended algorithm requires a lower number of assays than the previous algorithms to obtain accurate test results for HIV-1 and HIV-2 for most specimens. Both the previous and recommended algorithms include 1 initial assay and 1 or 2 supplemental assays. The recommended algorithm requires one supplemental assay if HIV-1 or HIV-2 antibodies are present; it eliminates the need to use a second supplemental assay to test for HIV-2 antibodies. If results of the first supplemental assay are negative or indeterminate, it requires a second supplemental assay, HIV-1 NAT, to test for acute HIV-1 infection and eliminate indeterminate results. Three studies show that only $0.1 \%$ to $0.2 \%$ of all specimens required NAT testing to identify acute HIV-1 infections or false-positive immunoassay results. ${ }^{47,123,167}$ The previous algorithm requires 1 supplemental assay to test for HIV-1 antibodies. If the result of this first supplemental assay is negative or indeterminate, it requires a second supplemental assay to test for HIV-2 antibodies. The previous algorithm cannot identify acute HIV-1 infection, and indeterminate specimens that are negative for HIV-2 antibodies require testing of a follow-up specimen for HIV-1. Three studies indicate the previous algorithm produces indeterminate results in from $1.9 \%$ to $4.5 \%$ of specimens with repeatedly reactive $3 \mathrm{rd}$ or 4th generation immunoassays. ${ }^{29,76,118}$ With both algorithms, HIV-1 antibody-positive specimens are resolved with 2 assays; specimens that are false-positive on the initial assay require 3 tests.

b. HIV-1 NAT screening of specimens negative for HIV antibodies

HIV-1 NAT screening after a negative 3rd or 4th generation immunoassay can identify more acute HIV infections than 4th generation immunoassays, but an antibody immunoassay must also be used on all specimens with a negative HIV-1 NAT because HIV-1 NAT is negative in $2 \%$ to $4 \%$ of specimens with established HIV-1 infection and in all specimens with HIV-2 infection. ${ }^{18,49,145}$ If used as the second test in the algorithm, HIV-1 NAT would fail to distinguish acute from established infections, and tests for HIV-1 and HIV-2 antibody would still be required for specimens with negative HIV-1 NAT results. Using HIV-1 NAT as the first or second test in the algorithm would increase the number of tests necessary for accurate diagnosis, increase turnaround time for final results, and increase costs. ${ }^{142,171}$

c. HIV-1/HIV-2 Differentiation Assay

Using an HIV-1/HIV-2 antibody differentiation assay as the supplemental test in the recommended algorithm can reduce the number of assays because it can identify and differentiate HIV-1 and HIV-2 antibodies in a single step. The differentiation assay also incorporates two different antigenic determinants for HIV-1 (synthetic gp41 peptide and recombinant gp41 protein), so a laboratory diagnosis of HIV-1 is based on 3 concordant 
reactive test results (the initial immunoassay and both HIV-1 determinants in the differentiation assay) ${ }^{76,88,149,166}$ CLIA classifies the FDA-approved differentiation assay as "moderate complexity"166 so it can be performed by laboratories that are not certified to conduct high complexity assays, such as the Western blot, increasing the number of laboratories that can perform both the initial and supplemental assays in the recommended algorithm.

d. Testing specimens submitted after reactive single-use rapid HIV test results CDC's 2004 recommendation to confirm all reactive rapid tests by HIV-1 Western blot or HIV-1 IFA regardless of results of initial laboratory immunoassays was based on observations of false-negative results from the laboratory immunoassay then in predominant use,${ }^{74}$ which was discontinued by the manufacturer in 2007. Three studies that conducted all HIV tests approved by the FDA as of December 2013 on the same 166 plasma specimens from 16 seroconverters indicated that, for tests FDA-approved as of May 2014, 4th generation laboratory-based combination antigen/antibody immunoassays become reactive earlier during early infection than any of the single-use rapid HIV tests, including the 4th generation antigen/antibody combination rapid HIV test. ${ }^{46,49,63}$ One prospective evaluation of 428 specimens submitted after reactive rapid test results demonstrated all were correctly classified by the recommended algorithm. ${ }^{123} \mathrm{~A}$ nonreactive antigen/antibody combination immunoassay result after a reactive rapid HIV test result indicates a false-positive rapid HIV test result and averts the need to conduct additional supplemental testing.

5. Do the costs and cost-effectiveness of the recommended algorithm for the diagnosis of HIV infection differ from the costs and cost-effectiveness of the previous algorithm?

Comparing laboratory costs for testing algorithms is difficult because assay costs vary over time, in different laboratories, and with different testing volumes. Testing costs also depend on the prevalence of established and acute HIV infections in tested specimens (and thus the number of supplemental tests required) ${ }^{99}$ Investigators collected cost information from 17 clinical and public health laboratories and used the median cost in a model to compare the cost of previous algorithm and the recommended algorithm. (The model did not include costs or effectiveness for the laboratory diagnosis of HIV-2 infection.) The recommended algorithm identified more specimens with HIV-1 infection. It was less costly than the previous algorithm for specimens positive for HIV antibody, but more costly for the subset of specimens that required HIV-1 NAT to evaluate acute infection or false-positive initial immunoassay results. ${ }^{99}$ Estimates of both the number of HIV infections detected and overall laboratory testing costs were higher with the recommended algorithm than with the previous algorithm. ${ }^{99}$ In specimens with $1 \%$ prevalence of established HIV-1 infection and $0.1 \%$ prevalence of acute HIV-1 infection (characteristic of specimens from high-risk populations), the model estimated that, compared with the previous algorithm, the incremental cost per additional HIV-1 infection detected ranged from $\$ 5,027$ to $\$ 14,400$. In contrast, for specimens in which 
the prevalence of established and acute HIV-1 infections is very low $(0.01 \%$ and $0.001 \%$, respectively), incremental cost-effectiveness of the recommended algorithm exceeds $\$ 100,000$ per additional infection detected compared with the previous algorithm. A different costeffectiveness model that included as an outcome the costs of cases averted by early detection of HIV infection concluded that HIV testing remained cost saving until costs per new HIV diagnosis exceeded $\$ 22,903 .{ }^{172}$

Two other U.S. models evaluated the cost-effectiveness of alternative algorithms in which pooled HIV-1 NAT would directly follow an initial nonreactive 3rd generation immunoassay. Both used cost per quality adjusted life year as outcomes. One found that the incremental cost-effectiveness of pooled HIV-1 NAT exceeded $\$ 100,000$ per quality-adjusted life year unless prevalence of acute HIV infection in tested specimens exceeded $0.4 \% .{ }^{173}$ The second model found that screening with a 4 th generation immunoassay was more economical than pooled NAT screening after a negative 3rd generation immunoassay. ${ }^{171}$ In both studies, the cost-effectiveness of each strategy varied considerably with the prevalence of undiagnosed HIV infection and the frequency of re-testing (which influences the proportion of specimens with acute HIV-1 infection).

6. Do benefits and harms for patients associated with the proposed diagnostic algorithm differ from benefits and harms associated with the previous diagnostic algorithm?

The recommended algorithm is associated with additional benefits and fewer harms for patients than the previous algorithm. By reducing the number of false-negative and indeterminate results and misclassified HIV-2 infections, the recommended algorithm is more accurate. The previous algorithm produces indeterminate results in from $2 \%$ to $4.5 \%$ of persons with repeatedly reactive 3 rd or 4 th generation immunoassays, which require testing of additional follow-up specimens. ${ }^{29,76,118}$ By reducing indeterminate test results, the recommended algorithm reduces delays in HIV diagnosis, anxiety for tested persons, and the inconvenience and cost of collecting additional specimens for more testing. ${ }^{174,175}$ The recommended algorithm only rarely requires additional specimens; for example, when an HIV-1 NAT is required and the original specimen is unsuitable. This may be inconvenient or provoke anxiety in tested persons. However, one testing program that initiated a new shipping service to speed delivery of specimens found that the laboratory considered only $1.6 \%$ of specimens submitted unsuitable for testing. ${ }^{167}$

The recommended algorithm can also reduce turnaround time for test results compared with the previous algorithm. One public health laboratory using the recommended algorithm was able to report $96 \%$ of antibody-positive test results in 2 workdays or less, compared with $22 \%$ when specimens were tested with the previous algorithm. ${ }^{123}$ Another testing program that replaced the previous algorithm with the recommended algorithm was able to shorten the interval between specimen collection and routine notification of test results by 1 week. ${ }^{167}$ Turnaround time for test results is longer for specimens that required HIV-1 NAT testing as part of the algorithm, but no studies documented the time necessary to obtain the NAT results. 


\section{E. Tables of Evidence}

The following tables identify the specific studies and their limitations and strengths for sensitivity, specificity, and accuracy (key questions 1a, 1b, 2, 3a, 3b, 3c, and 3d). The tables of evidence denote the limitations and strengths that influenced the quality of evidence provided by each study using the following key:

\section{Limitations:}

A. Possible selection bias: Selection of specimens was not consecutive or random. Specimen collections that were comprised of previously tested specimens known to have a laboratory diagnosis of established HIV-1 infection, acute HIV-1 infection, or HIV-2 infection do not reflect pre-test probability of these infections in different populations in the United States that undergo HIV testing.

B. Incomplete information or lack of peer review: Evidence quality reduced when format of information from manufacturer's product inserts did not provide detailed information needed for interpretation such as source of specimens or the identity of all tests used as reference standards, or summaries of unpublished data are based on studies that were not subject to independent peer review (other than by FDA experts).

C. Indirect comparisons of test performance: Evidence quality is reduced when a study evaluates only one index test against a reference standard, and not directly against other index tests on the same specimens in the same study. Indirect comparisons can be prone to selection bias.

D. Comparison with different, composite, or unspecified reference standards: Evidence quality is reduced if different reference standards were employed (for example, in the absence of a published standard for HIV-2 infection), if the same standard was not used for all specimens (for example, HIV-1 NAT applied to specimens with negative or indeterminate but not positive HIV-1 Western blot results), or if the study did not define the reference standard used for all specimens.

E. Uncertainty about specimen integrity: Evidence quality is reduced if uncertainty exists about whether handling or storage of previously tested specimens was inconsistent with the requirements for reliable test results from subsequent testing by index or reference tests.

F. Small size of specimen collections: Testing of $<100$ specimens yields very wide confidence intervals around point estimates and might be more affected by selection bias.

\section{Strengths:}

AA. Specimens prospectively collected for diagnostic testing: Studies that conducted testing on specimen sets obtained as part of routine diagnostic testing are more 
representative of the populations that will be tested with the recommended algorithm and less likely to be affected by selection bias.

BB. All studies evaluated, except manufacturers' package inserts, were subject to peer review. Therefore, peer review was not denoted as a strength for any study and BB is not an entry in the Strengths column of the evidence tables.

CC. Direct comparisons of different tests on the same specimen sets: Direct comparisons improve the validity of performance comparisons of index tests.

DD. Comparison with the same reference standard: Evidence quality is improved if all specimens in the study were compared to the same reference standard, and results were compared to other studies that applied the same reference standard.

EE. Although specimen handling, when uncertain, is noted as a weakness, appropriate handling and storage of specimens consistent with obtaining reliable test results were not specifically denoted as strengths. Therefore, EE is not an entry in the Strengths column of the evidence tables.

FF. Large sample size: Testing of $>1,000$ specimens yields narrow confidence intervals around point estimates. 
Evidence Table 1.a. Sensitivity of assays for established HIV-1 and HIV-2 infection, by corresponding section in Summary of Evidence

\begin{tabular}{|c|c|c|c|c|c|c|c|c|}
\hline Publication & Test evaluated & Specimen characteristics & $\begin{array}{l}\text { Number of } \\
\text { specimens }\end{array}$ & Reference standard & $\begin{array}{l}\text { Sensitivity } \\
\text { n reactive/n tested (\%) }\end{array}$ & $\begin{array}{l}95 \% \text { confidence } \\
\text { interval }\end{array}$ & Limitations & Strengths \\
\hline \multicolumn{9}{|c|}{ 1.a.1. Third generation immunoassay sensitivity for established HIV-1 } \\
\hline Owen; $2008^{49}$ & GS Plus 0 & $\begin{array}{l}\text { Previously tested, WB-positive } \\
\text { specimens from U.S. and non- } \\
\text { U.S. blood donors }\end{array}$ & 621 & HIV-1 WB & $620 / 621(99.8)$ & Not reported & A & CC,DD \\
\hline $\begin{array}{l}\text { Masciotra; } \\
2011^{46}\end{array}$ & GS Plus 0 & $\begin{array}{l}\text { Previously tested, WB-positive } \\
\text { specimens from high-risk U.S. } \\
\text { populations }\end{array}$ & 416 & HIV-1 WB & $416 / 416(100)$ & $99.09-100$ & A & CC,DD \\
\hline $\begin{array}{l}\text { Nasrullah; } \\
2013^{47}\end{array}$ & GS Plus 0 & $\begin{array}{l}\text { Previously tested, WB-positive } \\
\text { specimens from a U.S. } \\
\text { commercial laboratory }\end{array}$ & 493 & HIV-1 WB & $493 / 493(100)$ & Not reported & A & CC,DD \\
\hline $\begin{array}{l}\text { Wesolowski; } \\
2011^{94}\end{array}$ & $\begin{array}{l}\text { a) GS Plus } 0 \\
\text { b) VITROS } \\
\text { c) ADVIA }\end{array}$ & $\begin{array}{l}\text { Previously tested, WB-positive } \\
\text { specimens from high-risk U.S. } \\
\text { populations }\end{array}$ & $\begin{array}{l}\text { a) } n=2,202 \\
\text { b) } n=1,109 \\
\text { c) } n=1,108\end{array}$ & HIV-1 WB & $\begin{array}{l}\text { a) } 2,202 / 2,202(100) \\
\text { b) } 1,109 / 1,109(100) \\
\text { c) } 1,108 / 1,108(100)\end{array}$ & $\begin{array}{l}\text { a) } 99.83-100 \\
\text { b) } 99.67-100 \\
\text { c) } 99.67-100\end{array}$ & A & CC,DD,FF \\
\hline Product insert ${ }^{157}$ & GS Plus 0 & $\begin{array}{l}\text { Prospectively collected } \\
\text { specimens from a) U.S. and } \\
\text { b) non-U.S. persons known to } \\
\text { be positive for HIV-1 antibody, } \\
\text { c) persons with AIDS, and } \\
\text { d) } 1,011 \text { high-risk persons from } \\
\text { United States and Canada }\end{array}$ & $\begin{array}{l}\text { a) } 490 \\
\text { b) } 199 \\
\text { c) } 313 \\
\text { d) } 19\end{array}$ & HIV-1 WB & $\begin{array}{l}\text { a) } 490 / 490(100) \\
\text { b) } 199 / 199(100) \\
\text { c) } 313 / 313(100) \\
\text { d) } 19 / 19(100)\end{array}$ & $\begin{array}{l}\text { a) Not reported } \\
\text { b) Not reported } \\
\text { c) } 99.84-100 \\
\text { d) Not reported }\end{array}$ & $\begin{array}{l}\text { a) } A, B, C \\
\text { b) } A, B, C \\
\text { c) } A, B, C \\
\text { d) } B, C, F\end{array}$ & $\begin{array}{l}\text { a) } D D \\
\text { b) } D D \\
\text { c) } D D \\
\text { d) } A A, D D\end{array}$ \\
\hline Product insert ${ }^{158}$ & VITROS & $\begin{array}{l}\text { Prospectively collected } \\
\text { specimens from a) U.S. adults } \\
\text { and children known to be } \\
\text { infected with HIV-1 and b) } 2,424 \\
\text { U.S. high-risk adults }\end{array}$ & $\begin{array}{l}\text { a) } 1,161 \\
\text { b) } 59\end{array}$ & $\begin{array}{l}\text { a) Medical record } \\
\text { evidence of HIV-1 } \\
\text { antibody } \\
\text { b) HIV-1 WB }\end{array}$ & $\begin{array}{l}\text { a) } 1,161 / 1,161(100) \\
\text { b) } 59 / 59(100)\end{array}$ & $\begin{array}{l}\text { a) } 99.68-100 \\
\text { b) Not reported }\end{array}$ & $\begin{array}{l}\text { a) } A, B, C, D \\
\text { b) } B, C, F\end{array}$ & $\begin{array}{l}\text { a) FF } \\
\text { b) } A A, D D\end{array}$ \\
\hline Product insert ${ }^{159}$ & ADVIA & $\begin{array}{l}\text { Prospectively collected } \\
\text { specimens from a) U.S. persons } \\
\text { known to be infected with HIV-1 } \\
\text { and b) } 554 \text { U.S. persons from } \\
\text { high-risk populations }\end{array}$ & $\begin{array}{l}\text { a) } 1,059 \\
\text { b) } 14\end{array}$ & HIV-1 WB & $\begin{array}{l}\text { a) } 1,059 / 1,059(100) \\
\text { b) } 14 / 14(100)\end{array}$ & $\begin{array}{l}\text { a) } 99.72-100 \\
\text { b) Not reported }\end{array}$ & $\begin{array}{l}\text { a) A,B,C } \\
\text { b) B,C,F }\end{array}$ & $\begin{array}{l}\text { a) } D D, F F \\
\text { b) } A A, D D\end{array}$ \\
\hline $\begin{array}{l}\text { Masciotra; } \\
2011^{46}\end{array}$ & Architect Ag/Ab & $\begin{array}{l}\text { Previously tested, WB-positive } \\
\text { specimens from high-risk U.S. } \\
\text { populations }\end{array}$ & 416 & HIV-1 WB & $415 / 416(99.76)$ & $99.08-100$ & A & $\mathrm{CC}, \mathrm{DD}$ \\
\hline
\end{tabular}




\begin{tabular}{|c|c|c|c|c|c|c|c|c|}
\hline Publication & Test evaluated & Specimen characteristics & $\begin{array}{l}\text { Number of } \\
\text { specimens }\end{array}$ & Reference standard & $\begin{array}{l}\text { Sensitivity } \\
\text { n reactive/n tested (\%) }\end{array}$ & $\begin{array}{l}95 \% \text { confidence } \\
\text { interval }\end{array}$ & Limitations & Strengths \\
\hline Chavez; $2011^{72}$ & Architect Ag/Ab & $\begin{array}{l}\text { Previously tested WB-positive } \\
\text { and WB-negative specimens } \\
\text { from high-risk U.S. populations }\end{array}$ & 3,386 & $\begin{array}{l}\text { HIV-1 WB or other } \\
\text { antibody test and HIV- } \\
1 \text { NAT }\end{array}$ & $3,384 / 3,386(99.94)$ & $99.79-99.99$ & $A, D$ & $\mathrm{FF}$ \\
\hline $\begin{array}{l}\text { Nasrullah; } \\
2013^{47}\end{array}$ & GS Ag/Ab & $\begin{array}{l}\text { Previously tested WB-positive } \\
\text { specimens from a U.S. } \\
\text { commercial laboratory }\end{array}$ & 493 & HIV-1 WB & $493 / 493(100)$ & Not reported & A & $\mathrm{CC}, \mathrm{DD}$ \\
\hline Bentsen; $2011^{143}$ & GS Ag/Ab & $\begin{array}{l}\text { Previously tested HIV-1 } \\
\text { antibody-positive specimens } \\
\text { from a) U.S. adults, b) non-U.S. } \\
\text { adults, c) persons with AIDS, } \\
\text { d) children, and f) 1,000 high- } \\
\text { risk STD clinic patients }\end{array}$ & $\begin{array}{l}\text { a) } 1000 \\
\text { b) } 200 \\
\text { c) } 100 \\
\text { d) } 40 \\
\text { e) Total } \\
\text { f) } 40\end{array}$ & $\begin{array}{l}\text { a,b,c,d,e) FDA- } \\
\text { licensed HIV-1/HIV-2 } \\
\text { enzyme IA } \\
\text { f) HIV-1 WB }\end{array}$ & $\begin{array}{l}\text { a) } 1000 / 1000(100) \\
\text { b) } 200 / 200(100) \\
\text { c) } 100 / 100(100) \\
\text { d) } 40 / 40(100) \\
\text { e) } 1,340 / 1,340(100) \\
\text { f) } 40 / 40(100)\end{array}$ & $\begin{array}{l}\text { a) Not reported } \\
\text { b) Not reported } \\
\text { c) Not reported } \\
\text { d) Not reported } \\
\text { e) } 99.71-100 \\
\text { f) Not reported }\end{array}$ & $\begin{array}{l}\text { a) } A, C, D \\
\text { b) } A, C, D \\
\text { c) } A, C, D \\
\text { d) } A, C, D \\
\text { e) } A, C, D \\
\text { f) } F\end{array}$ & $\begin{array}{l}\text { a) FF } \\
\text { b) } \\
\text { c) } \\
\text { d) } \\
\text { e) FF } \\
\text { f) AA,DD }\end{array}$ \\
\hline Product insert ${ }^{160}$ & Architect Ag/Ab & $\begin{array}{l}\text { Prospectively collected } \\
\text { specimens from a) HIV-infected } \\
\text { and b) } 693 \text { high-risk U.S. adults }\end{array}$ & $\begin{array}{l}\text { a) } 1,003 \\
\text { b) } 65\end{array}$ & HIV-1 WB & $\begin{array}{l}\text { a) } 1,003 / 1,003(100) \\
\text { b) } 65 / 65(100)\end{array}$ & $\begin{array}{l}\text { a) } 99.63-100 \\
\text { b) Not reported }\end{array}$ & $\begin{array}{l}\text { a) } A, B, C \\
\text { b) } B, C, F\end{array}$ & $\begin{array}{l}\text { a) DD,FF } \\
\text { b) } A A, D D\end{array}$ \\
\hline Product insert ${ }^{161}$ & GS Ag/Ab & $\begin{array}{l}\text { Previously tested known HIV-1 } \\
\text { antibody-positive specimens } \\
\text { from U.S. and non-U.S. } \\
\text { populations }\end{array}$ & 1,300 & $\begin{array}{l}\text { FDA-licensed HIV- } \\
\text { 1/HIV-2 enzyme IA }\end{array}$ & $1,300 / 1,300(100)$ & $99.70-100$ & $A, B, C, D$ & $\mathrm{FF}$ \\
\hline \multicolumn{9}{|c|}{ 1.a.1. Immunoassay sensitivity for HIV-2 } \\
\hline Owen; $2008^{49}$ & GS Plus 0 & $\begin{array}{l}\text { Previously tested HIV-2-positive } \\
\text { specimens obtained } \\
\text { commercially and from a non- } \\
\text { U.S. study }\end{array}$ & 34 & $\begin{array}{l}\text { HIV-2 NAT or } \\
\text { immunoblot }\end{array}$ & $34 / 34(100)$ & Not reported & $A, D, F$ & $\mathrm{CC}$ \\
\hline Malm; $2009^{144}$ & Architect Ag/Ab & $\begin{array}{l}\text { Previously tested HIV-2-positive } \\
\text { specimens obtained from non- } \\
\text { U.S. sources }\end{array}$ & 52 & Not specified & $52 / 52(100)$ & Not reported & $A, C, D, F$ & \\
\hline Product insert ${ }^{157}$ & GS Plus 0 & $\begin{array}{l}\text { Previously tested specimens } \\
\text { from known HIV-2-positive } \\
\text { persons, source not specified }\end{array}$ & 302 & $\begin{array}{l}\text { HIV-2 IA and HIV-2 } \\
\text { WB }\end{array}$ & $302 / 302(100)$ & $99.83-100$ & $A, B, C$ & \\
\hline Product insert ${ }^{158}$ & VITROS & $\begin{array}{l}\text { Previously tested specimens } \\
\text { from HIV-2 antibody-positive } \\
\text { persons from Ivory Coast }\end{array}$ & 208 & Not specified & $208 / 208(100)$ & $98.24-100$ & $A, B, C, D$ & \\
\hline
\end{tabular}




\begin{tabular}{|c|c|c|c|c|c|c|c|c|}
\hline Publication & Test evaluated & Specimen characteristics & $\begin{array}{l}\text { Number of } \\
\text { specimens }\end{array}$ & Reference standard & $\begin{array}{l}\text { Sensitivity } \\
\text { n reactive/n tested (\%) }\end{array}$ & $\begin{array}{l}95 \% \text { confidence } \\
\text { interval }\end{array}$ & Limitations & Strengths \\
\hline Product insert 159 & ADVIA & $\begin{array}{l}\text { Previously tested HIV-2 } \\
\text { antibody-positive specimens } \\
\text { from commercial vendors in } \\
\text { Africa }\end{array}$ & 197 & HIV-2 immunoblot & $197 / 197(100)$ & $98.49-100$ & $A, B, C$ & \\
\hline Bentsen; $2011^{143}$ & $\mathrm{GS} A g / \mathrm{Ab}$ & $\begin{array}{l}\text { Previously tested HIV-2 } \\
\text { antibody-positive specimens } \\
\text { from United States and Africa }\end{array}$ & 200 & $\begin{array}{l}\text { HIV-2 reactive on HIV- } \\
1 / \text { HIV-2 differentiation } \\
\text { IA }\end{array}$ & $200 / 200(100)$ & $98.11-100$ & $A, B$ & \\
\hline Product insert ${ }^{160}$ & Architect Ag/Ab & $\begin{array}{l}\text { Previously tested HIV-2 } \\
\text { antibody-positive specimens } \\
\text { from Cote d'Ivoire }\end{array}$ & 201 & HIV-2 WB & $201 / 201(100)$ & $98.18-100$ & $A, B, C$ & \\
\hline Product insert ${ }^{161}$ & GS Ag/Ab & $\begin{array}{l}\text { Known HIV-2 antibody-positive } \\
\text { specimens from U.S. and non- } \\
\text { U.S. sources }\end{array}$ & 200 & Not specified & $200 / 200(100)$ & $98.11-100$ & $A, B, C, D$ & \\
\hline \multicolumn{9}{|c|}{ 1.a.2. Sensitivity of HIV-1 nucleic acid test for established HIV-1 } \\
\hline Patel; $2010^{18}$ & APTIMA & $\begin{array}{l}\text { Prospectively collected } \\
\text { specimens from high-risk } \\
\text { persons in U.S. HIV testing sites }\end{array}$ & 1,136 & HIV-1 WB & $\begin{array}{l}1,094 / 1,136(96.3) \\
{[28 / 42 \text { specimens with negative }} \\
\text { APTIMA results from persons on } \\
\text { ART] }\end{array}$ & Not reported & C & $A A, D D, F F$ \\
\hline Owen; $2008^{49}$ & Procleix & $\begin{array}{l}\text { Previously tested HIV-1 WB- } \\
\text { positive specimens from U.S. } \\
\text { and non-U.S. blood donors }\end{array}$ & 621 & HIV-1 WB & $605 / 621(97.4)$ & Not reported & A & $\mathrm{DD}$ \\
\hline Ethridge; $2011^{142}$ & APTIMA & $\begin{array}{l}\text { Previously tested HIV-1 WB- } \\
\text { positive serum and plasma } \\
\text { specimens from U.S. HIV clinics }\end{array}$ & 325 & HIV-1 WB & $\begin{array}{l}\text { Serum } 316 / 325(97.23) \\
\text { Plasma } 317 / 325(97.54)\end{array}$ & $\begin{array}{l}94.81-98.73 \\
95.21-98.93\end{array}$ & $A, C$ & $\mathrm{DD}$ \\
\hline Ren; $2008^{145}$ & APTIMA & $\begin{array}{l}\text { Prospectively collected } \\
\text { specimens from 1,361 persons } \\
\text { in San Francisco HIV testing } \\
\text { sites }\end{array}$ & 25 & HIV-1 IFA & $24 / 25(96.0)$ & Not reported & $\mathrm{D}, \mathrm{F}$ & $\mathrm{AA}$ \\
\hline \multicolumn{9}{|c|}{ 1.a.3. HIV-1/HIV-2 Ab differentiation assay sensitivity for established HIV-1 } \\
\hline $\begin{array}{l}\text { Nasrullah; } \\
2011^{29}\end{array}$ & Multispot & $\begin{array}{l}\text { Retrospective analysis of test } \\
\text { results from prospectively } \\
\text { collected and tested specimens } \\
\text { from New York State testing } \\
\text { sites }\end{array}$ & 1,790 & HIV-1 WB & $\begin{array}{l}\text { 1,787/1,790 (99.83) } \\
\text { [1 specimen HIV-2 positive] }\end{array}$ & Not reported & & $\mathrm{AA}, \mathrm{DD}, \mathrm{FF}$ \\
\hline Pandori; $2013^{118}$ & Multispot & $\begin{array}{l}\text { Prospectively collected and } \\
\text { tested specimens from } 3 \text { U.S. } \\
\text { study sites }\end{array}$ & 405 & HIV-1 WB & $\begin{array}{l}398 / 405 \text { (98.3) } \\
{[5 \text { specimens with Multispot }} \\
\text { indeterminate results] }\end{array}$ & Not reported & & $A A, D D$ \\
\hline
\end{tabular}




\begin{tabular}{|c|c|c|c|c|c|c|c|c|}
\hline Publication & Test evaluated & Specimen characteristics & $\begin{array}{l}\text { Number of } \\
\text { specimens }\end{array}$ & Reference standard & $\begin{array}{l}\text { Sensitivity } \\
\text { n reactive/n tested (\%) }\end{array}$ & $\begin{array}{l}95 \% \text { confidence } \\
\text { interval }\end{array}$ & Limitations & Strengths \\
\hline Delaney; $2011^{63}$ & Multispot & $\begin{array}{l}\text { Prospectively collected } \\
\text { specimens from a high-risk U.S. } \\
\text { population }\end{array}$ & 103 & HIV-1 WB & $103 / 103(100)$ & $(97.13-100.0)$ & & $\mathrm{AA}, \mathrm{CC}$ \\
\hline $\begin{array}{l}\text { Nasrullah; } \\
2013^{47}\end{array}$ & Multispot & $\begin{array}{l}\text { Previously tested WB-positive } \\
\text { tested specimens from } \\
\text { commercial laboratory }\end{array}$ & 493 & HIV-1 WB & $\begin{array}{l}491 / 493 \text { (99.6) } \\
\text { [2 specimens HIV-2 positive] }\end{array}$ & Not reported & A & $\mathrm{CC}, \mathrm{DD}$ \\
\hline Ramos; $2013^{146}$ & Multispot & $\begin{array}{l}\text { Retrospective testing of } 21,317 \\
\text { diagnostic specimens from } \\
\text { Seattle }\end{array}$ & 413 & HIV-1 WB & $413 / 413(100)$ & Not reported & & $A A, D D$ \\
\hline Ramos; $2013^{107}$ & Multispot & $\begin{array}{l}\text { Retrospective analysis of } 46,061 \\
\text { prospectively collected and } \\
\text { tested diagnostic specimens } \\
\text { from Seattle }\end{array}$ & 871 & HIV-1 WB & $871 / 871(100)$ & Not reported & C & $A A, D D$ \\
\hline $\begin{array}{l}\text { Cardenas; } \\
2013^{147}\end{array}$ & Multispot & $\begin{array}{l}\text { Previously tested HIV-1 WB- } \\
\text { positive specimens }\end{array}$ & 141 & HIV-1 WB & $141 / 141(100)$ & Not reported & $A, C$ & $\mathrm{DD}$ \\
\hline Styer; $2011^{76}$ & Multispot & $\begin{array}{l}\text { Prospectively collected } \\
\text { specimens from } 38,257 \text { persons } \\
\text { in New York State testing sites }\end{array}$ & 1,546 & HIV-1 WB & $1,545 / 1,546(99.94)$ & Not reported & & $\mathrm{AA}, \mathrm{CC}, \mathrm{DD}, \mathrm{FF}$ \\
\hline Product insert ${ }^{166}$ & Multispot & $\begin{array}{l}\text { Specimens collected from } \\
\text { a) known HIV-1 positive persons } \\
\text { and b) } 1,441 \text { high-risk U.S. } \\
\text { persons }\end{array}$ & $\begin{array}{l}\text { a) } 801 \\
\text { b) } 70\end{array}$ & HIV-1 WB & $\begin{array}{l}801 / 801(100) \\
70 / 70(100)\end{array}$ & $(99.94-100)$ & $A, B, C$ & $\mathrm{DD}$ \\
\hline \multicolumn{9}{|c|}{ 1.a.3. HIV-1/HIV-2 Ab differentiation assay sensitivity for HIV-2 } \\
\hline Owen; $2008^{49}$ & Multispot & $\begin{array}{l}\text { Previously tested HIV-2 } \\
\text { specimens from Ivory Coast }\end{array}$ & 34 & HIV-2 NAT & $34 / 34(100)$ & Not reported & $A, D, F$ & $\mathrm{CC}, \mathrm{DD}$ \\
\hline Ramos; $2013^{107}$ & Multispot & $\begin{array}{l}\text { Retrospective analysis of } 46,061 \\
\text { prospectively collected and } \\
\text { tested diagnostic specimens } \\
\text { from Seattle }\end{array}$ & 4 & HIV-2 immunoblot & $\begin{array}{l}\text { 4/4 (100) HIV-2 positive; } \\
3 \text { with positive HIV-1 WB }\end{array}$ & Not reported & $\mathrm{D}, \mathrm{F}$ & AA \\
\hline
\end{tabular}

Abbreviations: Ag/Ab, antigen/antibody; AIDS, acquired immunodeficiency syndrome; IA, immunoassay; IFA, immunofluorescence assay; NAT, nucleic acid test; WB, Western blot. 
Evidence Table 1.b. Sensitivity of assays for acute HIV-1 infections, by corresponding section in Summary of Evidence

\begin{tabular}{|c|c|c|c|c|c|c|c|}
\hline Publication & Test evaluated & Specimen characteristics & $\begin{array}{l}\text { Number of } \\
\text { specimens }\end{array}$ & Reference standard & Outcomes & Limitations & Strengths \\
\hline \multicolumn{8}{|c|}{ 1.b.1. Sensitivity of third and fourth generation immunoassays for acute HIV-1 infection } \\
\hline $\begin{array}{l}\text { Owen; } 2008^{49} \\
\text { Masciotra; } 2011^{46}\end{array}$ & $\begin{array}{l}\text { Advia } \\
\text { GS Plus } 0 \\
\text { Vitros }\end{array}$ & $\begin{array}{l}\text { Previously tested specimens } \\
\text { from seroconversion panels } \\
\text { obtained from blood donors }\end{array}$ & $\begin{array}{l}183 \text { specimens from } \\
15 \text { donors }\end{array}$ & HIV-1 RNA NAT & $\begin{array}{l}\text { 3rd generation IAs detected infection } \\
12-14 \text { days before Western blot } \\
\text { positive }\end{array}$ & $A, F$ & CC,DD \\
\hline $\begin{array}{l}\text { Masciotra; } 2011^{46} \\
\text { Masciotra; } 2013^{66}\end{array}$ & $\begin{array}{l}\text { GS Ag/Ab } \\
\text { Architect Ag/Ab }\end{array}$ & $\begin{array}{l}\text { Previously tested specimens } \\
\text { from seroconversion panels } \\
\text { obtained from blood donors }\end{array}$ & $\begin{array}{l}183 \text { specimens from } \\
15 \text { donors }\end{array}$ & HIV-1 RNA NAT & $\begin{array}{l}\text { 4th generation IAs detected infection } \\
19-20 \text { days before Western blot } \\
\text { positive }\end{array}$ & $A, F$ & CC,DD \\
\hline Patel; $2010^{18}$ & Pooled APTIMA & $\begin{array}{l}\text { Prospectively collected } \\
\text { specimens from high-risk } \\
\text { persons in U.S. HIV testing } \\
\text { sites }\end{array}$ & $\begin{array}{l}\text { 1,162 HIV-1 positive } \\
\text { specimens }\end{array}$ & $\begin{array}{l}\text { 3rd generation IA } \\
\text { 4th generation IA }\end{array}$ & $\begin{array}{l}\text { Pooled NAT detected } 2.2 \% \text { more } \\
\text { infections than } 3 r d \text { generation IA and } \\
0.7 \% \text { more than } 4 \text { th generation IA }\end{array}$ & & AA,CC,DD,FF \\
\hline Pandori; 200971 & $\begin{array}{l}\text { GS Plus } 0 \\
\text { Architect Ag/Ab }\end{array}$ & $\begin{array}{l}\text { Previously tested specimens } \\
\text { from high-risk persons in San } \\
\text { Francisco testing sites }\end{array}$ & 64 & HIV-1 RNA NAT & $\begin{array}{l}\text { 3rd generation IA detected } 42.2 \% \\
\text { (27/64) of infections detected by NAT, } \\
\text { 4th generation IA detected } 89.1 \% \\
(57 / 64)\end{array}$ & $A, F$ & CC,DD \\
\hline $\begin{array}{l}\text { Masciotra; } 2011^{46} \\
\text { Nasrullah; } 2013^{47}\end{array}$ & $\begin{array}{l}\text { Western blot } \\
\text { GS Plus O } \\
\text { Advia } \\
\text { Vitros } \\
\text { Architect Ag/Ab } \\
\text { GS Ag/Ab }\end{array}$ & $\begin{array}{l}\text { Previously tested specimens } \\
\text { from seroconversion panels } \\
\text { obtained from blood donors }\end{array}$ & $\begin{array}{l}228 \text { specimens from } \\
26 \text { seroconverters }\end{array}$ & HIV-1 RNA NAT & $\begin{array}{l}\text { Number of HIV-positive specimens } \\
\text { detected by } \\
\text { WB: } 56 \\
\text { 3rd generation assays: 108-111 } \\
\text { 4th generation assays: } 131-135\end{array}$ & $A, F$ & CC,DD \\
\hline $\begin{array}{l}\text { Owen; } 2008^{49} \\
\text { Masciotra; } 2011^{46}\end{array}$ & Multispot & $\begin{array}{l}\text { Previously tested specimens } \\
\text { from seroconversion panels } \\
\text { from blood donors }\end{array}$ & $\begin{array}{l}183 \text { specimens from } \\
15 \text { donors }\end{array}$ & HIV-1 RNA NAT & $\begin{array}{l}\text { Multispot became reactive } 7 \text { days } \\
\text { before Western blot positive }\end{array}$ & $A, F$ & $\mathrm{CC}, \mathrm{DD}$ \\
\hline Nasrullah; $2013^{47}$ & Multispot & $\begin{array}{l}\text { Previously tested } \\
\text { seroconversion panels from } \\
\text { U.S. blood donors }\end{array}$ & $\begin{array}{l}228 \text { specimens from } \\
26 \text { seroconverters }\end{array}$ & HIV-1 RNA NAT & $\begin{array}{l}\text { Number of specimens detected by } \\
\text { WB: } 56 \\
\text { Multispot: } 90\end{array}$ & $A, F$ & $\mathrm{CC}, \mathrm{DD}$ \\
\hline Styer; $2011^{76}$ & Multispot & $\begin{array}{l}\text { Prospectively collected } \\
\text { specimens from } 38,257 \\
\text { persons in New York State } \\
\text { testing sites }\end{array}$ & $\begin{array}{l}1,659 \text { 3rd generation } \\
\text { IA repeatedly } \\
\text { reactive }\end{array}$ & $\begin{array}{l}\text { Positive HIV-1 NAT } \\
\text { or follow-up test }\end{array}$ & $\begin{array}{l}30 \text { positive Multispot results in } \\
\text { specimens negative or indeterminate } \\
\text { by HIV-1 WB }\end{array}$ & $D, F$ & $\mathrm{AA}, \mathrm{CC}$ \\
\hline
\end{tabular}




\begin{tabular}{|c|c|c|c|c|c|c|c|}
\hline Publication & Test evaluated & Specimen characteristics & $\begin{array}{l}\text { Number of } \\
\text { specimens }\end{array}$ & Reference standard & Outcomes & Limitations & Strengths \\
\hline Ramos; 2013107 & Multispot & $\begin{array}{l}\text { Retrospective analysis of } \\
46,061 \text { prospectively collected } \\
\text { and tested diagnostic } \\
\text { specimens from Seattle }\end{array}$ & $\begin{array}{l}599 \text { 3rd generation, } \\
\text { and } 394 \text { 4th } \\
\text { generation IA } \\
\text { repeatedly reactive }\end{array}$ & Follow-up test & $\begin{array}{l}\text { Positive differentiation assay results in } \\
11 \text { specimens with indeterminate HIV- } \\
1 \text { WB; positive on follow-up test in } 6 \\
\text { patients located }\end{array}$ & $\mathrm{F}$ & $\mathrm{AA}, \mathrm{DD}$ \\
\hline Linley; $2013^{149}$ & Multispot & $\begin{array}{l}\text { 3rd generation repeatedly } \\
\text { reactive, WB negative or } \\
\text { indeterminate previously tested } \\
\text { specimens from public health } \\
\text { laboratories }\end{array}$ & $\begin{array}{l}570 \text { HIV-1 WB } \\
\text { negative or } \\
\text { indeterminate } \\
\text { specimens }\end{array}$ & HIV-1 RNA NAT & $\begin{array}{l}27 \text { positive differentiation assay results } \\
\text { in specimens with positive HIV-1 NAT } \\
\text { results }\end{array}$ & $A, E, F$ & DD \\
\hline Wesolowski; $2013^{148}$ & Multispot & $\begin{array}{l}\text { 3rd generation repeatedly } \\
\text { reactive, WB negative or } \\
\text { indeterminate previously tested } \\
\text { specimens from a commercial } \\
\text { laboratory }\end{array}$ & $\begin{array}{l}3,273 \text { HIV-1 WB } \\
\text { negative or } \\
\text { indeterminate } \\
\text { specimens }\end{array}$ & HIV-1 RNA NAT & $\begin{array}{l}88 \text { positive differentiation assay results } \\
\text { in specimens with positive NAT results }\end{array}$ & $\mathrm{A}, \mathrm{E}, \mathrm{F}$ & $\mathrm{DD}$ \\
\hline
\end{tabular}

Abbreviations: Ag/Ab, antigen/antibody; IA, immunoassay; NAT, nucleic acid test; RNA, ribonucleic acid; WB, Western blot. 
Evidence Table 2. Specificity of assays, by corresponding section in Summary of Evidence

\begin{tabular}{|c|c|c|c|c|c|c|c|c|}
\hline Publication & Test evaluated & Specimen characteristics & $\begin{array}{l}\text { Number of } \\
\text { specimens }\end{array}$ & Reference standard & $\begin{array}{l}\text { Specificity } \\
\text { n negative/n tested (\%) }\end{array}$ & $\begin{array}{l}95 \% \text { confidence } \\
\text { interval }\end{array}$ & Limitations & Strengths \\
\hline \multicolumn{9}{|c|}{ 2.a. Specificity of third generation assays } \\
\hline Masciotra; $2011^{46}$ & GS Plus 0 & $\begin{array}{l}\text { Previously tested specimens from } \\
\text { blood donors }\end{array}$ & 414 & $\begin{array}{l}\text { Negative on } 11 \text { IAs or } \\
\text { negative HIV-1 WB } \\
\text { and HIV-1 NAT }\end{array}$ & $412 / 414$ (99.52) & $98.26-99.87$ & $A, D$ & $\mathrm{CC}$ \\
\hline Nasrullah; $2013^{47}$ & GS Plus 0 & $\begin{array}{l}\text { Prospectively collected specimens } \\
\text { submitted for diagnostic testing to a } \\
\text { commercial laboratory }\end{array}$ & 10,012 & $\begin{array}{l}\text { Negative on } 3 \text { rd and } \\
\text { 4th gen IA or HIV- } \\
\text { 1/HIV-2 differentiation } \\
\text { IA and HIV-1 NAT }\end{array}$ & $10,010 / 10,012(99.98)$ & $99.93-100 \%$ & D & $\mathrm{AA}, \mathrm{CC}, \mathrm{FF}$ \\
\hline Owen; $2008^{49}$ & GS Plus 0 & $\begin{array}{l}\text { Previously tested specimens } \\
\text { collected from blood donors }\end{array}$ & 513 & $\begin{array}{l}\text { Negative on } 11 \text { IAs or } \\
\text { negative HIV-1 WB } \\
\text { and HIV-1 NAT }\end{array}$ & $510 / 513(99.4)$ & Not reported & $A, D$ & $\mathrm{CC}$ \\
\hline $\begin{array}{l}\text { Wesolowski; } \\
2011^{94}\end{array}$ & $\begin{array}{l}\text { a) GS Plus O } \\
\text { b) VITROS } \\
\text { c) Advia }\end{array}$ & $\begin{array}{l}\text { Previously tested specimens from } \\
\text { blood donors }\end{array}$ & $\begin{array}{l}\text { a) } 1,510 \\
\text { b) } 1,484 \\
\text { c) } 1,486\end{array}$ & $\begin{array}{l}\text { Negative 3rd } \\
\text { generation IA and } \\
\text { pooled HIV-1 NAT }\end{array}$ & $\begin{array}{l}\text { a) } 1,500 / 1,510(99.34) \\
\text { b) } 1,461 / 1,484(98.45) \\
\text { c) } 1,473 / 1,486(99.13)\end{array}$ & $\begin{array}{l}\text { a) } 98.79-99.68 \\
\text { b) } 97.68-99.02 \\
\text { c) } 98.51-99.53\end{array}$ & $\begin{array}{l}\text { a) } A, D \\
\text { b) } A, D \\
\text { c) } A, D\end{array}$ & $\begin{array}{l}\text { a) } C C, D D, F F \\
\text { b) } C C, D D, F F \\
\text { c) } C C, D D, F F\end{array}$ \\
\hline Dubravac; $2013^{168}$ & GS Plus 0 & $\begin{array}{l}\text { Prospectively collected and tested } \\
\text { specimens submitted for diagnostic } \\
\text { testing to public health laboratory }\end{array}$ & 2,024 & $\begin{array}{l}\text { Negative HIV-1 WB } \\
\text { and HIV-1 NAT }\end{array}$ & $2,020 / 2,024(99.80)$ & $99.49-99.94$ & & $\mathrm{AA}, \mathrm{CC}, \mathrm{DD}, \mathrm{FF}$ \\
\hline Product insert ${ }^{157}$ & GS Plus 0 & $\begin{array}{l}\text { Previously tested specimens from } \\
\text { blood donors }\end{array}$ & 11,159 & $\begin{array}{l}\text { Negative 3rd } \\
\text { generation IA and } \\
\text { pooled HIV-1 NAT }\end{array}$ & $11,147 / 11,159(99.89)$ & $99.83-99.96$ & $A, B, C, D$ & $\mathrm{DD}, \mathrm{FF}$ \\
\hline Product insert' ${ }^{158}$ & VITROS & $\begin{array}{l}\text { Specimens from low risk } \\
\text { populations (pregnant women, } \\
\text { insurance applicants, children) }\end{array}$ & 1,438 & $\begin{array}{l}\text { Negative 3rd } \\
\text { generation IA or HIV-1 } \\
\text { WB }\end{array}$ & 1,432/1,438 (99.58) & $99.09-99.85$ & $A, B, C, D$ & $\mathrm{FF}$ \\
\hline Product insert ${ }^{159}$ & Advia & $\begin{array}{l}\text { Specimens from low risk } \\
\text { populations (healthy adults and } \\
\text { prenatal women) }\end{array}$ & 6,060 & $\begin{array}{l}\text { Negative 3rd } \\
\text { generation IA or HIV-1 } \\
\text { WB }\end{array}$ & $6,052 / 6,060(99.90)$ & $99.78-99.96$ & $A, B, C, D$ & $\mathrm{FF}$ \\
\hline Mitchell; $2013^{141}$ & $\begin{array}{l}\text { a) VITROS } \\
\text { b) Advia }\end{array}$ & $\begin{array}{l}\text { Previously tested specimens from } \\
\text { blood donors }\end{array}$ & $\begin{array}{l}\text { a) } 994 \\
\text { b) } 1,000\end{array}$ & $\begin{array}{l}\text { Negative pooled HIV-1 } \\
\text { NAT }\end{array}$ & $\begin{array}{l}\text { a) } 991 / 994(99.7) \\
\text { b) } 1,000 / 1,000(100)\end{array}$ & $\begin{array}{l}\text { a) } 99.1-99.9 \\
\text { b) } 99.6-100\end{array}$ & $\begin{array}{l}\text { a) } A \\
\text { b) } A\end{array}$ & $\begin{array}{l}\text { a) } C C \\
\text { b) } C C, D D, F F\end{array}$ \\
\hline 2.b. Specificity of fo & ith generation ass & & & & & & & \\
\hline Masciotra; $2011^{46}$ & Architect Ag/Ab & $\begin{array}{l}\text { Previously tested specimens from } \\
\text { blood donors }\end{array}$ & 414 & $\begin{array}{l}\text { Negative on } 11 \text { IAs or } \\
\text { negative HIV-1 WB } \\
\text { and HIV-1 NAT }\end{array}$ & $414 / 414(100)$ & $99.08-100.00$ & A & $\mathrm{CC}, \mathrm{DD}$ \\
\hline
\end{tabular}




\begin{tabular}{|c|c|c|c|c|c|c|c|c|}
\hline Publication & Test evaluated & Specimen characteristics & $\begin{array}{l}\text { Number of } \\
\text { specimens }\end{array}$ & Reference standard & $\begin{array}{l}\text { Specificity } \\
\text { n negative/n tested (\%) }\end{array}$ & $\begin{array}{l}95 \% \text { confidence } \\
\text { interval }\end{array}$ & Limitations & Strengths \\
\hline Nasrullah; $2013^{47}$ & $\mathrm{GS} A g / \mathrm{Ab}$ & $\begin{array}{l}\text { Prospectively collected specimens } \\
\text { submitted for diagnostic testing to a } \\
\text { commercial laboratory }\end{array}$ & 10,012 & $\begin{array}{l}\text { Negative on 3rd and } \\
\text { 4th gen IAs or HIV- } \\
\text { 1/HIV-2 differentiation } \\
\text { IA and HIV-1 NAT }\end{array}$ & $10,003 / 10,012(99.91)$ & $99.84-99.96$ & $\mathrm{D}$ & $\mathrm{AA}, \mathrm{CC}, \mathrm{FF}$ \\
\hline Chavez; $2011^{72}$ & Architect Ag/Ab & $\begin{array}{l}\text { Previously tested specimens from } \\
\text { blood donors and high-risk } \\
\text { populations }\end{array}$ & 7,551 & $\begin{array}{l}\text { Negative 3rd } \\
\text { generation IA and } \\
\text { HIV-1 NAT }\end{array}$ & $7,513 / 7,551$ (99.5) & $99.31-99.64$ & $A$ & $\mathrm{DD}, \mathrm{FF}$ \\
\hline Bentsen; 2011143 & $\mathrm{GS} A g / \mathrm{Ab}$ & $\begin{array}{l}\text { Specimens from a) low-risk } \\
\text { populations (routine testing, } \\
\text { repositories, commercial vendors) } \\
\text { and b) high-risk STD clinic }\end{array}$ & $\begin{array}{l}\text { a) } 6,100 \\
\text { b) } 960\end{array}$ & $\begin{array}{l}\text { Negative 3rd gen IA or } \\
\text { HIV-1 WB }\end{array}$ & $\begin{array}{l}\text { a) } 6,089 / 6,096(99.89) \\
\text { b) } 959 / 93(99.90)\end{array}$ & $\begin{array}{l}\text { a) } 99.76-99.94 \\
\text { b) } 99.41-99.98\end{array}$ & $A, C, D$ & $\mathrm{DD}, \mathrm{FF}$ \\
\hline Dubravac; $2013^{168}$ & Architect Ag/Ab & $\begin{array}{l}\text { Prospectively collected and tested } \\
\text { specimens submitted for diagnostic } \\
\text { testing to public health laboratory }\end{array}$ & 2,024 & $\begin{array}{l}\text { Negative HIV-1 WB } \\
\text { and HIV-1 NAT }\end{array}$ & 2,021/2,024 (99.85) & $99.57-99.97$ & & $\mathrm{AA}, \mathrm{CC}, \mathrm{DD}, \mathrm{FF}$ \\
\hline Product insert ${ }^{160}$ & Architect Ag/Ab & $\begin{array}{l}\text { Prospectively collected specimens } \\
\text { from low risk populations }\end{array}$ & 6,127 & $\begin{array}{l}\text { Negative 3rd gen IA or } \\
\text { HIV-1 WB and HIV-1 } \\
\text { NAT }\end{array}$ & $6,113 / 6,127(99.77)$ & $99.62-99.88$ & $B, C, D$ & $\mathrm{DD}, \mathrm{FF}$ \\
\hline Product insert ${ }^{161}$ & GS Ag/Ab & $\begin{array}{l}\text { Specimens from low risk } \\
\text { populations (insurance applicants, } \\
\text { pregnant women, military recruits) }\end{array}$ & 6996 & $\begin{array}{l}\text { Negative 3rd gen IA or } \\
\text { HIV-1 WB and HIV- } \\
\text { 1/HIV-2 differentiation } \\
\text { IA }\end{array}$ & 6,987/6,996 (99.87) & $99.76-99.93$ & $B, C, D$ & $\mathrm{DD}, \mathrm{FF}$ \\
\hline Mitchell; $2013^{141}$ & $\begin{array}{l}\text { a) } \mathrm{GS} \mathrm{Ag/Ab} \\
\text { b) Architect } \\
\mathrm{Ag} / \mathrm{Ab}\end{array}$ & $\begin{array}{l}\text { Previously tested negative } \\
\text { specimens from blood donors }\end{array}$ & $\begin{array}{l}\text { a) } 1,000 \\
\text { b) } 998\end{array}$ & $\begin{array}{l}\text { Negative pooled HIV-1 } \\
\text { NAT }\end{array}$ & $\begin{array}{l}\text { a) } 1,000 / 1,000(100) \\
\text { b) } 995 / 998(99.7)\end{array}$ & $\begin{array}{l}\text { a) } 99.6-00 \\
\text { b) } 99.0-99.8\end{array}$ & $\begin{array}{l}\text { a) } A \\
\text { b) } A\end{array}$ & $\begin{array}{l}\text { a) } C C, D D, F F \\
\text { b) } C C, D D\end{array}$ \\
\hline \multicolumn{9}{|c|}{ 2.c. Specificity of HIV-1/HIV/2 antibody differentiation assay } \\
\hline Masciotra; $2011^{46}$ & Multispot & $\begin{array}{l}\text { Previously tested specimens from } \\
\text { blood donors }\end{array}$ & 414 & $\begin{array}{l}\text { Negative on } 11 \text { IAs or } \\
\text { negative HIV-1 WB } \\
\text { and HIV-1 NAT }\end{array}$ & $410 / 414(99.03)$ & $97.54-99.61$ & $A, D$ & CC,DD \\
\hline Delaney; $2011^{63}$ & Multispot & $\begin{array}{l}\text { Previously collected specimens } \\
\text { from high-risk populations }\end{array}$ & 4,799 & $\begin{array}{l}\text { Negative 3rd gen IA or } \\
\text { HIV-1 WB }\end{array}$ & $4,768 /, 4799(99.35)$ & $99.08-99.56$ & $A, C, D$ & $\mathrm{DD}, \mathrm{FF}$ \\
\hline Product insert ${ }^{166}$ & Multispot & $\begin{array}{l}\text { Prospectively collected specimens } \\
\text { from low- and high-risk populations }\end{array}$ & 1,495 & $\begin{array}{l}\text { Negative 3rd } \\
\text { generation IA or HIV-1 } \\
\text { WB }\end{array}$ & $1,494 / 1,495(99.93)$ & $99.79-100.00$ & $\mathrm{~B}, \mathrm{C}$ & $\mathrm{AA}, \mathrm{DD}, \mathrm{FF}$ \\
\hline
\end{tabular}




\begin{tabular}{|c|c|c|c|c|c|c|c|c|}
\hline Publication & Test evaluated & Specimen characteristics & $\begin{array}{l}\text { Number of } \\
\text { specimens }\end{array}$ & Reference standard & $\begin{array}{l}\text { Specificity } \\
\text { n negative/n tested (\%) }\end{array}$ & $\begin{array}{l}95 \% \text { confidence } \\
\text { interval }\end{array}$ & Limitations & Strengths \\
\hline \multicolumn{9}{|c|}{ 2.e. Specificity of NAT } \\
\hline Owen; $2008^{49}$ & Procleix & $\begin{array}{l}\text { Previously tested specimens from } \\
\text { blood donors }\end{array}$ & 513 & $\begin{array}{l}\text { Negative 3rd } \\
\text { generation IA or HIV-1 } \\
\text { WB }\end{array}$ & $511 / 513(99.6)$ & Not reported & $A, D$ & $\mathrm{DD}$ \\
\hline Pilcher; $2002^{16}$ & $\begin{array}{l}\text { Pooled Roche } \\
\text { HIV-1 NAT }\end{array}$ & $\begin{array}{l}\text { Prospectively collected specimens } \\
\text { submitted for diagnostic testing to } \\
\text { North Carolina public health } \\
\text { laboratory }\end{array}$ & $\begin{array}{l}8,155 \text { IA- } \\
\text { negative; } \\
5 \text { HIV-1 NAT } \\
\text { positive }\end{array}$ & $\begin{array}{l}\text { IA and WB testing of } \\
\text { follow-up specimens } \\
\text { from persons with } \\
\text { reactive HIV-1 NAT }\end{array}$ & $\begin{array}{l}8,151 / 8,155 \text { (99.95); } \\
1 \text { of } 5 \text { persons with reactive } \\
\text { NAT results did not } \\
\text { seroconvert }\end{array}$ & Not reported & C & $\mathrm{AA}, \mathrm{FF}$ \\
\hline Patel; $2010^{18}$ & Pooled APTIMA & $\begin{array}{l}\text { Prospectively collected specimens } \\
\text { submitted for diagnostic testing to } \\
\text { Florida public health laboratory }\end{array}$ & $\begin{array}{l}54,253 \text { IA } \\
\text { negative; } \\
15 \text { HIV-1 NAT } \\
\text { positive }\end{array}$ & $\begin{array}{l}\text { IA and WB testing of } \\
\text { follow-up specimens } \\
\text { from persons with } \\
\text { reactive NAT }\end{array}$ & $\begin{array}{l}54,241 / 54,253(99.98) \\
3 \text { of } 15 \text { persons with reactive } \\
\text { NAT results did not } \\
\text { seroconvert }\end{array}$ & Not reported & c & $\mathrm{AA}, \mathrm{DD}, \mathrm{FF}$ \\
\hline
\end{tabular}

Abbreviations: Ag/Ab, antigen/antibody; IA, immunoassay; NAT, nucleic acid test; WB, Western blot. 
Evidence Table 3. Accuracy of the previous and recommended diagnostic algorithms, by corresponding section in Summary of Evidence

\begin{tabular}{|c|c|c|c|c|c|c|c|}
\hline Publication & Study design & $\begin{array}{l}\text { Specimen } \\
\text { characteristics }\end{array}$ & $\begin{array}{l}\text { Number of } \\
\text { specimens }\end{array}$ & Reference standard & Correct results $\mathrm{N}(\%)$ & Limitations & Strengths \\
\hline \multicolumn{8}{|c|}{ 3a. Accuracy of algorithms for established HIV-1 infection } \\
\hline Styer; $2011^{76}$ & $\begin{array}{l}\text { Retrospective analysis of } \\
\text { data from prospective } \\
\text { testing (GS Plus } 0 \\
\text { repeatedly reactive) }\end{array}$ & $\begin{array}{l}\text { Prospectively collected } \\
\text { specimens from } 38,257 \\
\text { persons in New York } \\
\text { State testing sites }\end{array}$ & $\begin{array}{l}1,578 \text { HIV- } \\
\text { positive }\end{array}$ & $\begin{array}{l}\text { HIV-1 WB, HIV-1 NAT, } \\
\text { follow up test results }\end{array}$ & $\begin{array}{l}\text { Previous: } 1,546 / 1,578(98) \\
\text { Recommended: } 1,578 / 1,578(100)\end{array}$ & $\mathrm{D}$ & $\mathrm{AA}, \mathrm{CC}, \mathrm{FF}$ \\
\hline Delaney; $2011^{70}$ & $\begin{array}{l}\text { Retrospective testing of } \\
\text { frozen specimens }\end{array}$ & $\begin{array}{l}\text { Previously tested } \\
\text { specimens from } 3,447 \\
\text { high-risk persons in HIV } \\
\text { testing sites }\end{array}$ & $\begin{array}{l}367 \text { WB- } \\
\text { positive }\end{array}$ & $\begin{array}{l}\text { 3rd gen IA repeatedly } \\
\text { reactive, WB positive }\end{array}$ & $\begin{array}{l}\text { Previous: } 367 / 367(100) \\
\text { Recommended: } 367 / 367(100)\end{array}$ & A & CC,DD \\
\hline $\begin{array}{l}\text { Wesolowski; } \\
2011^{194}\end{array}$ & $\begin{array}{l}\text { Retrospective testing of } \\
\text { frozen specimens }\end{array}$ & $\begin{array}{l}\text { Previously tested } \\
\text { specimens from known } \\
\text { HIV-positive, high-risk, } \\
\text { and HIV-negative blood } \\
\text { donors }\end{array}$ & $\begin{array}{l}4,828 \text { total } \\
\text { specimens, } \\
2,202 \text { WB- } \\
\text { positive }\end{array}$ & $\begin{array}{l}\text { 3rd gen IA repeatedly } \\
\text { reactive, WB positive }\end{array}$ & $\begin{array}{l}\text { Previous: 2,202/2,202 (100) } \\
\text { Recommended: 2,201/2,202 (99.95) }\end{array}$ & A & $\mathrm{CC}, \mathrm{DD}, \mathrm{FF}$ \\
\hline Masciotra; $2011^{46}$ & $\begin{array}{l}\text { Retrospective testing of } \\
\text { frozen samples with 3rd } \\
\text { generation and 4th } \\
\text { generation IAs }\end{array}$ & $\begin{array}{l}\text { Previously tested } \\
\text { specimens from plasma } \\
\text { donors }\end{array}$ & $\begin{array}{l}830 \text { total } \\
\text { specimens, } \\
416 \text { WB-positive }\end{array}$ & WB positive & $\begin{array}{l}\text { 3rd gen IA: } \\
\text { Previous: 416/416 (100) } \\
\text { Recommended: } 415 / 416(99.8) \\
\text { 4th gen IA: } \\
\text { Previous: } 415 / 416(99.8) \\
\text { Recommended: } 415 / 416(99.8)\end{array}$ & A & $\mathrm{CC}, \mathrm{DD}$ \\
\hline Nasrullah; $2013^{47}$ & $\begin{array}{l}\text { Prospective testing and } \\
\text { retrospective testing, } \\
\text { frozen specimens, GS Plus } \\
\mathrm{O} \text { and } \mathrm{GS} \mathrm{Ag} / \mathrm{Ab}\end{array}$ & $\begin{array}{l}\text { Specimens submitted for } \\
\text { diagnostic testing to a } \\
\text { commercial laboratory }\end{array}$ & $\begin{array}{l}\mathrm{n}=10,014 \\
\text { prospective, } \\
2 \text { WB-positive; } \\
491 \text { previously } \\
\text { tested HIV-1; } \\
2 \text { HIV-2 }\end{array}$ & $\begin{array}{l}\text { 3rd gen or 4th gen IA } \\
\text { repeatedly reactive; HIV-1 } \\
\text { WB, HIV-2 WB }\end{array}$ & $\begin{array}{l}\text { Previous: } 493 / 495 \text { (99.6) } \\
\text { Recommended: } 495 / 495(100)\end{array}$ & A & $\mathrm{CC}$ \\
\hline Bennett; $2013^{123}$ & $\begin{array}{l}\text { Retrospective comparison } \\
\text { of GS Plus } \mathrm{O} \text { and Architect } \\
\mathrm{Ag} / \mathrm{Ab}\end{array}$ & $\begin{array}{l}\text { Previously tested } \\
\text { diagnostic specimens } \\
\text { submitted to public } \\
\text { health laboratory }\end{array}$ & $\begin{array}{l}29 \text { HIV-1 WB } \\
\text { positive }\end{array}$ & HIV-1 WB & $\begin{array}{l}\text { Previous: 29/29 (100) } \\
\text { Recommended: } 29 / 29(100)\end{array}$ & $\mathrm{F}$ & $A A, C C, D D$ \\
\hline
\end{tabular}




\begin{tabular}{|c|c|c|c|c|c|c|c|}
\hline Publication & Study design & $\begin{array}{l}\text { Specimen } \\
\text { characteristics }\end{array}$ & $\begin{array}{l}\text { Number of } \\
\text { specimens }\end{array}$ & Reference standard & Correct results $\mathbf{N}(\%)$ & Limitations & Strengths \\
\hline \multicolumn{8}{|c|}{ 3b. Accuracy of algorithms in specimens from persons with acute HIV-1 infection } \\
\hline Masciotra; $2011^{46}$ & $\begin{array}{l}\text { Retrospective testing of } \\
\text { frozen specimens with GS } \\
\text { Plus } \mathrm{O}, \mathrm{Advia} \text {, Vitros, } \\
\text { Architect } \mathrm{Ag} / \mathrm{Ab}\end{array}$ & $\begin{array}{l}\text { Previously tested } \\
\text { specimens from } \\
\text { seroconversion panels } \\
\text { from blood donors }\end{array}$ & 228 & $\begin{array}{l}\text { HIV-1 RNA NAT positive, } \\
\text { HIV-1 WB negative }\end{array}$ & $\begin{array}{l}\text { Previous: } 0 \\
\text { Recommended: } \\
14 \text { acute after initial 3rd gen IA } \\
36 \text { acute after initial 4th gen IA }\end{array}$ & A & $\mathrm{CC}, \mathrm{DD}$ \\
\hline Nasrullah; $2013^{47}$ & $\begin{array}{l}\text { Retrospective testing of } \\
\text { frozen specimens with GS } \\
\text { Plus } O, G S A g / A b\end{array}$ & $\begin{array}{l}\text { Previously tested } \\
\text { specimens from } \\
\text { seroconversion panels } \\
\text { from blood donors }\end{array}$ & 230 & $\begin{array}{l}\text { HIV-1 RNA NAT positive, } \\
\text { HIV-1 WB negative }\end{array}$ & $\begin{array}{l}\text { Previous: } 0 \\
\text { Recommended: } \\
12 \text { acute after initial 3rd gen IA } \\
41 \text { acute after initial } 4 \text { th gen IA }\end{array}$ & A & $\mathrm{CC}, \mathrm{DD}$ \\
\hline $\begin{array}{l}\text { Wesolowski; } \\
2013^{148}\end{array}$ & $\begin{array}{l}\text { Retrospective testing of } \\
\text { frozen specimens with } \\
\text { Multispot, APTIMA }\end{array}$ & $\begin{array}{l}\text { 3rd gen IA repeatedly } \\
\text { reactive specimens } \\
\text { submitted for diagnostic } \\
\text { testing to commercial } \\
\text { laboratory }\end{array}$ & $\begin{array}{l}3,273 \text { HIV-1 WB } \\
\text { negative or } \\
\text { indeterminate }\end{array}$ & HIV-1 RNA NAT positive & $\begin{array}{l}\text { Previous: } 0 \\
\text { Recommended: } 96 \text { acute after initial 3rd gen IA }\end{array}$ & $A, E$ & $\mathrm{CC}, \mathrm{DD}, \mathrm{FF}$ \\
\hline Bennett; $2013^{123}$ & $\begin{array}{l}\text { Prospective testing with } \\
\text { Architect Ag/Ab, Multispot, } \\
\text { APTIMA }\end{array}$ & $\begin{array}{l}\text { Specimens from testing } \\
\text { sites submitted for } \\
\text { testing to FL public } \\
\text { health lab }\end{array}$ & $\begin{array}{l}51,953 \text { total } \\
\text { specimens } \\
922 \text { HIV-1 } \\
\text { positive }\end{array}$ & $\begin{array}{l}\text { Recommended algorithm } \\
\text { only }\end{array}$ & $\begin{array}{l}4(0.4 \%) \text { of } 922 \text { HIV- } 1 \text { infections identified were } \\
\text { acute } \\
\text { NAT required in } 74(0.14 \%) \text { of all specimens } \\
\text { submitted }\end{array}$ & $\mathrm{D}$ & AA \\
\hline Goodhue; $2013^{167}$ & $\begin{array}{l}\text { Prospective testing with } \\
\text { GS Ag/Ab, Multispot, } \\
\text { APTIMA }\end{array}$ & $\begin{array}{l}\text { Specimens from testing } \\
\text { sites submitted to MA } \\
\text { public health lab }\end{array}$ & $\begin{array}{l}7,984 \text { total } \\
\text { specimens } \\
258 \text { HIV-1 } \\
\text { positive } \\
1 \text { HIV-2 positive }\end{array}$ & $\begin{array}{l}\text { Recommended algorithm } \\
\text { only }\end{array}$ & $\begin{array}{l}8(3 \%) \text { of } 258 \text { HIV-1 infections identified were } \\
\text { acute } \\
\text { NAT required in } 16(0.2 \%) \text { of all specimens } \\
\text { submitted }\end{array}$ & $\mathrm{D}$ & AA \\
\hline \multicolumn{8}{|c|}{ 3c. Accuracy of algorithm in specimens from persons with HIV-2 infection } \\
\hline Torian; $2011^{88}$ & $\begin{array}{l}\text { Prospective testing with } \\
\text { retrospective data analysis }\end{array}$ & $\begin{array}{l}\text { Specimens submitted to } \\
\text { NY City public health lab } \\
\text { for diagnostic testing }\end{array}$ & $\begin{array}{l}8,760 \text { 3rd gen } I A \\
\text { repeatedly } \\
\text { reactive }\end{array}$ & $\begin{array}{l}\text { HIV-2 immunoassay } \\
\text { HIV-2 WB }\end{array}$ & $\begin{array}{l}38 \text { HIV-2 positive: } \\
26 \text { classified as HIV-1 positive and } \\
12 \text { as indeterminate by HIV-1 WB }\end{array}$ & $\mathrm{D}$ & AA \\
\hline
\end{tabular}




\begin{tabular}{|c|c|c|c|c|c|c|c|}
\hline Publication & Study design & $\begin{array}{l}\text { Specimen } \\
\text { characteristics }\end{array}$ & $\begin{array}{l}\text { Number of } \\
\text { specimens }\end{array}$ & Reference standard & Correct results $\mathrm{N}(\%)$ & Limitations & Strengths \\
\hline Nasrullah; $2013^{47}$ & $\begin{array}{l}\text { Retrospective testing of } \\
\text { previously tested frozen } \\
\text { samples }\end{array}$ & $\begin{array}{l}\text { Diagnostic specimens } \\
\text { submitted to a } \\
\text { commercial laboratory }\end{array}$ & $\begin{array}{l}493 \text { HIV-1 WB } \\
\text { positive }\end{array}$ & $\begin{array}{l}\text { HIV-2 immunoassay } \\
\text { HIV-2 WB }\end{array}$ & $\begin{array}{l}\text { Previous: } 0 \text { (2 misclassified as HIV-1) } \\
\text { Recommended: } 2 / 493(0.4 \%) \text { HIV-2 }\end{array}$ & D & CC \\
\hline \multicolumn{8}{|c|}{ 3d. Accuracy of algorithm in specimens from persons not infected with HIV } \\
\hline Styer; $2011^{76}$ & $\begin{array}{l}\text { Prospective testing with } \\
\text { retrospective data analysis }\end{array}$ & $\begin{array}{l}\text { Specimens submitted to } \\
\text { NY State public health } \\
\text { lab for diagnostic testing }\end{array}$ & 33,257 & $\begin{array}{l}\text { NY State algorithm: } \\
\text { HIV-1 WB, Multispot, HIV- } \\
1 \text { NAT, HIV-2 NAT, follow- } \\
\text { up specimens }\end{array}$ & $\begin{array}{l}\text { Recommended algorithm: } \\
39 \text { fewer indeterminate/inconclusive results, with } \\
17 \text { fewer in HIV-negative individuals; } \\
1 \text { false-positive by both previous and } \\
\text { recommended algorithm }\end{array}$ & & $\mathrm{AA}, \mathrm{CC}, \mathrm{DD}, \mathrm{FF}$ \\
\hline Nasrullah; $2013^{47}$ & $\begin{array}{l}\text { Prospective testing of fresh } \\
\text { specimens; retrospective } \\
\text { testing of frozen } \\
\text { specimens }\end{array}$ & $\begin{array}{l}\text { Specimens from low-risk } \\
\text { population submitted to a } \\
\text { commercial laboratory; } \\
\text { seroconversion panels } \\
\text { from blood donors }\end{array}$ & $\begin{array}{l}10,014 \\
\text { prospective } \\
\text { specimens; } \\
230 \text { specimens } \\
\text { from } \\
\text { seroconversion } \\
\text { panels }\end{array}$ & $\begin{array}{l}\text { HIV-1 WB } \\
\text { HIV-1 NAT }\end{array}$ & $\begin{array}{l}\text { Recommended algorithm: } \\
2 \text { fewer indeterminate results in specimens from } \\
\text { low risk population; } \\
39 \text { fewer indeterminate results after } 4 \text { th gen } \\
\text { screening of seroconversion panel specimens }\end{array}$ & & $\mathrm{AA}, \mathrm{CC}, \mathrm{DD}, \mathrm{FF}$ \\
\hline Bennett; $2013^{123}$ & $\begin{array}{l}\text { Prospective testing with } \\
\text { recommended algorithm }\end{array}$ & $\begin{array}{l}\text { Diagnostic specimens } \\
\text { from high-risk persons } \\
\text { submitted to FL public } \\
\text { health lab }\end{array}$ & 51,953 & $\begin{array}{l}\text { HIV-1 NAT for repeatedly } \\
\text { reactive 4th gen, Multispot } \\
\text { negative or indeterminate } \\
\text { One follow-up specimen }\end{array}$ & $\begin{array}{l}\text { Recommended algorithm: } \\
69 \text { fewer inconclusive results from negative } \\
\text { individuals resolved by NAT; } \\
1 \text { false-positive based on follow-up specimen } \\
\text { testing }\end{array}$ & c & $A A, D D, F F$ \\
\hline
\end{tabular}

Abbreviations: Ag/Ab, antigen/antibody; IA, immunoassay; NAT, nucleic acid test; RNA, ribonucleic acid; WB, Western blot. 


\section{References}

1. CDC. Interpretation and use of the Western blot assay for serodiagnosis of human immunodeficiency virus type 1 infections. MMWR Morb Mortal Wkly Rep. 1989;38(S-7):1-7. Available at: http://www.cdc.gov/mmwr/preview/mmwrhtm//00001431.htm.

2. O'Brien TR, George JR, Epstein JS, Holmberg SD, Schochetman G. Testing for antibodies to human immunodeficiency virus type 2 in the United States. MMWR Recomm Rep. 1992;41(RR-12):1-9. Available at: http://www.cdc.gov/mmwr/preview/mmwrhtml/00038078.htm.

3. CDC. Protocols for confirmation of rapid HIV tests. MMWR Morb Mortal Wkly Rep. 2004;53(10):221-2. Available at: http://www.cdc.gov/mmwr/PDF/wk/mm5310.pdf.

4. Stekler JD, Swenson PD, Coombs RW, et al. HIV testing in a high-incidence population: is antibody testing alone good enough? Clin Infect Dis. 2009;49(3):444-53. Available at: http://www.ncbi.nlm.nih.gov/pubmed/19538088.

5. Priddy FH, Pilcher $\mathrm{CD}$, Moore RH, et al. Detection of acute HIV infections in an urban HIV counseling and testing population in the United States. J Acquir Immune Defic Syndr. 2007;44(2):196-202. Available at: http://www.ncbi.nlm.nih.gov/pubmed/17312561.

6. Pilcher CD, Fiscus SA, Nguyen TQ, et al. Detection of acute infections during HIV testing in North Carolina. N Engl J Med. 2005;352(18):1873-83. Available at: http://www.ncbi.nlm.nih.gov/pubmed/15872202.

7. Facente SN, Pilcher CD, Hartogensis WE, et al. Performance of risk-based criteria for targeting acute HIV screening in San Francisco. PLoS One. 2011;6(7):e21813. Available at: http://www.ncbi.nlm.nih.gov/pubmed/21755003.

8. Patel P, Klausner JD, Bacon OM, et al. Detection of acute HIV infections in high-risk patients in California. J Acquir Immune Defic Syndr. 2006;42(1):75-9. Available at: http://www.ncbi.nlm.nih.gov/pubmed/16763493.

9. CDC. Acute HIV infection-New York City, 2008. MMWR. 2009;58(46):1296-9. Available at: http://www.ncbi.nlm.nih.gov/pubmed/19940835.

10. CDC. Detection of acute HIV infection in two evaluations of a new HIV diagnostic testing algorithm-United States, 20112013. MMWR Morb Mortal Wkly Rep. 2013;62:489-94. Available at: http://www.cdc.gov/mmwr/pdf/wk/mm6224.pdf.

11. Branson BM. The future of HIV testing. J Acquir Immune Defic Syndr. 2010;55(Suppl 2):S102-5. Available at: http://www.ncbi.nlm.nih.gov/pubmed/21406978.

12. Ly TD, Ebel A, Faucher V, Fihman V, Laperche S. Could the new HIV combined p24 antigen and antibody assays replace p24 antigen specific assays? J Virol Methods. 2007;143(1):86-94. Available at: http://www.ncbi.nlm.nih.gov/pubmed/17395277.

13. Pierce VM, Neide B, Hodinka RL. Evaluation of the Gen-Probe Aptima HIV-1 RNA qualitative assay as an alternative to Western blot analysis for confirmation of HIV infection. J Clin Microbiol. 2011;49(4):1642-5. Available at: http://www.ncbi.nlm.nih.gov/pubmed/21346052.

14. Walensky RP. APTIMA assay approved for HIV testing. AIDS Clin Care. 2006;18(12):109-10. Available at: http://www.ncbi.nlm.nih.gov/pubmed/17228444.

15. Hecht FM, Busch MP, Rawal B, et al. Use of laboratory tests and clinical symptoms for identification of primary HIV infection. AIDS. 2002;16(8):1119-29. Available at: http://www.ncbi.nlm.nih.gov/pubmed/12004270.

16. Pilcher $\mathrm{CD}$, McPherson JT, Leone PA, et al. Real-time, universal screening for acute HIV infection in a routine HIV counseling and testing population. JAMA. 2002;288(2):216-21. Available at: http://www.ncbi.nlm.nih.gov/pubmed/12095386.

17. Patel $P$, Bennett $B$, Sullivan $T$, et al. Rapid HIV screening: missed opportunities for HIV diagnosis and prevention. $J$ Clin Virol. 2012;54(1):42-7. Available at: http://www.ncbi.nlm.nih.gov/pubmed/22381919.

18. Patel $P$, Mackellar $D$, Simmons $P$, et al. Detecting acute human immunodeficiency virus infection using 3 different screening immunoassays and nucleic acid amplification testing for human immunodeficiency virus RNA, 2006-2008. Arch Intern Med. 2010;170(1):66-74. Available at: http://www.ncbi.nlm.nih.gov/pubmed/20065201.

19. Koopman JS, Jacquez JA, Welch GW, et al. The role of early HIV infection in the spread of HIV through populations. $J$ Acquir Immune Defic Syndr Hum Retrovirol. 1997;14(3):249-58. Available at: http://www.ncbi.nlm.nih.gov/pubmed/9117458.

20. Hollingsworth TD, Anderson RM, Fraser C. HIV-1 transmission, by stage of infection. J Infect Dis. 2008;198(5):687-93. Available at: http://www.ncbi.nlm.nih.gov/pubmed/18662132.

21. Brenner BG, Roger M, Routy JP, et al. High rates of forward transmission events after acute/early HIV-1 infection. J Infect Dis. 2007;195(7):951-9. Available at: http://www.ncbi.nlm.nih.gov/pubmed/17330784.

22. Prabhu VS, Hutchinson AB, Farnham PG, Sansom SL. Sexually acquired HIV infections in the United States due to acutephase HIV transmission: an update. AIDS. 2009;23(13):1792-4. Available at: http://www.ncbi.nlm.nih.gov/pubmed/19684485.

23. Panel on Antiretroviral Guidelines for Adults and Adolescents. Guidelines for the use of antiretroviral agents in HIV-1infected adults and adolescents. 2013. http://www.aidsinfo.nih.gov/ContentFiles/AdultandAdolescentGL.pdf. Accessed May $27,2014$. 
24. Hogan CM, Degruttola V, Sun X, et al. The setpoint study (ACTG A5217): effect of immediate versus deferred antiretroviral therapy on virologic set point in recently HIV-1-infected individuals. J Infect Dis. 2012;205(1):87-96. Available at: http://www.ncbi.nlm.nih.gov/pubmed/22180621.

25. Saez-Cirion A, Bacchus $C$, Hocqueloux L, et al. Post-treatment HIV-1 controllers with a long-term virological remission after the interruption of early initiated antiretroviral therapy ANRS VISCONTI Study. PLoS Pathog. 2013;9(3):e1003211. Available at: http://www.ncbi.nlm.nih.gov/pubmed/23516360.

26. Hocqueloux L, Saez-Cirion A, Rouzioux C. Immunovirologic control 24 months after interruption of antiretroviral therapy initiated close to HIV seroconversion. JAMA Intern Med. 2013;173(6):475-6. Available at: http://www.ncbi.nlm.nih.gov/pubmed/23529554.

27. CDC. HIV-2 infection surveillance-United States, 1987-2009. MMWR Morb Mortal Wkly Rep. 2011;60(29):985-8. Available at: http://www.ncbi.nlm.nih.gov/pubmed/21796096.

28. Torian LV, Eavey JJ, Punsalang AP, et al. HIV type 2 in New York City, 2000-2008. Clin Infect Dis. 2010;51(11):1334-42. Available at: http://www.ncbi.nlm.nih.gov/pubmed/21039219.

29. Nasrullah M, Ethridge SF, Delaney KP, et al. Comparison of alternative interpretive criteria for the HIV-1 Western blot and results of the Multispot HIV-1/HIV-2 Rapid Test for classifying HIV-1 and HIV-2 infections. J Clin Virol. 2011;52(Suppl 1):S23-7. Available at: http://www.ncbi.nlm.nih.gov/pubmed/21993309.

30. CDC. Monitoring selected national HIV prevention and care objectives by using HIV surveillance data—United States and 6 U.S. dependent areas-2011. HIV Surveillance Supplemental Report. 2013;18(No. 5). http://www.cdc.gov/hiv/pdf/2011_Monitoring_HIV_Indicators_HSSR_FINAL.pdf. Accessed December 10, 2013.

31. CDC. HIV Surveillance Report, 2011. 2013;23. http://www.cdc.gov/hiv/pdf/statistics_2011_HIV Surveillance_Report_vol_23.pdf. Accessed June 5, 2013.

32. CDC. Estimated HIV incidence in the United States, 2007-2010. HIV Surveillance Supplemental Report. 2012;17(4):1-26. http://www.cdc.gov/hiv/pdf/statistics_hssr_vol_17_no_4.pdf. Accessed July 9, 2013.

33. CDC. Vital signs: HIV testing and diagnosis among adults-United States, 2001-2009. MMWR Morb Mortal Wkly Rep. 2010;59(47):1550-5. Available at: http://www.cdc.gov/mmwr/PDF/wk/mm5947.pdf.

34. CDC. Vital signs: HIV prevention through care and treatment-United States. MMWR Morb Mortal Wkly Rep. 2011;60(47):1618-23. Available at: http://www.cdc.gov/mmwr/PDF/wk/mm6047.pdf.

35. FFDA. Clinical Laboratory Improvement Amendments (CLIA). 2009; http://www.fda.gov/medicaldevices/deviceregulationandguidance/ivdregulatoryassistance/ucm124105.htm. Accessed May 27, 2014.

36. Jendis JB, Tomasik Z, Hunziker U, et al. Evaluation of diagnostic tests for HIV infection in infants born to HIV-infected mothers in Switzerland. AIDS. 1988;2(4):273-9. Available at: http://www.ncbi.nlm.nih.gov/pubmed/3140833.

37. Rogers MF, Ou CY, Rayfield M, et al. Use of the polymerase chain reaction for early detection of the proviral sequences of human immunodeficiency virus in infants born to seropositive mothers. New York City Collaborative Study of Maternal HIV Transmission and Montefiore Medical Center HIV Perinatal Transmission Study Group. N Engl J Med. 1989;320(25):164954. Available at: http://www.ncbi.nlm.nih.gov/pubmed/2725615.

38. Panel on Antiretroviral Therapy and Medical Management of HIV-Infected Children-A Working Group of the Office of AIDS Research Advisory Council (OARAC). "Diagnosis of HIV Infection in Infants and Children" in Guidelines for the use of antiretroviral agents in pediatric HIV infection. 2014. http://aidsinfo.nih.gov/guidelines/htm//2/pediatric-arvquidelines/55/diagnosis-of-hiv-infection-in-infants-and-children. Accessed July 7, 2013.

39. FDA. Revised recommendations for the prevention of human immunodeficiency virus (HIV) transmission by blood and blood products. 1992; http://www.fda.gov/downloads/BiologicsBloodVaccines/GuidanceComplianceRegulatorylnformation/OtherRecommendation sforManufacturers/MemorandumtoBloodEstablishments/UCM062834.pdf. Accessed July 8, 2013.

40. FDA. Guidance for Industry: Nucleic Acid Testing (NAT) for Human Immunodeficiency Virus Type 1 (HIV-1) and Hepatitis C Virus (HCV): Testing, Product Disposition, and Donor Deferral and Reentry. 2010; http://www.fda.gov/downloads/BiologicsBloodVaccines/GuidanceComplianceRegulatorylnformation/Guidances/Blood/UCM2 10270.pdf. Accessed July 8, 2013.

41. Seem DL, Lee I, Umscheid CA, Kuehnert MJ, United States Public Health S. PHS guideline for reducing human immunodeficiency virus, hepatitis $B$ virus, and hepatitis $C$ virus transmission through organ transplantation. Public Health Rep. 2013;128(4):247-343. Available at: http://www.ncbi.nlm.nih.gov/pubmed/23814319.

42. Albritton WL, Vittinghoff E, Padian NS. Human immunodeficiency virus testing for patient-based and population-based diagnosis. J Infect Dis. 1996;174(Suppl 2):S176-S81. Available at: http://www.ncbi.nlm.nih.gov/pubmed/8843247.

43. FDA. Approval of HIV-1 RNA qualitative assay for diagnostic use. 2006; http://www.fda.gov/ForConsumers/ByAudience/ForPatientAdvocates/HIVandAIDSActivities/ucm124430.htm. Accessed August 30, 2013. 
44. FDA. Supplement letter-Multispot HIV-1/HIV-2 Rapid Test. March 25, 2013; http://www.fda.gov/BiologicsBloodVaccines/BloodBloodProducts/ApprovedProducts/PremarketApprovalsPMAs/ucm357028. htm. Accessed August 30, 2013.

45. Forsgren A, Nordstrom K. Protein A from Staphylococcus aureus: the biological significance of its reaction with $\operatorname{lgG}$. Ann N Y Acad Sci. 1974;236(0):252-66. Available at: http://www.ncbi.nlm.nih.gov/pubmed/4278611.

46. Masciotra S, McDougal JS, Feldman J, Sprinkle P, Wesolowski L, Owen SM. Evaluation of an alternative HIV diagnostic algorithm using specimens from seroconversion panels and persons with established HIV infections. J Clin Virol. 2011;52(Suppl 1):S17-22. Available at: http://www.ncbi.nlm.nih.gov/pubmed/21981983.

47. Nasrullah M, Wesolowski LG, Meyer WA, 3rd, et al. Performance of a fourth-generation HIV screening assay and an alternative HIV diagnostic testing algorithm. AIDS. 2013;27(5):731-7. Available at: http://www.ncbi.nlm.nih.gov/pubmed/23135170.

48. Fiebig EW, Wright DJ, Rawal BD, et al. Dynamics of HIV viremia and antibody seroconversion in plasma donors: implications for diagnosis and staging of primary HIV infection. AIDS. 2003;17(13):1871-9. Available at: http://www.ncbi.nlm.nih.gov/pubmed/12960819.

49. Owen SM, Yang C, Spira T, et al. Alternative algorithms for human immunodeficiency virus infection diagnosis using tests that are licensed in the United States. J Clin Microbiol. 2008;46(5):1588-95. Available at: http://www.ncbi.nlm.nih.gov/pubmed/18322061.

50. Busch MP, Satten GA. Time course of viremia and antibody seroconversion following human immunodeficiency virus exposure. Am J Med. 1997;102(5B):117-24. Available at: http://www.ncbi.nlm.nih.gov/pubmed/9845513.

51. Fiebig EW, Heldebrant CM, Smith RI, Conrad AJ, Delwart EL, Busch MP. Intermittent low-level viremia in very early primary HIV-1 infection. J Acquir Immune Defic Syndr. 2005;39(2):133-7. Available at: http://www.ncbi.nlm.nih.gov/pubmed/15905727.

52. Keele BF, Giorgi EE, Salazar-Gonzalez JF, et al. Identification and characterization of transmitted and early founder virus envelopes in primary HIV-1 infection. Proc Natl Acad Sci U S A. 2008;105(21):7552-7. Available at: http://www.ncbi.nlm.nih.gov/pubmed/18490657.

53. Lee HY, Giorgi EE, Keele BF, et al. Modeling sequence evolution in acute HIV-1 infection. J Theor Biol. 2009;261(2):34160. Available at: http://www.ncbi.nlm.nih.gov/pubmed/19660475.

54. Lindback S, Karlsson AC, Mittler J, et al. Viral dynamics in primary HIV-1 infection. Karolinska Institutet Primary HIV Infection Study Group. AIDS. 2000;14(15):2283-91. Available at: http://www.ncbi.nlm.nih.gov/pubmed/11089616.

55. Lindback S, Thorstensson R, Karlsson AC, et al. Diagnosis of primary HIV-1 infection and duration of follow-up after HIV exposure. Karolinska Institute Primary HIV Infection Study Group. AIDS. 2000;14(15):2333-9. Available at: http://www.ncbi.nlm.nih.gov/pubmed/11089621.

56. Vermeulen M, Coleman C, Mitchel J, et al. Comparison of human immunodeficiency virus assays in window phase and elite controller samples: viral load distribution and implications for transmission risk. Transfusion. 2013;53(10 Pt 2):3284-98. Available at: http://www.ncbi.nlm.nih.gov/pubmed/23445273.

57. Goudsmit J, de Wolf F, Paul DA, et al. Expression of human immunodeficiency virus antigen (HIV-Ag) in serum and cerebrospinal fluid during acute and chronic infection. Lancet. 1986;2(8500):177-80. Available at: http://www.ncbi.nlm.nih.gov/pubmed/2873436.

58. McRae B, Lange JA, Ascher MS, et al. Immune response to HIV p24 core protein during the early phases of human immunodeficiency virus infection. AIDS Res Hum Retroviruses. 1991;7(8):637-43. Available at: http://www.ncbi.nlm.nih.gov/pubmed/1931233.

59. Bollinger RC, Jr., Kline RL, Francis HL, Moss MW, Bartlett JG, Quinn TC. Acid dissociation increases the sensitivity of p24 antigen detection for the evaluation of antiviral therapy and disease progression in asymptomatic human immunodeficiency virus-infected persons. J Infect Dis. 1992;165(5):913-6. Available at: http://www.ncbi.nlm.nih.gov/pubmed/1569343.

60. Schupbach J, Tomasik Z, Knuchel M, et al. Optimized virus disruption improves detection of HIV-1 p24 in particles and uncovers a p24 reactivity in patients with undetectable HIV-1 RNA under long-term HAART. J Med Virol. 2006;78(8):100310. Available at: http://www.ncbi.nlm.nih.gov/pubmed/16789014.

61. Tomaras GD, Yates NL, Liu P, et al. Initial B-cell responses to transmitted human immunodeficiency virus type 1: virionbinding immunoglobulin $\mathrm{M}(\mathrm{IgM})$ and $\lg \mathrm{G}$ antibodies followed by plasma anti-gp41 antibodies with ineffective control of initial viremia. J Virol. 2008;82(24):12449-63. Available at: http://www.ncbi.nlm.nih.gov/pubmed/18842730.

62. Louie B, Wong E, Klausner JD, et al. Assessment of rapid tests for detection of human immunodeficiency virus-specific antibodies in recently infected individuals. J Clin Microbiol. 2008;46(4):1494-7. Available at: http://www.ncbi.nlm.nih.gov/pubmed/18234875.

63. Delaney KP, Branson BM, Uniyal A, et al. Evaluation of the performance characteristics of 6 rapid HIV antibody tests. Clin Infect Dis. 2011;52(2):257-63. Available at: http://www.ncbi.nlm.nih.gov/pubmed/21288853. 
64. Ananworanich J, Fletcher JL, Pinyakorn S, et al. A novel acute HIV infection staging system based on 4th generation immunoassay. Retrovirology. 2013;10:56. Available at: http://www.ncbi.nlm.nih.gov/pubmed/23718762.

65. Carlson JR, Yee J, Hinrichs SH, Bryant ML, Gardner MB, Pedersen NC. Comparison of indirect immunofluorescence and Western blot for detection of anti-human immunodeficiency virus antibodies. J Clin Microbiol. 1987;25(3):494-7. Available at: http://www.ncbi.nlm.nih.gov/pubmed/3553225.

66. Masciotra S, Luo W, Youngpairoj AS, et al. Performance of the Alere Determine HIV-1/2 Ag/Ab Combo Rapid Test with specimens from HIV-1 seroconverters from the US and HIV-2 infected individuals from Ivory Coast. J Clin Virol. 2013;58(Suppl 1):e54-8. Available at: http://www.ncbi.nlm.nih.gov/pubmed/23911678.

67. Kleinman S, Busch MP, Hall L, et al. False-positive HIV-1 test results in a low-risk screening setting of voluntary blood donation. Retrovirus Epidemiology Donor Study. JAMA. 1998;280(12):1080-5. Available at: http://www.ncbi.nlm.nih.gov/pubmed/9757856.

68. Stramer SL. Nucleic acid testing for transfusion-transmissible agents. Curr Opin Hematol. 2000;7(6):387-91. Available at: http://www.ncbi.nlm.nih.gov/pubmed/11055512.

69. Louie B, Pandori MW, Wong E, Klausner JD, Liska S. Use of an acute seroconversion panel to evaluate a third-generation enzyme-linked immunoassay for detection of human immunodeficiency virus-specific antibodies relative to multiple other assays. J Clin Microbiol. 2006;44(5):1856-8. Available at: http://www.ncbi.nlm.nih.gov/pubmed/16672422.

70. Delaney KP, Heffelfinger JD, Wesolowski LG, et al. Performance of an alternative laboratory-based algorithm for HIV diagnosis in a high-risk population. J Clin Virol. 2011;52(Suppl 1):S5-10. Available at: http://www.ncbi.nlm.nih.gov/pubmed/22019251.

71. Pandori MW, Hackett J, Jr., Louie B, et al. Assessment of the ability of a fourth-generation immunoassay for human immunodeficiency virus (HIV) antibody and p24 antigen to detect both acute and recent HIV infections in a high-risk setting. J Clin Microbiol. 2009;47(8):2639-42. Available at: http://www.ncbi.nlm.nih.gov/pubmed/19535523.

72. Chavez P, Wesolowski L, Patel P, Delaney K, Owen SM. Evaluation of the performance of the Abbott ARCHITECT HIV Ag/Ab Combo Assay. J Clin Virol. 2011;52(Suppl 1):S51-5. Available at: http://www.ncbi.nlm.nih.gov/pubmed/21983253.

73. Eshleman SH, Khaki L, Laeyendecker $\mathrm{O}$, et al. Detection of individuals with acute HIV-1 infection using the ARCHITECT HIV Ag/Ab Combo assay. J Acquir Immune Defic Syndr. 2009;52(1):121-4. Available at: http://www.ncbi.nlm.nih.gov/pubmed/19506484.

74. Association of Public Health Laboratories. Public Health Laboratory Issues in Brief: 2006 HIV Diagnostics Survey. 2007; http://www.aphl.org/AboutAPHL/publications/Documents/HIV_issue_brief_2007.pdf. Accessed May 27, 2014.

75. Association of Public Health Laboratories. Issues in Brief: HIV Diagnostics Survey. 2012; http://www.aphl.org/AboutAPHL/publications/Documents/ID_2012Dec HIV-Diagnostics-Survey-Issue-Brief.pdf. Accessed May 27, 2014.

76. Styer LM, Sullivan TJ, Parker MM. Evaluation of an alternative supplemental testing strategy for HIV diagnosis by retrospective analysis of clinical HIV testing data. J Clin Virol. 2011;52(Suppl 1):S35-40. Available at: http://www.ncbi.nlm.nih.gov/pubmed/22018662.

77. Cohen MS, Shaw GM, McMichael AJ, Haynes BF. Acute HIV-1 Infection. N Engl J Med. 2011;364(20):1943-54. Available at: http://www.ncbi.nlm.nih.gov/pubmed/21591946.

78. Morrison CS, Demers K, Kwok C, et al. Plasma and cervical viral loads among Ugandan and Zimbabwean women during acute and early HIV-1 infection. AIDS. 2010;24(4):573-82. Available at: http://www.ncbi.nlm.nih.gov/pubmed/20154581.

79. Pilcher CD, Joaki G, Hoffman IF, et al. Amplified transmission of HIV-1: comparison of HIV-1 concentrations in semen and blood during acute and chronic infection. AIDS. 2007;21(13):1723-30. Available at: http://www.ncbi.nlm.nih.gov/pubmed/17690570.

80. Jacquez JA, Koopman JS, Simon CP, Longini IM, Jr. Role of the primary infection in epidemics of HIV infection in gay cohorts. J Acquir Immune Defic Syndr. 1994;7(11):1169-84. Available at: http://www.ncbi.nlm.nih.gov/pubmed/7932084.

81. Hecht FM, Wang L, Collier A, et al. A multicenter observational study of the potential benefits of initiating combination antiretroviral therapy during acute HIV infection. J Infect Dis. 2006;194(6):725-33. Available at: http://www.ncbi.nlm.nih.gov/pubmed/16941337.

82. Hamlyn E, Jones V, Porter K, Fidler S. Antiretroviral treatment of primary HIV infection to reduce onward transmission. Curr Opin HIV AIDS. 2010;5(4):283-90. Available at: http://www.ncbi.nlm.nih.gov/pubmed/20543602.

83. Smith MK, Rutstein SE, Powers KA, et al. The detection and management of early HIV infection: a clinical and public health emergency. J Acquir Immune Defic Syndr. 2013;63(Suppl 2):S187-99. Available at: http://www.ncbi.nlm.nih.gov/pubmed/23764635.

84. Pilcher CD, Christopoulos KA, Golden M. Public health rationale for rapid nucleic acid or p24 antigen tests for HIV. J Infect Dis. 2010;201(Suppl 1):S7-15. Available at: http://www.ncbi.nlm.nih.gov/pubmed/20225950. 
85. Ntemgwa ML, d'Aquin Toni T, Brenner BG, Camacho RJ, Wainberg MA. Antiretroviral drug resistance in human immunodeficiency virus type 2. Antimicrob Agents Chemother. 2009;53(9):3611-9. Available at: http://www.ncbi.nlm.nih.gov/pubmed/19470514.

86. Hizi A, Tal R, Shaharabany M, et al. Specific inhibition of the reverse transcriptase of human immunodeficiency virus type 1 and the chimeric enzymes of human immunodeficiency virus type 1 and type 2 by nonnucleoside inhibitors. Antimicrob Agents Chemother. 1993;37(5):1037-42. Available at: http://www.ncbi.nlm.nih.gov/pubmed/7685994.

87. FDA. Complete list of donor screening assays for infectious agents and HIV diagnostic assays. 2014; http://www.fda.gov/BiologicsBloodVaccines/BloodBloodProducts/ApprovedProducts/LicensedProductsBLAs/BloodDonorScr eening/InfectiousDisease/ucm080466.htm. Accessed May 26, 2014.

88. Torian LV, Forgione LA, Punsalang AE, Pirillo RE, Oleszko WR. Comparison of Multispot EIA with Western blot for confirmatory serodiagnosis of HIV. J Clin Virol. 2011;52(Suppl 1):S41-4. Available at: http://www.ncbi.nlm.nih.gov/pubmed/21995935.

89. CDC. Conference Summary. 2007 HIV Diagnostics Conference. Available at: http://www.hivtestingconference.org/hivtesting2007/cs.htm. Accessed May 26, 2014.

90. Association of Public Health Laboratories, Centers for Disease Control and Prevention. HIV testing algorithms: a status report. 2009; http://stacks.cdc.gov/view/cdc/5696. Accessed May 26, 2014.

91. CDC. Conference Summary. 2010 HIV Diagnostics Conference. Available at: http://www.hivtestingconference.org/hivtesting2010/PDF/2010HIVDiagnosticsConfSummary.pdf. Accessed May 26, 2014.

92. Ginocchio CG, Carman WF, Arens MQ. Update on HIV diagnostic testing algorithms. Journal of Clinical Virology Supplement: 2011;52(Suppl 1):S1-S89. Available at: http://download.journals.elsevierhealth.com/pdfs/journals/13866532/PIIS138665321100388X.pdf. Accessed June 8, 2013.

93. Pandori MW, Branson BM. 2010 HIV Diagnostics Conference. Expert Rev Anti Infect Ther. 2010;8(6):631-3. Available at: http://www.ncbi.nlm.nih.gov/pubmed/20521890.

94. Wesolowski LG, Delaney KP, Hart C, et al. Performance of an alternative laboratory-based algorithm for diagnosis of HIV infection utilizing a third generation immunoassay, a rapid HIV-1/HIV-2 differentiation test and a DNA or RNA-based nucleic acid amplification test in persons with established HIV-1 infection and blood donors. J Clin Virol. 2011;52(Suppl 1):S45-9. Available at: http://www.ncbi.nlm.nih.gov/pubmed/21995934.

95. CDC. Draft recommendations: diagnostic laboratory testing for HIV infection in the United States. 2012; http://www.cdc.gov/hiv/pdf/policies_Draft_HIV_Testing_Alg_Rec_508.2.pdf. Accessed May 26, 2014.

96. CDC. Verbatim transcript of 2012 HIV Diagnostics Conference final feedback session: proposed recommendations for diagnostic HIV testing algorithm. 2012; http://www.cdc.gov/hiv/pdf/policies_Transcript_HIV_Alg_DiagConf 508.pdf. Accessed May 26, 2014.

97. CDC. Conference Proceedings. 2012 HIV Diagnostics Conference. Available at: http://hivtestingconference.orgl. Accessed May 26, 2014.

98. Branson BM, Pandori M. 2012 HIV Diagnostics Conference: the molecular diagnostics perspective. Expert Rev Mol Diagn. 2013;13(3):243-5. Available at: http://www.ncbi.nlm.nih.gov/pubmed/23570401.

99. Hutchinson AB, Ethridge SF, Wesolowski LG, et al. Costs and outcomes of laboratory diagnostic algorithms for the detection of HIV. J Clin Virol. 2013;58(Suppl 1):e2-7. Available at: http://www.ncbi.nlm.nih.gov/pubmed/24342475.

100. Branson BM, Ginocchio CG. HIV laboratory diagnosis: new tests and a new algorithm. Journal of Clinical Virology Supplement: 2013;58(Suppl 1)e1-e133. Available at: http://www.journalofclinicalvirology.com/issues?issue key=S13866532\%2813\%29X0012-5. Accessed May 26, 2014.

101. CDC. Advancing Excellence \& Integrity of CDC Science: OMB information quality peer review agenda. 2013. Available at: http://www.cdc.gov/od/science/quality/support/peer-review.htm. Accessed May 26, 2014.

102. Sullivan PS, Schable C, Koch W, et al. Persistently negative HIV-1 antibody enzyme immunoassay screening results for patients with HIV-1 infection and AIDS: serologic, clinical, and virologic results. Seronegative AIDS Clinical Study Group. AIDS. 1999;13(1):89-96. Available at: http://www.ncbi.nlm.nih.gov/pubmed/10207549.

103. Gill MJ, Rachlis A, Anand C. Five cases of erroneously diagnosed HIV infection. CMAJ. 1991;145(12):1593-5. Available at: http://www.ncbi.nlm.nih.gov/pubmed/1742696.

104. Wood RW, Dunphy C, Okita K, Swenson P. Two "HIV-infected" persons not really infected. Arch Intern Med. 2003;163(15):1857-9. Available at: http://www.ncbi.nlm.nih.gov/pubmed/12912724.

105. Esteva MH, Blasini AM, Ogly D, Rodriguez MA. False positive results for antibody to HIV in two men with systemic lupus erythematosus. Ann Rheum Dis. 1992;51(9):1071-3. Available at: http://www.ncbi.nlm.nih.gov/pubmed/1417140.

106. Shida S, Takahashi N, Fujishima N, et al. False-positive human immunodeficiency virus antibody test and autoimmune hemolytic anemia in a patient with angioimmunoblastic T-cell lymphoma. Intern Med. 2011;50(20):2383-7. Available at: http://www.ncbi.nlm.nih.gov/pubmed/22001471. 
107. Ramos EM, Harb S, Dragavon J, Coombs RW. Clinical performance of the Multispot HIV-1/HIV-2 rapid test to correctly differentiate HIV-2 from HIV-1 infection in screening algorithms using third and fourth generation assays and to identify cross reactivity with the HIV-1 Western Blot. J Clin Virol. 2013;58(Suppl 1):e104-7. Available at: http://www.ncbi.nlm.nih.gov/pubmed/24342468.

108. Bonney EY, Sackey ST, Brandful JA. Laboratory diagnosis of dual HIV-1/HIV-2 infection in Ghanaian patients. East Afr Med J. 2008;85(11):537-43. Available at: http://www.ncbi.nlm.nih.gov/pubmed/19413206.

109. Gottlieb GS, Sow PS, Hawes SE, et al. Molecular epidemiology of dual HIV-1/HIV-2 seropositive adults from Senegal, West Africa. AIDS Res Hum Retroviruses. 2003;19(7):575-84. Available at: http://www.ncbi.nlm.nih.gov/pubmed/12908935.

110. Styer LM, Sullivan T, Parker MM. Detection of a rare HIV-1/HIV-2 co-infection using the new supplemental testing strategy. Paper presented at: 12th HIV Diagnostics Conference; December 12-14, 2012; Atlanta, Georgia. Available at: https://custom.cvent.com/ADE0EB81B3184D618E2FB8340F1EC28E/files/29f3717707a44f91859f65feb4cefec6.pdf. Accessed June 2, 2014.

111. Prada N, Davis $B$, Jean-Pierre $P$, et al. Drug-susceptible HIV-1 infection despite intermittent fixed-dose combination tenofovir/emtricitabine as prophylaxis is associated with low-level viremia, delayed seroconversion, and an attenuated clinical course. J Acquir Immune Defic Syndr. 2008;49(2):117-22. Available at: http://www.ncbi.nlm.nih.gov/pubmed/18769360.

112. Terzi R, Niero F, lemoli E, Capetti A, Coen M, Rizzardini G. Late HIV seroconversion after non-occupational postexposure prophylaxis against HIV with concomitant hepatitis C virus seroconversion. AIDS. 2007;21(2):262-3. Available at: http://www.ncbi.nlm.nih.gov/pubmed/17197828.

113. Amor A, Toro C, Jimenez V, Simon A, Ramos B, Soriano V. Seroreversion of HIV antibodies in patients with prolonged suppression of viraemia under HAART. AIDS. 2006;20(10):1460-2. Available at: http://www.ncbi.nlm.nih.gov/pubmed/16791025.

114. Hare CB, Pappalardo BL, Busch MP, et al. Seroreversion in subjects receiving antiretroviral therapy during acute/early HIV infection. Clin Infect Dis. 2006;42(5):700-8. Available at: http://www.ncbi.nlm.nih.gov/pubmed/16447118.

115. Kassutto S, Johnston MN, Rosenberg ES. Incomplete HIV type 1 antibody evolution and seroreversion in acutely infected individuals treated with early antiretroviral therapy. Clin Infect Dis. 2005;40(6):868-73. Available at: http://www.ncbi.nlm.nih.gov/pubmed/15736021.

116. O'Connell RJ, Merritt TM, Malia JA, et al. Performance of the OraQuick rapid antibody test for diagnosis of human immunodeficiency virus type 1 infection in patients with various levels of exposure to highly active antiretroviral therapy. $J$ Clin Microbiol. 2003;41(5):2153-5. Available at: http://www.ncbi.nlm.nih.gov/pmc/articles/PMC154669/.

117. O'Connell RJ, Agan BK, Anderson SA, Malia JA, Michael NL. Sensitivity of the Multispot HIV-1/HIV-2 rapid test using samples from human immunodeficiency virus type 1-positive individuals with various levels of exposure to highly active antiretroviral therapy. J Clin Microbiol. 2006;44(5):1831-3. Available at: http://www.ncbi.nlm.nih.gov/pubmed/16672414.

118. Pandori MW, Westheimer E, Gay C, et al. The Multispot rapid HIV-1/HIV-2 differentiation assay is comparable with the Western blot and an immunofluorescence assay at confirming HIV infection in a prospective study in three regions of the United States. J Clin Virol. 2013;58(Suppl 1):e92-6. Available at: http://www.ncbi.nlm.nih.gov/pubmed/24342485.

119. Niederhauser $C$, Strohle A, Stolz M, Muller F, Tinguely $C$. The risk of a second diagnostic window with 4th generation HIV assays: Two cases. J Clin Virol. 2009;45(4):367-9. Available at: http://www.ncbi.nlm.nih.gov/pubmed/19546027.

120. Speers $D$, Phillips $P$, Dyer J. Combination assay detecting both human immunodeficiency virus (HIV) p24 antigen and antiHIV antibodies opens a second diagnostic window. J Clin Microbiol. 2005;43(10):5397-9. Available at: http://www.ncbi.nlm.nih.gov/pubmed/16208030.

121. Meier T, Knoll E, Henkes M, Enders G, Braun R. Evidence for a diagnostic window in fourth generation assays for HIV. $J$ Clin Virol. 2001;23(1-2):113-6. Available at: http://www.ncbi.nlm.nih.gov/pubmed/11595590.

122. Eller LA, Manak M, Malia JA, et al. Reduction of HIV window period by 4th gen HIV combination tests. Poster O-142, Conference on Retroviruses and Opportunistic Infections 2013; http://hivresearch.org/media/pnc/7/media.737.pdf. Accessed April 16, 2014.

123. Bennett B, Neumann D, Fordan S, Villaraza R, Crowe S, Gillis L. Performance of the new HIV-1/2 diagnostic algorithm in Florida's public health testing population: a review of the first five months of utilization. J Clin Virol. 2013;58(Suppl 1):e2933. Available at: http://www.ncbi.nlm.nih.gov/pubmed/24342476.

124. Cooper CJ, Metch B, Dragavon J, Coombs RW, Baden LR, Force NHVTNV-IST. Vaccine-induced HIV seropositivity/reactivity in noninfected HIV vaccine recipients. JAMA. 2010;304(3):275-83. Available at: http://www.ncbi.nlm.nih.gov/pubmed/20639561.

125. HIV Vaccine Trials Network. HIV vaccine study participants need to get the right test for HIV. http://www.hvtn.org/en/participants/visp-hiv-testing.html. Accessed June 2, 2014.

126. Selik RM, Mokotoff ED, Branson B, Owen SM, Whitmore S, Hall HI. Revised surveillance case definition for HIV infectionUnited States, 2014. MMWR Recomm Rep. 2014;63(3):1-10. Available at: http://www.cdc.gov/mmwr/pdf/rr//r6303.pdf. 
127. Menendez-Arias L, Alvarez M. Antiretroviral therapy and drug resistance in human immunodeficiency virus type 2 infection. Antiviral Res. 2014;102:70-86. Available at: http://www.ncbi.nlm.nih.gov/pubmed/24345729.

128. Besnier JM, Barin F, Baillou A, Liard F, Choutet P, Goudeau A. Symptomatic HIV-2 primary infection. Lancet. 1990;335(8692):798. Available at: http://www.ncbi.nlm.nih.gov/pubmed/1969547.

129. Christiansen CB, Jessen TE, Nielsen C, Staun-Olsen P. False negative anti-HIV-1/HIV-2 ELISAs in acute HIV-2 infection. Vox Sang. 1996;70(3):144-7. Available at: http://www.ncbi.nlm.nih.gov/pubmed/8740005.

130. Andersson J, Fehniger TE, Patterson BK, et al. Early reduction of immune activation in lymphoid tissue following highly active HIV therapy. AIDS. 1998;12(11):F123-9. Available at: http://www.ncbi.nlm.nih.gov/pubmed/9708402.

131. Popper SJ, Sarr AD, Gueye-Ndiaye A, Mboup S, Essex ME, Kanki PJ. Low plasma human immunodeficiency virus type 2 viral load is independent of proviral load: low virus production in vivo. J Virol. 2000;74(3):1554-7. Available at: http://www.ncbi.nlm.nih.gov/pubmed/10627569.

132. Shanmugam V, Switzer WM, Nkengasong JN, et al. Lower HIV-2 plasma viral loads may explain differences between the natural histories of HIV-1 and HIV-2 infections. J Acquir Immune Defic Syndr. 2000;24(3):257-63. Available at: http://www.ncbi.nlm.nih.gov/pubmed/10969350.

133. Masciotra S, Yang C, Pieniazek D, et al. Detection of simian immunodeficiency virus in diverse species and of human immunodeficiency virus Type 2 by using consensus primers within the pol region. J Clin Microbiol. 2002;40(9):3167-71. Available at: http://www.ncbi.nlm.nih.gov/pubmed/12202548.

134. Styer LM, Miller TT, Parker MM. Validation and clinical use of a sensitive HIV-2 viral load assay that uses a whole virus internal control. J Clin Virol. 2013;58(Suppl 1):e127-33. Available at: http://www.ncbi.nlm.nih.gov/pubmed/24342472.

135. Shulman SH, Parker MM. Interim guidelines for laboratories on the use of a new diagnostic testing algorithm for human immunodeficiency virus (HIV) infection 2013;

http://www.health.ny.gov/diseases/aids/providers/regulations/testing/docs/guidelines_diagnostic_testing.pdf. Accessed February 11, 2014.

136. CLSI. Criteria for Laboratory Testing and Diagnosis of Human Immunodeficiency Virus Infection; Approved Guideline Wayne, PA: Clinical and Laboratory Standards Institute;2011.

137. CDC. HIV/AIDS Surveillance Report, 2009. 2011;21. http://www.cdc.gov/hiv/pdf/statistics 2009 HIV Surveillance Report vol 21.pdf. Accessed June 2, 2014.

138. Brozek JL, Akl EA, Jaeschke R, et al. Grading quality of evidence and strength of recommendations in clinical practice guidelines: Part 2 of 3 . The GRADE approach to grading quality of evidence about diagnostic tests and strategies. Allergy. 2009;64(8):1109-16. Available at: http://www.ncbi.nlm.nih.gov/pubmed/19489757.

139. Schunemann HJ, Oxman AD, Brozek J, et al. Grading quality of evidence and strength of recommendations for diagnostic tests and strategies. BMJ. 2008;336(7653):1106-10. Available at: http://www.ncbi.nlm.nih.gov/pubmed/18483053.

140. Hsu J, Brozek JL, Terracciano L, et al. Application of GRADE: making evidence-based recommendations about diagnostic tests in clinical practice guidelines. Implement Sci. 2011;6:62. Available at: http://www.ncbi.nlm.nih.gov/pubmed/21663655.

141. Mitchell EO, Stewart G, Bajzik O, Ferret M, Bentsen C, Shriver MK. Performance comparison of the 4th generation Bio-Rad Laboratories GS HIV Combo Ag/Ab EIA on the EVOLIS automated system versus Abbott ARCHITECT HIV Ag/Ab Combo, Ortho Anti-HIV 1+2 EIA on Vitros ECi and Siemens HIV-1/O/2 enhanced on Advia Centaur. J Clin Virol. 2013;58(Suppl 1):e79-84. Available at: http://www.ncbi.nlm.nih.gov/pubmed/24342482.

142. Ethridge SF, Wesolowski LG, Nasrullah M, et al. Comparative evaluation of Aptima HIV-1 Qualitative RNA assay performance using plasma and serum specimens from persons with established HIV-1 infection. J Clin Virol. 2011;52(Suppl 1):S63-6. Available at: http://www.ncbi.nlm.nih.gov/pubmed/21995932.

143. Bentsen C, McLaughlin L, Mitchell E, et al. Performance evaluation of the Bio-Rad Laboratories GS HIV Combo Ag/Ab EIA, a 4th generation HIV assay for the simultaneous detection of HIV p24 antigen and antibodies to HIV-1 (groups M and O) and HIV-2 in human serum or plasma. J Clin Virol. 2011;52(Suppl 1):S57-61. Available at: http://www.ncbi.nlm.nih.gov/pubmed/21995929.

144. Malm K, von Sydow M, Andersson S. Performance of three automated fourth-generation combined HIV antigen/antibody assays in large-scale screening of blood donors and clinical samples. Transfus Med. 2009;19(2):78-88. Available at: http://www.ncbi.nlm.nih.gov/pubmed/19320855.

145. Ren A, Louie B, Rauch L, et al. Screening and confirmation of human immunodeficiency virus type 1 infection solely by detection of RNA. J Med Microbiol. 2008;57(Pt 10):1228-33. Available at: http://www.ncbi.nlm.nih.gov/pubmed/18809550.

146. Ramos EM, Harb S, Dragavon J, Swenson P, Stekler JD, Coombs RW. Performance of an alternative HIV diagnostic algorithm using the ARCHITECT HIV Ag/Ab Combo assay and potential utility of sample-to-cutoff ratio to discriminate primary from established infection. J Clin Virol. 2013;58(Suppl 1):e38-43. Available at: http://www.ncbi.nlm.nih.gov/pubmed/24029686. 
147. Cardenas AM, Baughan E, Hodinka RL. Evaluation of the Bio-Rad Multispot HIV-1/HIV-2 Rapid Test as an alternative to Western blot for confirmation of HIV infection. J Clin Virol. 2013;58(Suppl 1):e97-e103. Available at: http://www.ncbi.nlm.nih.gov/pubmed/24113294.

148. Wesolowski LG, Delaney KP, Meyer WA, 3rd, et al. Use of rapid HIV assays as supplemental tests in specimens with repeatedly reactive screening immunoassay results not confirmed by HIV-1 Western blot. J Clin Virol. 2013;58(1):240-4. Available at: http://www.ncbi.nlm.nih.gov/pubmed/23838670.

149. Linley L, Ethridge SF, Oraka E, et al. Evaluation of supplemental testing with the Multispot HIV-1/HIV-2 Rapid Test and APTIMA HIV-1 RNA Qualitative Assay to resolve specimens with indeterminate or negative HIV-1 Western blots. J Clin Virol. 2013;58(Suppl 1):e108-12. Available at: http://www.ncbi.nlm.nih.gov/pubmed/24342469.

150. Branson BM, Handsfield HH, Lampe MA, et al. Revised recommendations for HIV testing of adults, adolescents, and pregnant women in health-care settings. MMWR Recomm Rep. 2006;55 (RR-14):1-17. Available at: http://www.cdc.gov/mmwr/PDF/rr/rr5514.pdf.

151. Qaseem A, Snow V, Shekelle P, Hopkins R, Jr., Owens DK, Clinical Efficacy Assessment Subcommittee ACoP. Screening for HIV in health care settings: a guidance statement from the American College of Physicians and HIV Medicine Association. Ann Intern Med. 2009;150(2):125-31. Available at: http://www.ncbi.nlm.nih.gov/pubmed/19047022.

152. American College of Obstetricians and Gynecologists. ACOG Committee Opinion. Routine human immunodeficiency virus screening. Obstet Gynecol. 2008;112(2 Pt 1):401-3. Available at: http://www.ncbi.nlm.nih.gov/pubmed/18669743.

153. Committee on Pediatric AIDS, Emmanuel PJ, Martinez J. Adolescents and HIV infection: the pediatrician's role in promoting routine testing. Pediatrics. 2011;128(5):1023-9. Available at: http://www.ncbi.nlm.nih.gov/pubmed/22042816.

154. Moyer VA, U. S. Preventive Services Task Force. Screening for HIV: U.S. Preventive Services Task Force Recommendation Statement. Ann Intern Med. 2013;159(1):51-60. Available at: http://www.ncbi.nlm.nih.gov/pubmed/23698354.

155. Thompson MA, Aberg JA, Hoy JF, et al. Antiretroviral treatment of adult HIV infection: 2012 recommendations of the International Antiviral Society-USA panel. JAMA. 2012;308(4):387-402. Available at: http://www.ncbi.nlm.nih.gov/pubmed/22820792.

156. U.S. Preventive Services Task Force. Behavioral counseling to prevent sexually transmitted infections: U.S. Preventive Services Task Force recommendation statement. Ann Intern Med. 2008;149(7):491-6, W95. Available at: http://www.ncbi.nlm.nih.gov/pubmed/18838729.

157. Bio-Rad. GS HIV-1/HIV-2 PLUS O EIA [product insert]. 2006; Available at: http://www.fda.gov/downloads/BiologicsBloodVaccines/BloodBloodProducts/ApprovedProducts/LicensedProductsBLAs/Blo odDonorScreening/InfectiousDisease/UCM091700.pdf. Accessed April 23, 2012.

158. Ortho Diagnostics. VITROS Immunodiagnostic Products, Anti-HIV 1+2 Reagent Pack [product insert]. 2008; http://www.fda.gov/downloads/BiologicsBloodVaccines/BloodBloodProducts/ApprovedProducts/PremarketApprovalsPMAs/u cm092018.pdf. Accessed July 14, 2013.

159. Siemens Healthcare. HIV 1/O/2 Enhanced (EHIV) [product insert]. 2006; http://www.fda.gov/downloads/Biologicsbloodvaccines/Bloodbloodproducts/Approvedproducts/PremarketApprovalsPMAs/U CM091286.pdf. Accessed July 12, 2013.

160. Abbott. Architect HIV Ag/Ab Combo [product insert]. 2010; http://www.abbottdiagnostics.com/Support/Technical_Library/Package_Inserts/getPIFile.cfm?controlNumber=345589. Accessed April 23, 2012.

161. Bio-Rad. GS HIV Combo Ag/Ab EIA [product insert]. 2011; http://www.fda.gov/downloads/BiologicsBloodVaccines/BloodBloodProducts/ApprovedProducts/PremarketApprovalsPMAs/ UCM266211.pdf. Accessed April 23, 2012.

162. Pieniazek D, Peralta JM, Ferreira JA, et al. Identification of mixed HIV-1/HIV-2 infections in Brazil by polymerase chain reaction. AIDS. 1991;5(11):1293-9. Available at: http://www.ncbi.nlm.nih.gov/pubmed/1768377.

163. Mendoza D, Johnson SA, Peterson BA, et al. Comprehensive analysis of unique cases with extraordinary control over HIV replication. Blood. 2012;119(20):4645-55. Available at: http://www.ncbi.nlm.nih.gov/pubmed/22490332.

164. Okulicz JF, Lambotte O. Epidemiology and clinical characteristics of elite controllers. Curr Opin HIV AIDS. 2011;6(3):163-8. Available at: http://www.ncbi.nlm.nih.gov/pubmed/21502920.

165. Walker BD. Elite control of HIV Infection: implications for vaccines and treatment. Top HIV Med. 2007;15(4):134-6. Available at: http://www.ncbi.nlm.nih.gov/pubmed/17720999.

166. Bio-Rad Laboratories. Product Information: Multispot HIV1/HIV-2 Rapid Test. 2013; Multispot HIV-1/JIV-2 Rapid Test. Available at: http://www.bio-rad.com/webroot/web/pdf/cdg/literature/P-120_Multispot_HIV_b_DG13-0177.pdf. Accessed June 10, 2013.

167. Goodhue T, Kazianis A, Werner BG, et al. 4th generation HIV screening in Massachusetts: a partnership between laboratory and program. J Clin Virol. 2013;58(Suppl 1):e13-8. Available at: http://www.ncbi.nlm.nih.gov/pubmed/24342473. 
168. Dubravac T, Gahan TF, Pentella MA. Use of the Abbott Architect HIV antigen/antibody assay in a low incidence population. J Clin Virol. 2013;58(Suppl 1):e76-8. Available at: http://www.ncbi.nlm.nih.gov/pubmed/24342481.

169. O'Connell RJ, Peel SA. Multispot HIV-1/HIV-2 Rapid Test: advantages over other rapid HIV tests. Expert Rev Mol Diagn. 2007;7(5):499-505. Available at: http://www.ncbi.nlm.nih.gov/pubmed/17892358.

170. Midthun K, Garrison L, Clements ML, Farzadegan H, Fernie B, Quinn T. Frequency of indeterminate western blot tests in healthy adults at low risk for human immunodeficiency virus infection. The NIAID AIDS Vaccine Clinical Trails Network. $J$ Infect Dis. 1990;162(6):1379-82. Available at: http://www.ncbi.nlm.nih.gov/pubmed/2230270.

171. Long EF. HIV screening via fourth-generation immunoassay or nucleic acid amplification test in the United States: a costeffectiveness analysis. PLoS One. 2011;6(11):e27625. Available at: http://www.ncbi.nlm.nih.gov/pubmed/22110698.

172. Farnham PG, Sansom SL, Hutchinson AB. How much should we pay for a new HIV diagnosis? A mathematical model of HIV screening in US clinical settings. Med Decis Making. 2012;32(3):459-69. Available at: http://www.ncbi.nlm.nih.gov/pubmed/22247422.

173. Hutchinson AB, Patel P, Sansom SL, et al. Cost-effectiveness of pooled nucleic acid amplification testing for acute HIV infection after third-generation HIV antibody screening and rapid testing in the United States: a comparison of three public health settings. PLoS Med. 2010;7(9):e1000342. Available at: http://www.ncbi.nlm.nih.gov/pubmed/20927354.

174. Grusky O, Roberts KJ, Swanson AN. Communicating indeterminate HIV Western blot test results to clients: an observational study of three community testing sites. AIDS Patient Care STDS. 2006;20(9):620-7. Available at: http://www.ncbi.nlm.nih.gov/pubmed/16987048.

175. Guan M. Frequency, causes, and new challenges of indeterminate results in Western blot confirmatory testing for antibodies to human immunodeficiency virus. Clin Vaccine Immunol. 2007;14(6):649-59. Available at: http://www.ncbi.nlm.nih.gov/pubmed/17409223. 